Portland State University

PDXScholar

$1-7-2020$

\title{
Geochemical Response to Thermal Energy Storage in the Columbia River Basalt Aquifer System Beneath the Portland Basin, Oregon
}

Ellen Elizabeth Svadlenak

Portland State University

Follow this and additional works at: https://pdxscholar.library.pdx.edu/open_access_etds

Part of the Geochemistry Commons, and the Geology Commons Let us know how access to this document benefits you.

\section{Recommended Citation}

Svadlenak, Ellen Elizabeth, "Geochemical Response to Thermal Energy Storage in the Columbia River Basalt Aquifer System Beneath the Portland Basin, Oregon" (2020). Dissertations and Theses. Paper 5362.

https://doi.org/10.15760/etd.7235

This Thesis is brought to you for free and open access. It has been accepted for inclusion in Dissertations and Theses by an authorized administrator of PDXScholar. Please contact us if we can make this document more accessible: pdxscholar@pdx.edu. 
Geochemical Response to Thermal Energy Storage in the Columbia River Basalt Aquifer System Beneath the Portland Basin, Oregon

by

Ellen Elizabeth Svadlenak

A thesis submitted in partial fulfillment of the requirements for the degree of

Master of Science

in

Geology

Thesis Committee:

Robert B. Perkins, Chair

Carl D. Palmer

John T. Bershaw

Portland State University

2019 
(C) 2019 Ellen Elizabeth Svadlenak 


\begin{abstract}
Deep direct use thermal energy storage (TES) is a low carbon emission method of geothermal energy storage and supply for large-scale residential, commercial, and manufacturing heating and cooling. The process entails repeated cycles of hot- or coldwater injection, storage, and extraction from slow groundwater flow zones within the deeper layers of an aquifer system. Though a promising technology, TES cycles may increase mineral dissolution and precipitation reactions, particularly at elevated temperatures. The ensuing mass transfer can form scale in heat exchange systems and alter aquifer porosity and permeability, processes that can reduce the operational efficiency of a TES system.

Within the Portland Basin, the underutilized Columbia River Basalt Group (CRBG) confined aquifer system has the potential to support TES operations. The feasibility of using TES in the Portland Basin CRBG was evaluated from a hydrogeochemical perspective by ascertaining the range of native groundwater chemistries associated with the target zone, identifying pertinent CRBG mineralogy, and determining geochemical processes that can impact the aquifer or heat exchanger both experimentally and using geochemical reaction modeling.

Analysis of CRBG groundwaters in western Oregon revealed that CRBG groundwater chemistry is influenced by calcite precipitation and mixing with underlying saline waters. A series of batch reaction experiments quantified the changes in water chemistry resulting from increasing aquifer temperatures and revealed that water-rock reactions are surface controlled. Results also suggest Ca concentrations are primarily
\end{abstract}


controlled by calcite precipitation and dissolution, while the concentrations of other major cations are controlled by a complex series of incongruent mineral reactions.

The impact of TES operation on aquifer porosity and permeability will ultimately depend on the composition of groundwater in the target zone, and on the nature and extent of available reactive surfaces in contact with injected waters. Equilibrium and kinetic transport reaction models were used to constrain the impacts of heating on the aquifer and heat exchanger using a variety of initial groundwater compositions, mineral assemblages, reactive surface areas, temperatures, and flow rates. Modeling results suggest that calcite, siderite, and smectite clays are significant secondary mineral phases. Most kinetic transport simulations indicate some loss of porosity near the injection point when injected waters are heated to $70^{\circ} \mathrm{C}$. This loss is minimized, though not necessarily eliminated, when waters are only heated to $\sim 50^{\circ} \mathrm{C}$. Under the most optimistic modeled conditions (using a less evolved water type, ample reactive silicate surfaces, lower temperatures, and low to modest flow rates) a slight increase in porosity near the injection point may occur. Under the most pessimistic conditions (using a mature water that is saturated or oversaturated with respect to calcite, little to no reactive silicates as in calcite-lined fracture porosity, higher temperatures, and higher flow rates), a greater than $10 \%$ porosity loss may occur within one seasonal cycle. Modeling the recycling of waters between two reservoirs maintained at $70^{\circ} \mathrm{C}$ and $40^{\circ} \mathrm{C}$ suggests porosity loss in both reservoirs, but that some porosity may be recovered in the $70^{\circ} \mathrm{C}$ reservoir over multiple cycles. These findings have implications for use of the basalts as a storage site for drinking water and carbon sequestration, in addition to TES. 


\section{ACKNOWLEDGEMENTS}

I would first and foremost like to thank my adviser Ben Perkins, and my committee members John Bershaw and Carl Palmer for their endless patience both with me and with this project. Your guidance, inquisitiveness, and assistance are incredibly appreciated. Ben in particular contributed an inordinate amount of time and energy to improving both this thesis and my understanding of modeling, chemistry, and hydrology. I would also like to acknowledge the entire Portland State University Geology Department faculty for the hard work, help, and enthusiasm they show to all of their students. To my fellow graduate students, thank you so much for all of the advice, support, and understanding. I could not imagine a better cohort with which to learn and grow.

I would also like to thank GSI Water Solutions, Inc. for showing interest and enthusiasm for this project, and for sharing their knowledge and samples of the local Columbia River Basalts. Your contributions to this project were incredibly helpful. I would also like to recognize the U.S. Department of Energy, Office of Energy Efficiency and Renewable Energy (EERE) for funding this project.

Lastly, a big thank you to my family and friends who supported me throughout the duration of my graduate education. Particular thanks go to my husband, Ben Kilfoil for the love, encouragement, and care. Your support has been unwavering through all of the decisions, changes, and challenges of the last two years, and for that I cannot thank you enough. 


\section{TABLE OF CONTENTS}

ABSTRACT

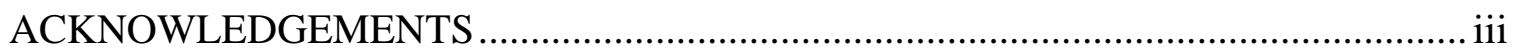

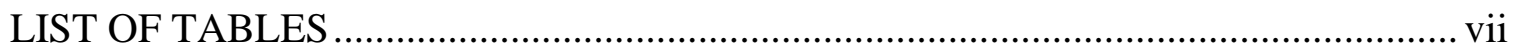

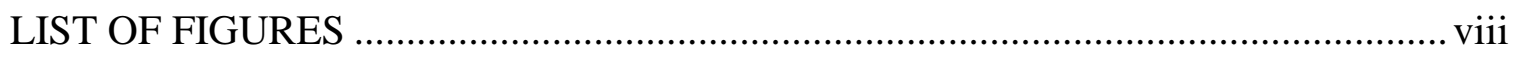

CHAPTER 1: INTRODUCTION, GEOLOGY, AND HYDROGEOLOGY OF THE

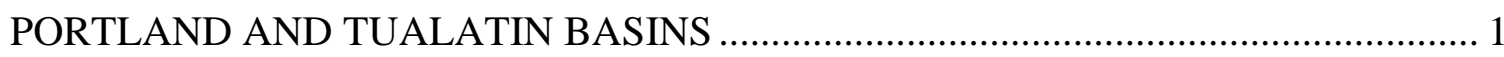

1.1 Deep Direct Use Thermal Energy Storage in the Portland Basin.................. 1

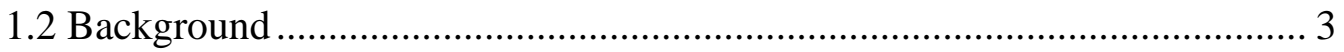

1.2.1 Geologic Setting.......................................................................... 3

1.2.2 Hydrogeology of the CRBG ……………………........................... 7

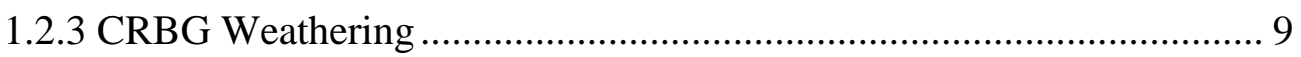

CHAPTER 2: ANALYSIS OF NATIVE GROUNDWATER WITHIN THE

COLUMBIA RIVER BASALTS .......................................................................... 12

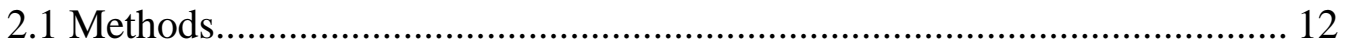

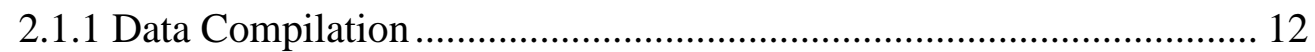

2.1.2 Mineral Saturation States .................................................................... 15

2.1.3 Hierarchical Cluster Analysis .......................................................... 15

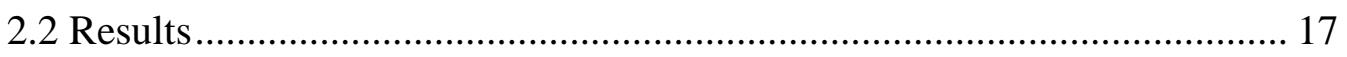

2.2.1 Chemical Characterization of CRBG Groundwater ............................ 17

2.2.2 Mineral Saturation States ................................................................... 20

2.2.3 Hierarchical Cluster Analysis ............................................................ 22

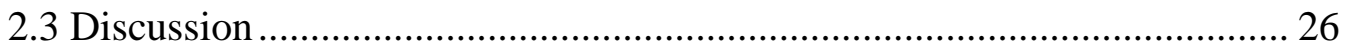

2.3.1 Groundwater Mixing......................................................................... 26 
2.3.2 Establishing Average Groundwater Composition ........................... 30

CHAPTER 3: THERMAL ROCK-WATER BATCH REACTIONS ............................ 32

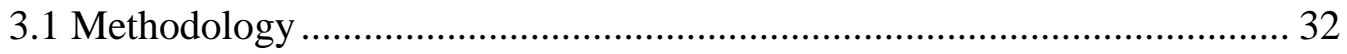

3.1.1 Sample and Water Preparation..................................................... 33

3.1.2 Rock Sample Characterization................................................... 33

3.1.3 Experiment Design............................................................ 34

3.1.4 Sample Analysis.............................................................. 40

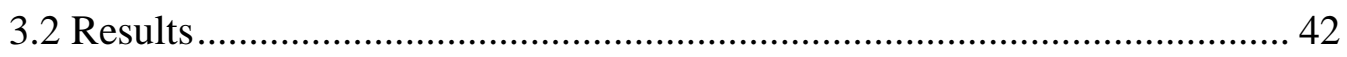

3.2.1 Rock Characterization................................................................... 42

3.2.2 Scanning Electron Microscopy …............................................... 44

3.2.3 Changes in Water Chemistry ...................................................... 47

3.2.4 Inverse Modeling of Experimental Results.................................... 53

3.2.5 Quantifying Mineral Precipitation and Dissolution ........................... 55

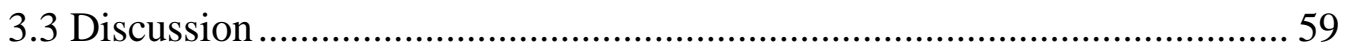

CHAPTER 4: GEOCHEMICAL REACTION MODELING OF TES CYCLES .......... 107

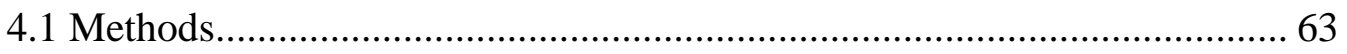

4.1.1 Equilibrium modeling of TES ............................................... 63

4.1.2 Kinetic Transport Model........................................................ 70

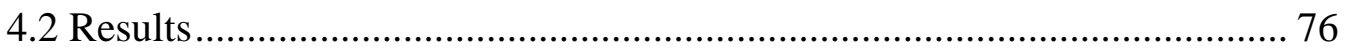

4.2.1 Equilibrium Modeling ............................................................ 76

4.2.2 Kinetic Transport Modeling ....................................................... 87

4.2.3 Successive Cycles .................................................................... 96

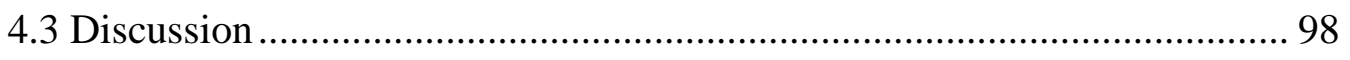

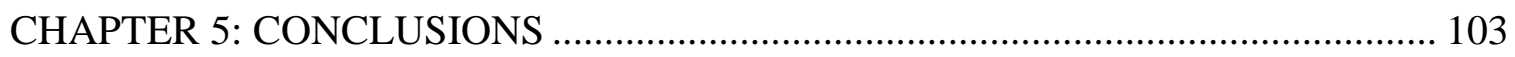




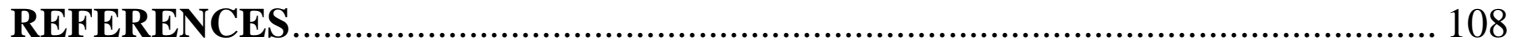

APPENDIX A: COMPILED GROUNDWATER CHEMISTRY DATA..................... 114

APPENDIX B: BATCH REACTION EXPERIMENTAL DATA .............................. 115

APPENDIX C: MODELING SCRIPTS AND PARAMETERS .................................. 116 


\section{LIST OF TABLES}

Table 2.1. Summary Statistics for the compiled Portland, Tualatin, and Willamette Basin groundwater chemistry data. See Appendix A for statistics by hydrogeologic unit......... 14

Table 2.2. Groups identified using HCA, ranging from recharge waters to deep saline waters. 25

Table 3.1. Sample reactants, temperature, vessel type, and reaction duration for each experimental round.

Table 3.2. Summary of operating parameters for each SEM task. SE refers to secondary electron, BSE refers to backscattered electron.

Table 3.3. Basalt flow mineralogy identified via XRD analysis.

Table 3.4. Mineral mass transfers (in moles) identified via inverse modeling of a basalt flow interior sample 688A and interflow zone sample 525A using phreeqC.

Table 3.5. Changes in porosity and permeability determined using equations 2 and 3 for an aquifer with a surface area of $10000 \mathrm{~cm}^{2}$, an initial porosity of 0.2 , and an increasing number of pore volumes through which water has flowed ( where pore volume $=1000$

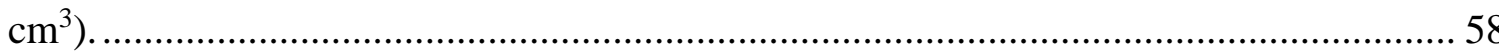

Table 4.1. Average water compositions for cluster groups used in geochemical reaction models.

Table 4.2. Primary and secondary minerals considered during modeling of the TES system.

Table 4.3. Example water-rock reactions that may cause mineral dissolution, precipitation, or buffering (modified from Rattray and Ginsbach, 2014)........................ 67

Table 4.4. Kinetic transport modeling parameters ........................................................... 72

Table 4.5. Dissolution rate constants $(\log (\mathrm{k}))$, activation energies $\left(\mathrm{E}_{\mathrm{a}}\right)$, pre-exponential factors $\left(\log \left(\mathrm{A}_{\mathrm{w}}\right)\right)$ and specific surface areas $(\mathrm{SA})$ at $25^{\circ} \mathrm{C}$ and neutral $\mathrm{pH}$ for primary and secondary minerals utilized in kinetic modeling. (Assuming dissolution rates approximate precipitation rates for secondary precipitates due to lack of available precipitation data). 


\section{LIST OF FIGURES}

Figure 1.1. Schematic of a thermal energy storage system. Arrows show direction of summer and winter flow. The process is as follows: water is pumped from an aquifer, heated via an exchange system, solar energy, or other method during the summer, then injected into the warm well and stored in aquifer. Heated water is then pumped out the following winter and used as a heat supply. As heat is extracted, cooled water is injected into the cold well and stored until the following summer, when this water is extracted, reheated, and injected into the warm well for subsequent storage and winter extraction (from Cabeza et al., 2015)

Figure 1.2. Generalized geologic map of the Portland Basin (study area). Inset map shows the location of the Portland Basin within the Puget-Willamette lowland (modified from Evarts et al., 2009).

Figure 1.3. Stratigraphic column schematic of the Portland Basin (Evarts et al., 2009).... 5

Figure 1.4. Generalization of interflow structures found within a typical Columbia River Basalt sheet flow. Interflow zones are boxed in red (modified from Reidel et al., 2013). . 8

Figure 1.5. CRBG Grande Ronde Basalt mineralogy and associated hydrothermal alteration products (modeled after Ames and McGarrah, 1980; Deutsch et al., 1982; Hearn et al., 1985a, 1990).

Figure 2.1. Location of wells with groundwater chemistry data in the Portland, Tualatin, and northern Willamette Basins, color coded by basin/region. Black lines represent faults.

Figure 2.2. A piper plot of CRB groundwaters generated with data from this study. Colors indicate regional location, while shapes indicate the well's hydrogeologic unit. . 18

Figure 2.3. Comparison of groundwater chemistry of waters east of the Cascades (black)

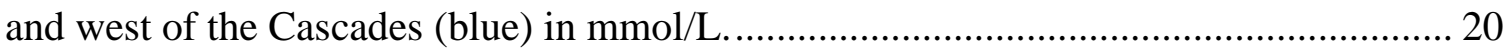

Figure 2.4. Average saturation indices of minerals with respect to CRB groundwater east (blue) and west (red) of the Cascades. Error bars are based on the standard deviation of the samples' average SI. Error bars about the origin provide the standard deviation of the SI calculation based on stoichiometry.

Figure 2.5. Calcite saturation by group with depth (a), bicarbonate concentration by the sum of major cations for clustered CRB wells (b), $\mathrm{Ca}$ and $\mathrm{Mg}$ versus the sum of major 
cations (c), and $\mathrm{Na}$ and $\mathrm{K}$ versus the sum of major cations (d) for $\mathrm{CRB}$ wells. Color indicates the groundwater group, with recharge waters plotting closest to the origin...... 23

Figure 2.6. $\mathrm{Ca}$ and $\mathrm{Mg}$ versus the sum of major cations (a) and $\mathrm{Na}$ and $\mathrm{K}$ versus the sum of major cations (b). Color indicates groundwater type, with recharge waters plotting closest to the origin. Group 7 is not pictured, as it plots outside the bounds of the chart axes.

Figure 2.7. $\mathrm{Ca}$ and $\mathrm{Mg}$ versus the sum of major cations. The composition of well PBCRB-4 can be duplicated by mixing wells TB-CRB-9 and TB-M-3

Figure 2.8. Western Oregon well locations, color coded by groundwater group. Lines represent faults. Note that group 6 wells (in green) are shallow wells with a brackish water chemistry that plot directly within the Gales Creek - Mount Angel Structural Zone.

Figure 3.1. a) Basalt flow interior sample rock chips from the Wapshilla Ridge, and b) interflow zone sample rock chips.

Figure 3.2. BSE images of both reacted and non-reacted Wapshilla ridge basalt flow interiors, showing identical mineralogies; a) is a reacted epoxy plug, and b) is an unreacted grain mount.

Figure 3.3. a) SE image of clay formation at the surface of an unreacted flow interior sample, and b) a BSE image of a reacted flow interior vesicle filled with secondary mineralization.

Figure 3.4. BSE images of both re-reacted and non-reacted interflow zone samples, showing similar mineralogies and surface textures; a) is a BSE micrograph of an epoxy plug, $b$ ) is a grain mount.

Figure 3.5. a) Lower magnification view of particles on filter paper as a result of cooling water, b) higher magnification image of a possible clay structure, and c) higher magnification image of a clay (or another aluminosilicate) particle pictured in (a). All images were collected using the secondary electron detector.

Figure 3.6. Elemental mass transfers resulting from batch reactions at $74^{\circ} \mathrm{C}$ for both major elements (a) and trace elements (b). Mass transfers resulting from batch reactions at $35^{\circ} \mathrm{C}$ for both major elements (c) and trace elements (d). Wapshilla Ridge samples are indicated by circles in shades of blue, Ortley as squares in shades of green, and the 
interflow zone as triangles in shades of red. Zero line represents the initial water composition.

Figure 3.7. Mass transfer based on a) water:rock ratio, and b) grain size at $35^{\circ} \mathrm{C}$, for samples from the Wapshilla ridge (blue), Ortley (green), and interflow zone (red).

Figure 3.8. (a) major cation concentrations in the initial water, water heated to $74^{\circ} \mathrm{C}$, and water cooled to room temperature, and (b) trace element concentrations in the same initial, heated, and cooled water (sample ASR $688 \mathrm{C} 1$, Table 3.1)................................ 50

Figure 3.9. Average element concentration versus time for the time series samples 698 $\mathrm{T} 1-\mathrm{T} 14$. Error bars represent one standard deviation $(\mathrm{n}=2)$. After 840 hours, samples were filtered with a $0.1 \mu \mathrm{m}$ filter rather than a $0.45 \mu \mathrm{m}$ filter.

Figure 3.10. Time in hours vs. the average Ca concentration. Error bars show one standard deviation. The linear trendline used to calculate the zero-order rate constant is shown in gray, and the exponential trendline and accompanying equation used to calculate the first order rate constant is shown in black.

Figure 4.1. Temperature-activity $(\mathrm{pH})$ diagram showing stability fields for various clay phases assuming the $A v g C R B$ water composition. (Nontronites and smectite-low-Fe-Mg and smectite-Reykjanes were permitted to form in this model).

Figure 4.2. Concentration of minerals precipitated from $1 \mathrm{~kg}$ of water after each equilibrium modeling step, when excluding gibbsite and chalcedony and including clay minerals in the mineral assemblage.

Figure 4.3. Concentration of minerals precipitated from $1 \mathrm{~kg}$ of water after each equilibrium modeling step, when including clinoptilolite in the mineral assemblage. .... 79

Figure 4.4. Saturation indices for calcite, siderite, and saponite-Mg with respect to temperature for different initial water compositions (from Table 4.1). A saturation index of 0 represents equilibrium; SI values $>0$ indicate the potential for mineral precipitation.

Figure 4.5. Amount of minerals precipitated per kilogram of water due to a) extraction and heating at the surface, $\mathbf{b}$ ) injection and reaction with aquifer rock, and c) mixing between injected and native groundwaters. Colors represent varying ground water compositions that may be present in the TES target zone (see Ch. 2) 
Figure 4.6.Concentration of precipitated minerals and resulting porosity per kilogram of injected water, in response to reaction of $40 \mathrm{mg} / \mathrm{L}$ of pyroxene and $60 \mathrm{mg} / \mathrm{L}$ of plagioclase.

Figure 4.7. Concentrations of precipitated minerals and resulting porosity, as injected and native groundwaters mix. Solid lines indicate $70^{\circ} \mathrm{C}$ results, dashed lines indicate $50^{\circ} \mathrm{C}$ results.

Figure 4.8. Concentrations of precipitated minerals and resulting porosity, per kilogram of injected water in response to reaction of $40 \mathrm{mg} / \mathrm{L}$ of pyroxene and $60 \mathrm{mg} / \mathrm{L}$ of plagioclase under both open and closed system conditions, and at 50 and $70^{\circ} \mathrm{C}$.

Figure 4.9. Concentrations of precipitated minerals and resulting porosity, as injected and native groundwaters mix. Injected waters have been heated to 50 and $70^{\circ} \mathrm{C}$, under both open and closed system conditions.

Figure 4.10. The concentration of minerals precipitated from $1 \mathrm{~kg}$ of water moving between 0 and $100 \mathrm{~m}$ from the injection well for the base case (solid lines) and when glass is included in the model (dashed lines) after 180 days and a flow rate of 1 $\mathrm{m}^{3} / \mathrm{m}^{2} /$ day (left). Aquifer porosity after 180 days of injection of $70^{\circ} \mathrm{C}$ water, as a result of excluding vs including basaltic glass (right). 88

Figure 4.11. a) The concentration of minerals precipitated from $1 \mathrm{~kg}$ of water moving between 0 and $100 \mathrm{~m}$ from the injection well for the base case (solid lines) and reactive surface area is reduced to $1 \%$ matrix. b) Aquifer porosity after 180 days of injection of $70^{\circ} \mathrm{C}$ water, with varying reactive solid volumes.

Figure 4.12. Calcite precipitated after 0,180 , and 365 days of injection of $70^{\circ} \mathrm{C}$ heated $C R B 3$ water (left) and the resulting changes in porosity each year for the first five years (right). Reactive solid volumes are $3 \%$ calcite, and $0.5 \%$ each plagioclase and pyroxene.

Figure 4.13. a) The concentration of minerals precipitated from $1 \mathrm{~kg}$ of water moving between 0 and $50 \mathrm{~m}$ from the injection well for the base case, when water is heated to $70^{\circ} \mathrm{C}$ prior to injection (solid lines) and when water is only heated to $50^{\circ} \mathrm{C}$ (dashed lines). Flow rate is $1 \mathrm{~m}$ /day shown after 180 days, and reactive solid volumes are $45 \%$ plagioclase and $35 \%$ pyroxene. b) Aquifer porosity after 180 days of injection of $70^{\circ} \mathrm{C}$ and $50^{\circ} \mathrm{C}$ water (initial porosity was 0.2 ).

Figure 4.14. a) The concentration of minerals precipitated from $1 \mathrm{~kg}$ of $70^{\circ} \mathrm{C}$ water moving between 0 and $50 \mathrm{~m}$ from the injection well. Closed system heating is shown by 
solid lines and open system heating by dashed lines. b) Aquifer porosity after 180 days of injection of $70^{\circ} \mathrm{C}$ water heated under closed and open system conditions. Reactive solid volumes are $45 \%$ plagioclase and $35 \%$ pyroxene for all cases....

Figure 4.15. a) Saponite distribution after 180 days injecting $70^{\circ} \mathrm{C} A v g C R B$ water into an aquifer with initial porosity of 0.2 at varying injection rates, and b) resulting changes in porosity near the injection site for the same scenarios. Reactive solid volumes are $4.5 \%$ plagioclase and $3.5 \%$ pyroxene for all cases.

Figure 4.16. Map views of the 2D kinetic transport model, showing calcite and amorphous silica distribution (left) and resulting porosity (right) after pumping hot water through the aquifer for 180 days, assuming reactive solid volumes of $45 \%$ plagioclase and $35 \%$ pyroxene.

Figure 4.17. Distribution of calcite and amorphous silica deposits after 180 days of injection (siderite, not shown, has similar distribution as calcite) (left). Map view of 2D model results showing changes in aquifer porosity (initially set a 0.20 ) near a well injecting $70^{\circ} \mathrm{C} \mathrm{CRB3}$ waters (with carbonate precipitates removed during heating) at 14 $\mathrm{L} / \mathrm{s}$, and $4.5 \%$ plagioclase and $3.5 \%$ pyroxene initial reactive solid volumes (right). Model coordinates in meters; well located at $\mathrm{x}=20, \mathrm{y}=80 \mathrm{~m}$. 96

Figure 4.18. Changes in porosity after 5 successive cycles of pumping/recovery/pumping in the primary aquifer $\left(" 70^{\circ} \mathrm{C}\right.$ ", right) and re-injection of cooled water into a separate reinjection zone (“40 $\mathrm{C}$ ", left).

Figure 4.19. Piper diagram of injected and recovered water compositions for each cycle, excluding glass (left) and including glass (right)..... 98 


\section{CHAPTER 1: INTRODUCTION, GEOLOGY, AND HYDROGEOLOGY OF THE PORTLAND AND TUALATIN BASINS}

\section{Deep Direct Use Thermal Energy Storage in the Portland Basin}

The Columbia River Basalt aquifers of Washington and Oregon have been used as storage sites for both excess surface water and sequestered carbon. Portland State

University and the U.S. Geological Survey have proposed that aquifers within these basalts could also be used to store hot water via Deep Direct Use Thermal Energy Storage (DDU-TES), providing district heating and cooling for buildings and developments. Thermal energy storage (TES) entails repeated cycles of hot or cold water injection and storage in slow-moving, confined groundwater-flow systems and subsequent pumping to a surface heat exchange network (Figure 1.1).

Portland, Oregon is underlain by the Columbia River Basalt Group (CRBG). Groundwater within the CRBG is largely constrained to thin "interflow zones" between individual, stacked basalt flows (Tolan, Lindsey, and Porcello 2009). The thicker, dense basalt flow interiors act as aquitards and limit vertical thermal transport between groundwater flow zones. Even though the CRBG aquifers underlying Portland are reasonably transmissive, they are little used for water supply because of their depth, and the accessibility of other readily available water sources of higher quality (including a thick overlying gravel aquifer and gravity-fed surface waters from Mt Hood's Bull Run Reservoir). These attributes, along with a variety of local government initiatives dedicated to expanding the use of low-carbon energy sources (City of Portland, 2017), 
make the CRBG aquifer system under Portland a promising candidate for TES

implementation.

An important factor in determining the efficacy of the proposed DDU-TES

system is the potential for mineral precipitation and dissolution, particularly at elevated temperatures (Perlinger et al. 1987). Mineralization can negatively affect the porosity and permeability of the aquifer, reduce well productivity, and decrease the efficiency of heat exchangers, resulting in reduced thermal storage-and-release efficiency over time.

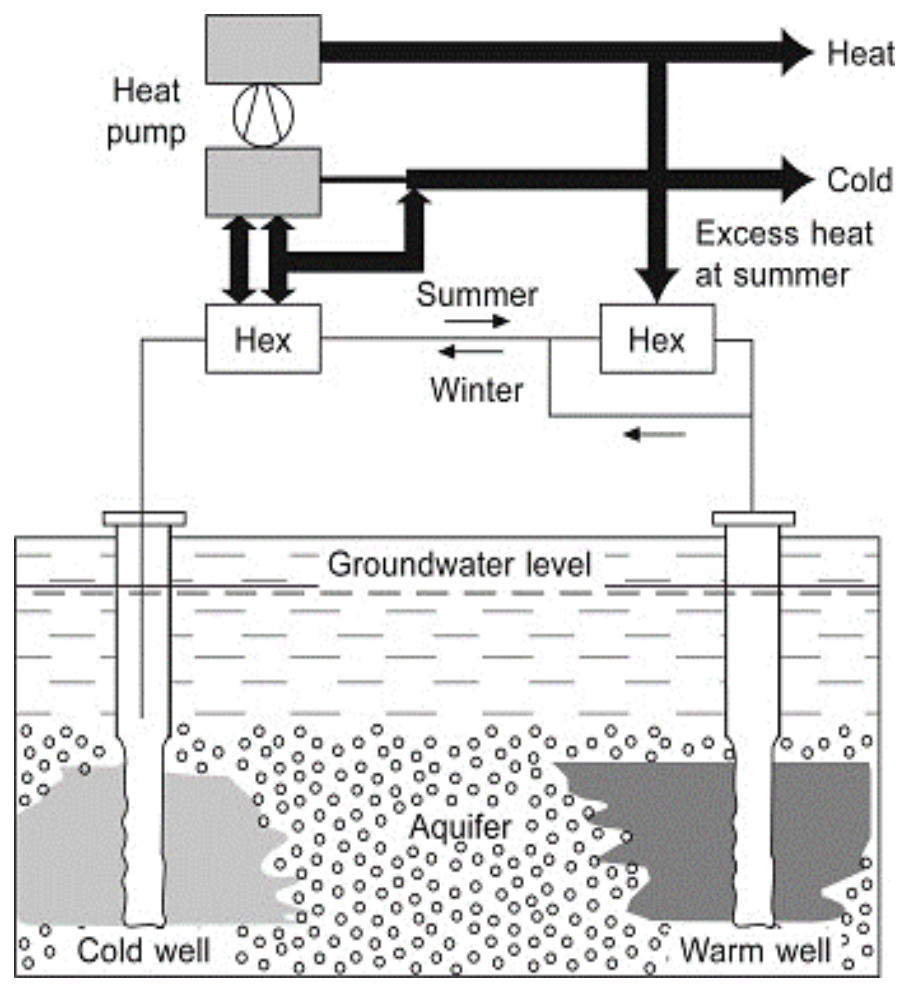

Figure 1.1. Schematic of a thermal energy storage system. Arrows show direction of summer and winter flow. The process is as follows: water is pumped from an aquifer, heated via an exchange system, solar energy, or other method during the summer, then injected into the warm well and stored in aquifer. Heated water is then pumped out the following winter and used as a heat supply. As heat is extracted, cooled water is injected into the cold well and stored until the following summer, when this water is extracted, reheated, and injected into the warm well for subsequent storage and winter extraction (from Cabeza et al., 2015). 
The primary objective of this study is to constrain the extent to which rock-water interactions can impact the DDU-TES system. To fulfill this objective, I: 1) determined the range of native groundwater chemistries associated with the CRBG aquifer system in the Portland Basin, 2) identified pertinent CRBG mineralogies and relevant geochemical processes that may impact the aquifer or heat exchanger, and 3) simulated the mass transfers and potential changes to water quality that result from cyclical heating, cooling, and mixing of waters. The simulations account for a range of temperatures, changes in $\mathrm{pH}, \mathrm{CO}_{2}$ fugacity, $\mathrm{O}_{2}$ content, and initial water compositions.

Besides identifying and modeling problematic chemical reactions that impact DDU-TES implementation in the Portland Basin, this study improves our overall understanding of groundwater chemical quality in the CRBG aquifer system. My findings may also assist with future evaluations of aquifer storage and recovery (ASR) systems and, potentially, the viability of carbon sequestration in basalt aquifers.

\section{Background}

\section{Geologic Setting}

The Cascadia Subduction Zone largely controls the geology of the northwestern United States. Located between the volcanic Cascade Mountains to the east, and the accreted terrane of the Coast Range to the west, the Portland Basin is within the northsouth trending Puget-Willamette lowland (Figure 1.2, Evarts et al., 2009). Oblique subduction of the Juan de Fuca oceanic plate beneath the North American plate drives clockwise rotation of the Oregon coastal block. This rotation leads to an overall trend of 
northwest striking crustal faults and folds across northwestern Oregon (Ray E. Wells 1998). The Portland Basin is a northwest trending synclinal basin with a paired anticline to the southwest that constitutes the uplifted Portland Hills (Evarts et al. 2009). The Sandy River and Frontal Faults bound the basin to the northeast, while the Portland Hills, Oatfield, and East Bank faults control the southwestern side of the basin (Liberty, Hemphill-Haley, and Madin 2003). The Portland Basin has been interpreted as both a compressional basin and a pull-apart basin (Beeson 1985; Richard J Blakely et al. 1995; Yelin and Patton 1991), but new mapping and geophysical data suggests a transpressional structure (Evarts et al. 2009).
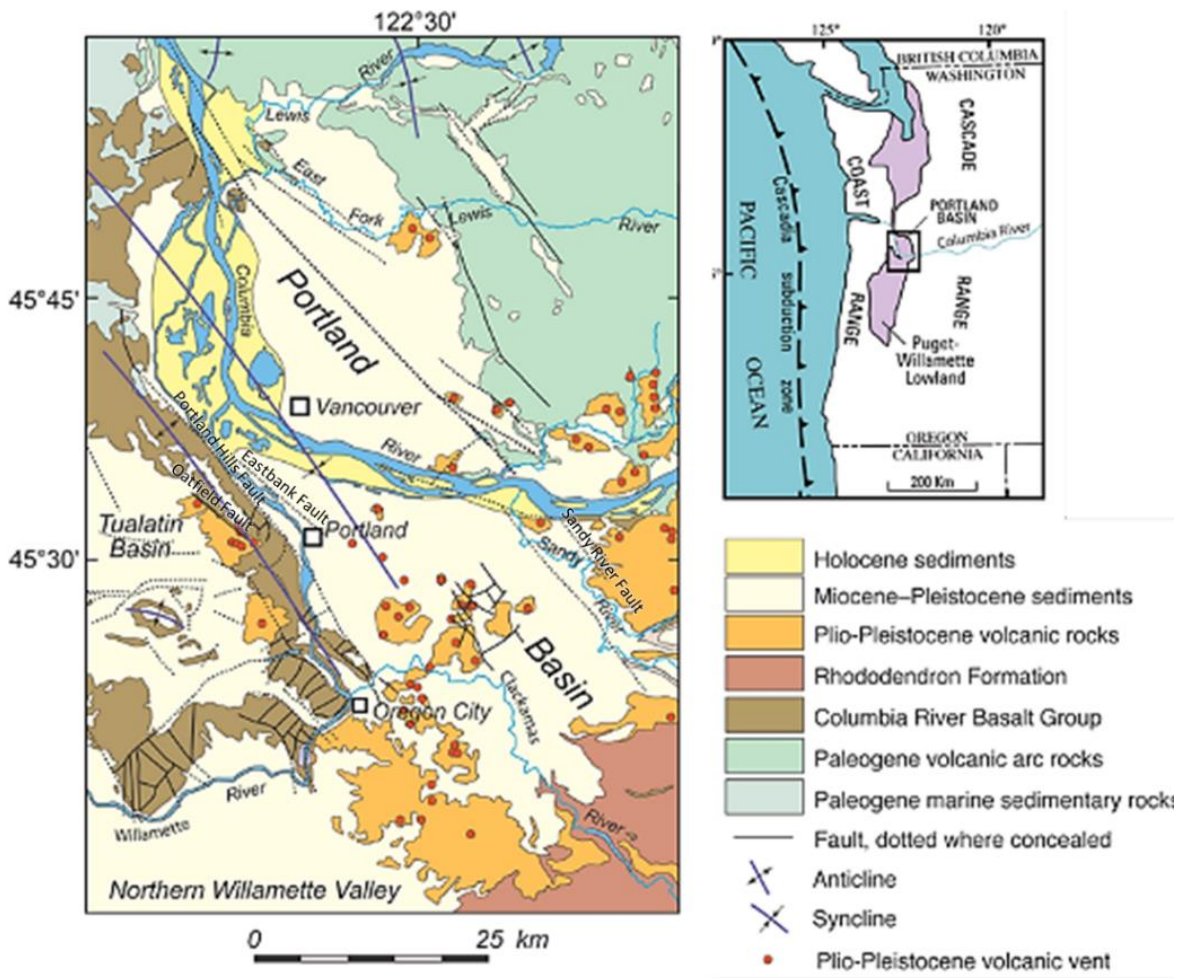

Figure 1.2. Generalized geologic map of the Portland Basin (study area). Inset map shows the location of the Portland Basin within the Puget-Willamette lowland (modified from Evarts et al., 2009). 
The Columbia River transects the Portland Basin and is one of few major rivers to crosscut an active magmatic arc. The resulting Portland Basin stratigraphy expresses the effects of regional tectonics, arc and flood-basalt volcanism, and glacier outburst flooding on sedimentation in a major trans-arc river system (Figure 1.3, Evarts et al., 2009). Basin basement rock comprises Eocene age Siletz River, Waverly Heights, and Goble Volcanics. This basement rock is overlain by Paleogene to early Miocene marine deposits, the top of which is exposed as the Scappoose Formation in the northwestern corner of the basin (Figure 1.2 and Figure 1.3). The Scappoose and early Columbia River Basalt Group (CRBG) are coeval and interfinger in the northern part of the basin (Van Atta and Kelty 1985). Paleogene to early Miocene Cascade volcanic deposits rim and underlie the basin on the eastern side (Evarts et al. 2009).

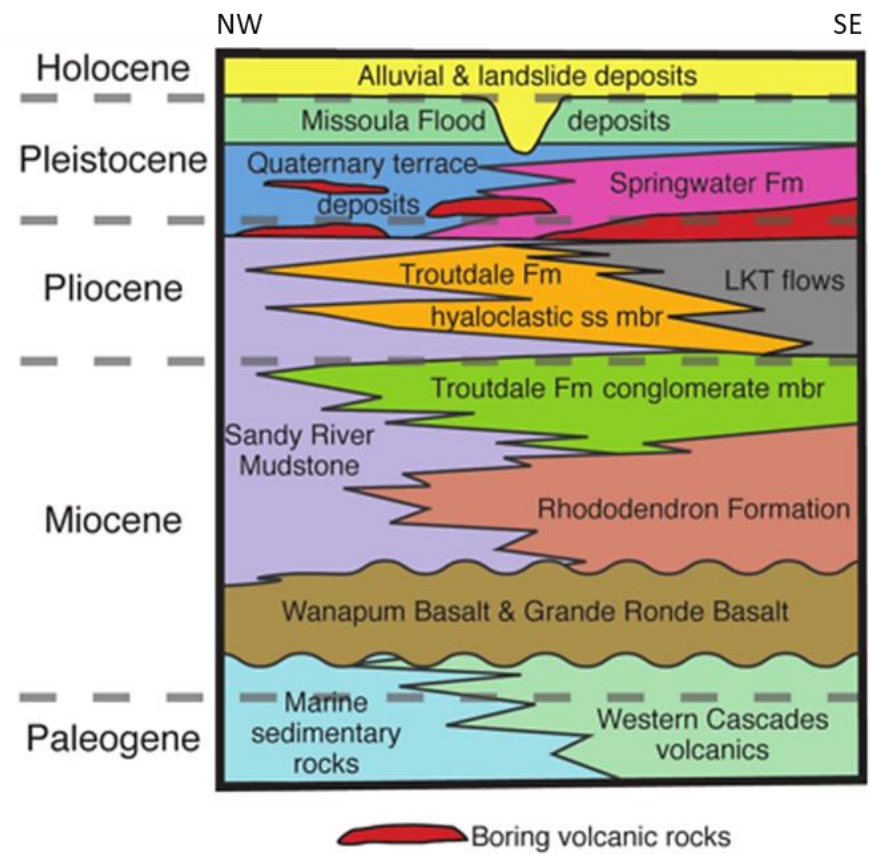

Figure 1.3. Stratigraphic column schematic of the Portland Basin (Evarts et al., 2009). 
The Columbia River continental flood basalts erupted between 17.5 and $6 \mathrm{Ma}$ (Tolan et al. 2009). The most voluminous of these flows, the Grande Ronde, erupted from 17 to 14.5 Ma. CRBG flows extend over $210,000 \mathrm{~km}^{2}$ from western Idaho, eastern and central Washington, and northern Oregon, through the Columbia Trans-Arc Lowland to the Pacific Ocean (Reidel et al. 2013). Flows are thickest in eastern Oregon and Washington, reaching up to 10,000 ft (Tolan et al., 2009b). Well logs indicate a thickness close to 1,000 ft in the Portland Basin and Northern Willamette Valley (Burt and Augustine, 2010; Scanlon, 2019). During the middle Miocene, some CRBG flows inundated the Portland Basin via the Columbia River trans-arc lowland. The CRBG within the basin more recently underwent faulting and folding in response to ongoing regional stress related to subduction (R. J. Blakely et al. 2000; Liberty, Hemphill-Haley, and Madin 2003). Though poorly exposed along the Portland Hills anticline today, weathering and laterization, coupled with overlying Quaternary alluvium and loess deposits, obscure researchers' understanding of the stratigraphy and structure of the CRBG within the basin.

Five out of seventeen members of the CRBG Grande Ronde Basalt flow are exposed in the Portland Hills and can be inferred as present in the Portland Basin. These are the Wapshilla Ridge, Grouse Creek, Ortley, Winter Water, and Sentinel Bluffs members. The Frenchman Springs member of the Wanapum basalt has also been identified in the Portland Hills, overlying members of the Grande Ronde. Individual CRBG flow members can be distinguished based on their paleomagnetic history and their geochemical composition (R.E. Wells et al. 2010). 
Above the CRBG, Sandy River Mudstone and conglomerate Troutdale Formation interfinger, and were deposited through the end of the Miocene and into the Pliocene. The late-Miocene volcaniclastic Rhododendron Formation also interfingers with the Troutdale. Early Quaternary Boring Lavas represent the most recent volcanic activity within the basin (Evarts et al. 2009).

\section{Hydrogeology of the CRBG}

The Troutdale Formation and the CRBG make up the primary groundwater bearing units within the Portland Basin (Tolan et al., 2009a). Older sedimentary marine strata also contain groundwater, but it tends to be saline and of poor chemical quality (Burt et al. 2010). The lower portion of the CRBG is the target zone for DDU-TES operations, as it is likely to be the slowest flowing zone within the aquifer system.

CRBG flows have impermeable flow interiors and permeable flow exteriors (Figure 1.4). Flow interiors are dense and massive and are characterized by colonnades and entablature. The hydraulic conductivity of flow interiors is five orders of magnitude less than that of flow tops and bottoms (Tolan, Lindsey, and Porcello 2009). Flow tops are commonly vesicular and/or scoriaceous due to rapid cooling and degassing, while both flow tops and bottoms are blocky and brecciated (Figure 1.4, Reidel et al., 2013). The porosity of brecciated zones within the CRBG ranges from 6 to 25 percent, while the porosity of vesicular flow segments ranges from 3 to 6 percent (Tolan et al., 2000). These more porous and permeable flow tops and bottoms make up the water bearing interflow zones of the CRBG aquifers. Measurements taken at the City of Beaverton's 
ASR Well No. 3 indicate that the storativity of CRBG interflow zones is on the order of $1 \times 10^{-3}$ (Eaton and Cook 2012).

The stratiform nature of the basalt sheet flows creates a "stacked" series of confined aquifers, which together comprise the CRBG aquifer system. Because interflow zones are laterally continuous with limited vertical permeability, they are a suitable candidate for DDU-TES applications. Vertical flow within the aquifer system is limited to zones where either a flow is truncated by an erosional window or flow pinch out, faulting or folding has occurred, or CRBG flow units are cross-connected by wells (Tolan, Lindsey, and Porcello 2009).

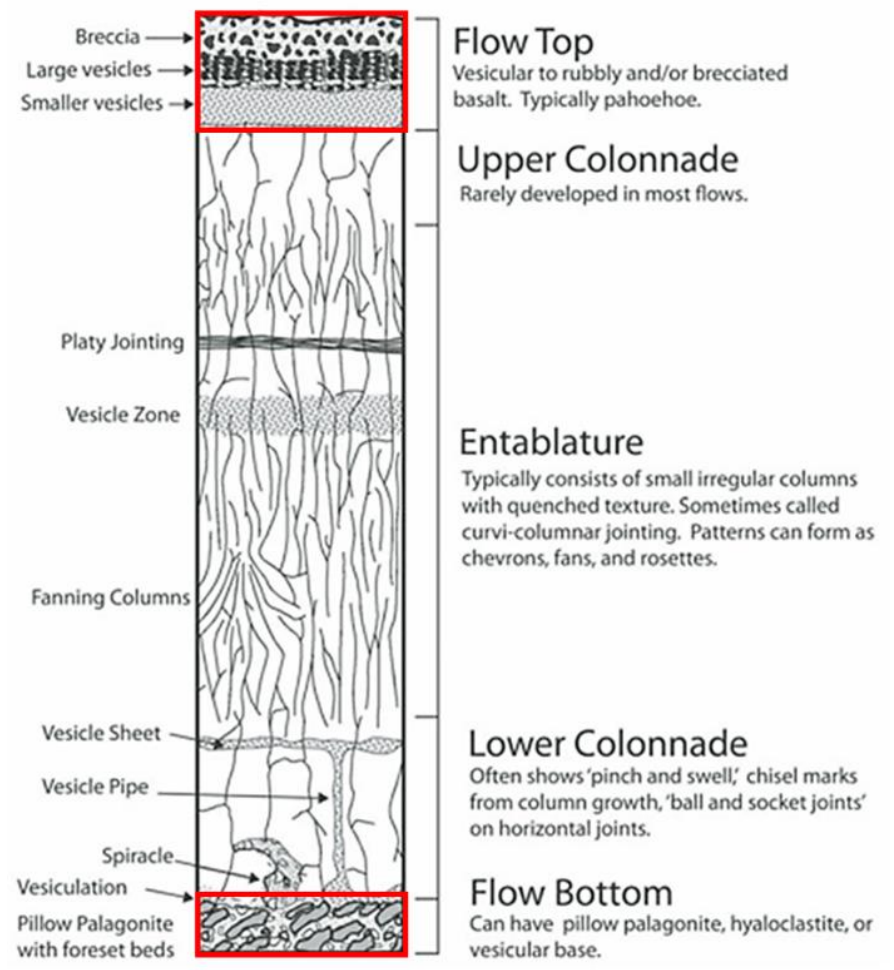

Figure 1.4. Generalization of interflow structures found within a typical Columbia River Basalt sheet flow. Interflow zones are boxed in red (modified from Reidel et al., 2013). 
The permeability of the faulted zones strongly depends on whether secondary mineralization has occurred. In zones where faults are brecciated and no minerals have formed, water can travel vertically with ease. However, the growth of clays and other secondary minerals can reduce the hydraulic conductivity along faults, limiting both vertical and horizontal movement of water (Burt et al. 2010; Tolan, Lindsey, and Porcello 2009).

\section{CRBG Weathering}

The mineralogy of the CRBG primarily comprises plagioclase feldspar, pyroxene (augite), and iron oxides (mostly titanomagnetite). It also includes minor amounts of apatite, olivine, and sulfides (Ames and McGarrah, 1980 and Hearn et al., 1985).

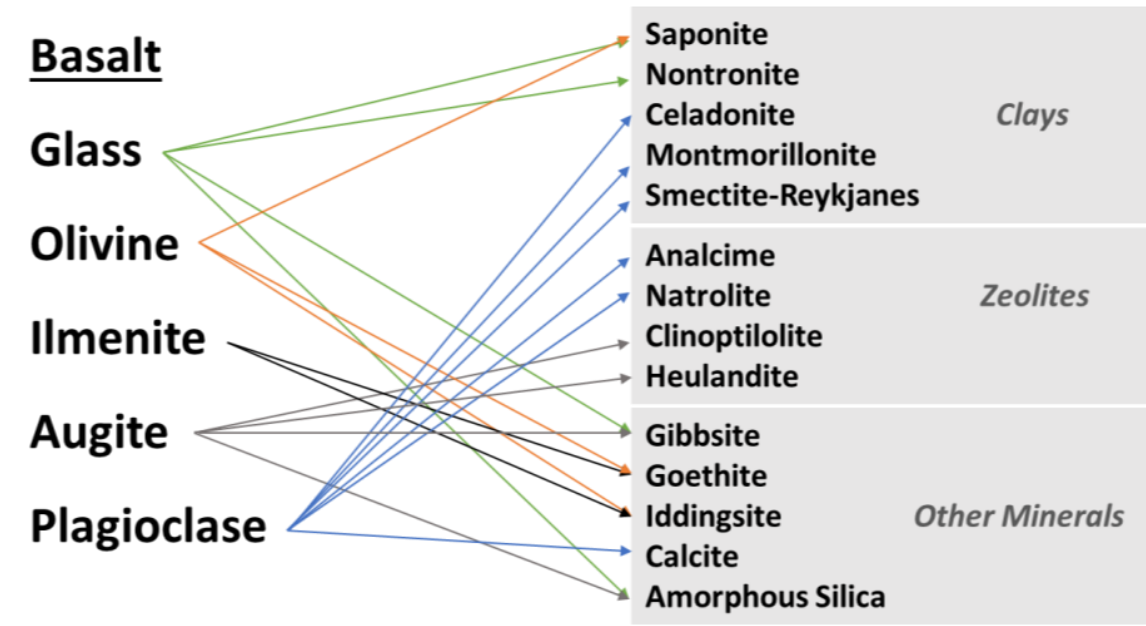

Figure 1.5. CRBG Grande Ronde Basalt mineralogy and associated hydrothermal alteration products (modeled after Ames and McGarrah, 1980; Deutsch et al., 1982; Hearn et al., 1985a, 1990). 
Secondary mineralization often occurs within CRB aquifers. CRBG igneous mineralogy and alteration products are summarized in Figure 1.5. Most secondary minerals are found within the more vesicular and brecciated flow tops and bottoms, which are the primary pathways for groundwater flow. Amorphous silica, cryptocrystalline quartz, smectites and other clays, zeolites, and various iron oxides are all common secondary mineralization products (Deutsch, Jenne, and Krupka 1982; Paul P. Hearn et al. 1990; Tolan, Lindsey, and Porcello 2009). Benson and Teague (1982) suggested secondary minerals in the CRB form in the order 1) smectite (mostly as high Fe-nontronite) and iron oxides, 2) clinoptilolite or other zeolites, and 3) silica and other clays, in response to dissolution of basaltic glass. Iron oxides can also form above depths of 1,000 ft (Hearn et al., 1985). Studies by Hearn and others (1985) and Benson and Teague (1982) found that almost all alteration seems to occur below $100{ }^{\circ} \mathrm{C}$, and that trace amounts of calcite are ubiquitous throughout the CRBG. (Baker et al. (2016) concurred that nontronite forms early in the weathering process of the CRB. However, they also found that at later stages of basalt weathering, dissolution of relict feldspars, apatite, and titanomagnetite coated with nontronite coincides with precipitation of montmorillonite and kaolinite clays. Celadonite (a mica group mineral) has also been found in scoriaceous flow tops of the Grande Ronde Basalt, filling vesicles and replacing the groundmass (Cummings et al., 1989; Baker, 2016). The K for celadonite formation comes from the dissolution of basaltic glass while $\mathrm{Mg}$ and $\mathrm{Fe}$ are weathering byproducts of groundmass augite (Strawn et al. 2012). Deutsch et al. (1982) found that groundwater sampled from the CRB aquifer near Hanford, Washington was in equilibrium with 
calcite, amorphous silica, and the zeolite wairakite. They also found that the groundwater was saturated to oversaturated with respect to secondary clay minerals and ferric hydroxide $\left(\mathrm{Fe}(\mathrm{OH})_{3}\right)$. 


\section{CHAPTER 2: ANALYSIS OF NATIVE GROUNDWATER WITHIN THE COLUMBIA RIVER BASALTS}

The Columbia River Basalt Group aquifer system within the Portland Basin has been used very little compared to the overlying gravel Troutdale Aquifer. As a result, groundwater quality in the CRBG has been less studied, and little is known about the spatial distribution of chemical species within the aquifer system. To better estimate the longevity and costs of DDU-TES in the CRBG, it is essential to determine the existing water quality in the aquifer. Identifying an 'initial' average groundwater chemical composition establishes the starting point for modeling TES and determines a baseline for comparison with simulated heated and re-injected water compositions.

\section{Methods}

\section{Data Compilation}

The groundwater chemistry data analyzed in this project was compiled from published literature, municipal, state and federal water quality reports, and well logs. Groundwater chemistry for Columbia River Basalt wells in western Oregon was gathered into a hydrogeochemical database for analysis (Appendix A). The geographic distribution of the wells is shown in Figure 2.1. The database is augmented with additional hydrogeochemical data for the east side of the Cascade Mountains, including data from the Columbia River Gorge near Mosier, Oregon collected by Jones (2016) and the Columbia Plateau (Vlassopoulos et al., 2009). 


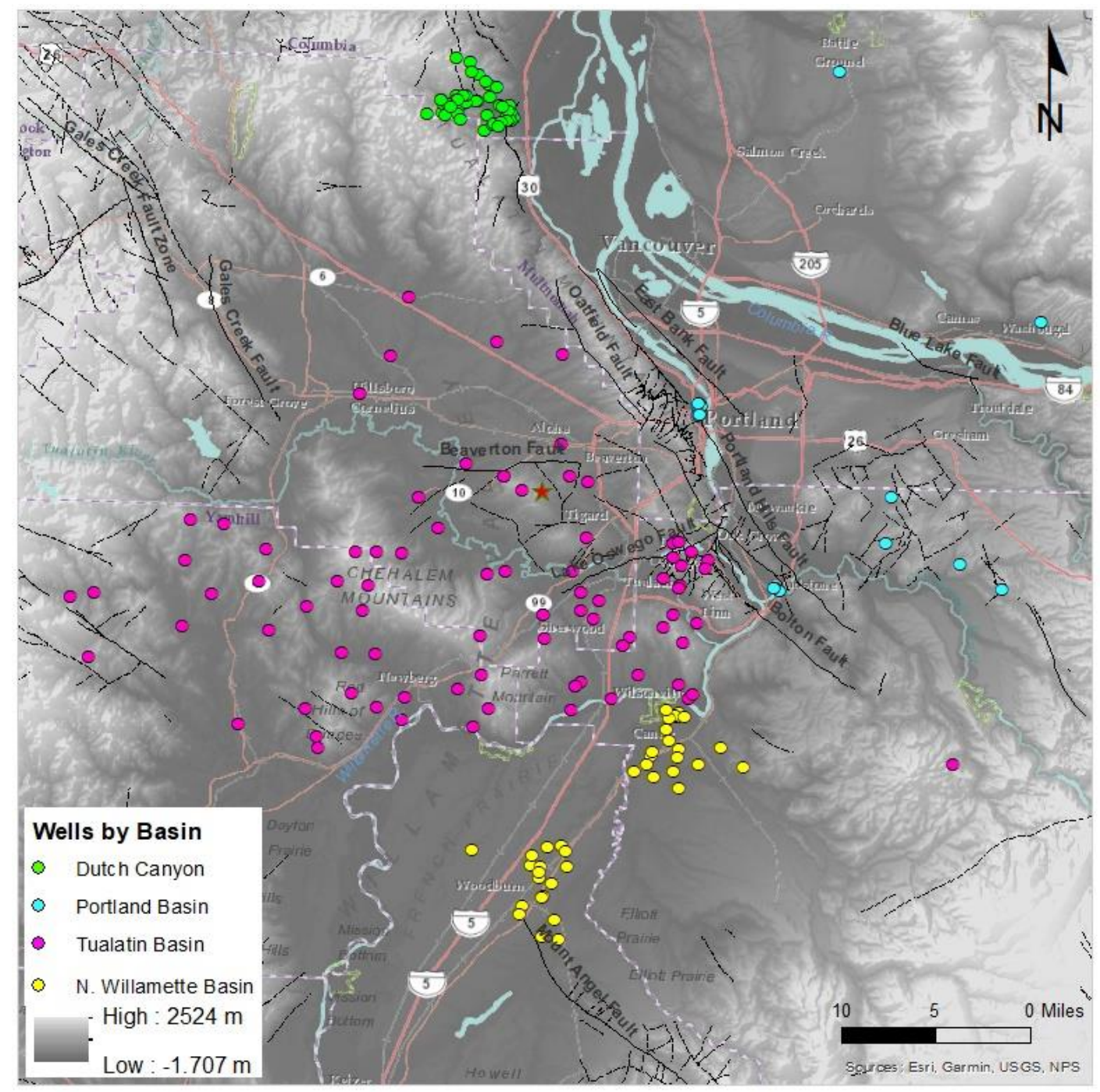

Figure 2.1. Location of wells with groundwater chemistry data in the Portland, Tualatin, and northern Willamette Basins, color coded by basin/region. Black lines represent faults.

Of the 206 wells included in the western Oregon database, 76 wells are in the Portland Basin (including 51 from the area around Dutch Canyon), 89 are in the Tualatin Basin, and 41 are in the northern Willamette Basin. The database includes 82 wells screened in the Columbia River Basalt Group, 60 screened in either basement volcanic units or marine sedimentary units that underlie the CRB, and 4 wells screened over both 
the $\mathrm{CRB}$ and the underlying marine sediments. There are also 15 wells that tap into either the overlying Troutdale aquifer, or both the CRBG and Troutdale, and several wells whose hydrogeology is unknown. Compiling data from the aquifers over- and underlying the CRB allows investigation into the extent to which these aquifers are hydrogeologically connected. The chemical parameters included in the western Oregon database are summarized in Table 2.1.

Table 2.1. Summary Statistics for the compiled Portland, Tualatin, and Willamette Basin groundwater chemistry data. See Appendix A for statistics by hydrogeologic unit.

\begin{tabular}{|c|c|c|c|c|c|}
\hline Parameter & Unit & $\begin{array}{c}\text { No. } \\
\text { Samples* }\end{array}$ & $\begin{array}{l}\text { Minimum } \\
\text { Value }\end{array}$ & $\begin{array}{c}\text { Maximum } \\
\text { Value }\end{array}$ & $\begin{array}{c}\text { Average } \\
\text { Value }\end{array}$ \\
\hline Date & -- & 193 & $2 / 16 / 1938$ & $12 / 10 / 2019$ & -- \\
\hline Well Depth & $\mathrm{Ft}$ & 153 & 0 & 9203 & 470 \\
\hline Temperature & ${ }^{\circ} \mathrm{C}$ & 149 & 7.5 & 23 & 12.5 \\
\hline Eh & $\mathrm{mV}$ & 58 & -248 & 793 & 60.1 \\
\hline $\mathrm{pH}$ & -- & 201 & 5.6 & 9.3 & 7.3 \\
\hline $\mathrm{SiO} 2$ & $\mathrm{mg} / \mathrm{L}$ & 191 & 0.6 & 81 & 39.3 \\
\hline $\mathrm{Na}$ & $\mathrm{mg} / \mathrm{L}$ & 178 & 0 & 8980 & 148.2 \\
\hline K & $\mathrm{mg} / \mathrm{L}$ & 170 & 0.1 & 608 & 7.3 \\
\hline $\mathrm{Ca}$ & $\mathrm{mg} / \mathrm{L}$ & 197 & 0 & 15400 & 147.9 \\
\hline $\mathrm{Mg}$ & $\mathrm{mg} / \mathrm{L}$ & 194 & 0 & 113 & 9.1 \\
\hline Total Hardness & $\mathrm{mg} / \mathrm{L}$ as $\mathrm{CaCO} 3$ & 203 & 0 & 76800 & 679 \\
\hline Alkalinity & $\mathrm{mg} / \mathrm{L}$ as $\mathrm{CaCO} 3$ & 163 & 1 & 836.6 & 99.1 \\
\hline $\mathrm{HCO} 3$ & $\mathrm{mg} / \mathrm{L}$ & 204 & 4.9 & 808 & 131.5 \\
\hline $\mathrm{Cl}$ & $\mathrm{mg} / \mathrm{L}$ & 205 & 0.6 & 43700 & 422.8 \\
\hline SO4 & $\mathrm{mg} / \mathrm{L}$ & 193 & 0 & 230 & 8.5 \\
\hline $\mathrm{Sr}$ & $\mathrm{mg} / \mathrm{L}$ & 11 & 0.03 & 0.14 & 0.06 \\
\hline $\mathrm{Mn}$ & $\mathrm{mg} / \mathrm{L}$ & 109 & 0 & 24.8 & 0.4 \\
\hline $\mathrm{Fe}$ & $\mathrm{mg} / \mathrm{L}$ & 163 & 0 & 16 & 1 \\
\hline $\mathrm{Al}$ & $\mathrm{mg} / \mathrm{L}$ & 10 & 0.01 & 5.6 & 0.73 \\
\hline As & $\mathrm{mg} / \mathrm{L}$ & 20 & 0.001 & 0.022 & 0.008 \\
\hline $\mathrm{F}$ & $\mathrm{mg} / \mathrm{L}$ & 171 & 0 & 3.2 & 0.2 \\
\hline $\mathrm{Ba}$ & $\mathrm{mg} / \mathrm{L}$ & 13 & 0.003 & 0.15 & 0.039 \\
\hline$B$ & $\mathrm{mg} / \mathrm{L}$ & 49 & 0 & 2.1 & 0.2 \\
\hline $\mathrm{Br}$ & $\mathrm{mg} / \mathrm{L}$ & 6 & 0.03 & 32 & 5.55 \\
\hline $\mathrm{NO} 2$ & $\mathrm{mg} / \mathrm{L}$ & 8 & 0.0014 & 4.8 & 1.12 \\
\hline NO3 & $\mathrm{mg} / \mathrm{L}$ & 93 & 0 & 1.9 & 0.3 \\
\hline $\mathrm{NH} 3$ & $\mathrm{mg} / \mathrm{L}$ & 32 & 0.02 & 1.7 & 0.5 \\
\hline TDS & $\mathrm{mg} / \mathrm{L}$ & 205 & 15.92 & 68800 & 1070 \\
\hline
\end{tabular}




\section{Mineral Saturation States}

Equilibrium modeling was used to determine mineral saturation states, aqueous species activities, and gas fugacities within the groundwater system. The equilibrium state of groundwaters east and west of the Cascades were calculated using the geochemical modeling programs PhreeqC (Parkhurst, 1995) and Geochemists Workbench (Bethke, 2008). Calculations were performed using both the Lawrence Livermore National Laboratory (LLNL) thermodynamic database (Johnson et al., 2000) and a modified version of the LLNL database. The modified database was developed to reflect a mineral assemblage relevant to low temperature hydrothermal alteration in the Columbia River Basalt Group and comprises minerals and species from the LLNL database, with the addition of basaltic glass, plagioclase, olivine, pyroxene, Fe-chlorite, Mg-chlorite, celadonite, Fe-celadonite, mesolite, and stilbite from the Carbfix thermodatabase (Aradóttir, Sonnenthal, and Jónsson 2012). The standard deviations of calculated minerals' saturation indices were determined after the methods of Palmer (2015). Minerals at or near saturation are those most likely to dissolve or precipitate in response to thermal energy storage processes to maintain equilibrium.

\section{Hierarchical Cluster Analysis}

Both summary statistics and hierarchical cluster analysis (HCA) were used to investigate the link between basin hydrogeology and groundwater chemistry in the Portland region. Hierarchical cluster analysis is a multivariate statistical method for grouping samples into clusters based on some measure of distance between the variates. 
This technique allows us to more easily investigate relationships between dissolved constituents, spatial location, and lithology. HCA was used to investigate the complete dataset, including all hydrogeologic units in the region, and to analyze only CRB groundwaters. Based on the clusters identified by HCA, several "average" groundwater compositions were identified within the TES target zone. These compositions serve as starting points for modeling geochemical changes induced by TES (Ch. 4).

Cluster analysis was conducted in R, using the "cluster" package (University of Cincinnati, 2018). Both the basin wide and CRB cluster analyses required that samples with missing data be excluded from the datasets. The number of useable samples was minimally decreased by only clustering based on observations of $\mathrm{pH}$, calcium, magnesium, the sum of sodium and potassium, chloride, sulfate, and bicarbonate concentrations for the basin wide analysis. The sum of $\mathrm{Na}$ and $\mathrm{K}$ was used because many of the Portland Basin wells did not have $\mathrm{Na}$ and $\mathrm{K}$ concentrations separately reported. The final basin-wide HCA was conducted using 172 out of 207 samples. The CRB analysis was conducted using the same parameters and included 71 out of 89 samples.

The reduced data sets were scaled via a z-score, then used to calculate Euclidean distance matrices. Both analyses used an agglomerative clustering approach and Ward's minimum variance method to determine the similarity/dissimilarity between samples. The gap statistic method was used to determine the statistically optimal number of clusters as six for the basin wide analysis and three for the CRB. (Gap statistics were also calculated using the "cluster" package in R; University of Cincinnati, 2018.) Because of the multiple water types and sources present in the Portland and surrounding basins, where the gap 
statistic method identified multiple numbers of possible clusters, we grouped data into more, rather than fewer clusters. Wells excluded from the HCA due to incomplete data were assigned to clusters based on similarities in their available chemistry and lithology data for both the basin wide and CRB analysis. Three samples not included in the original basin-wide cluster analysis (because of incomplete data) contained TDS much higher than any of the other wells and were designated as a seventh group.

\section{Results}

\section{Chemical Characterization of CRBG Groundwater}

Groundwater compositions vary significantly even within CRBG units. Piper plots of the western Oregon groundwater data compiled for this study reveal that groundwaters in the Portland Basin and surrounding areas are primarily $\mathrm{Ca}-\mathrm{Mg}-\mathrm{HCO}_{3}{ }^{-}$ type waters (Figure 2.2), although the basin also contains calcium or sodium sulfate or chloride type waters, typically observed in wells with higher TDS.

Compared to CRB groundwater east of the Cascades, waters in the Portland Basin have a lower temperature and $\mathrm{pH}$ and lower $\mathrm{SiO}_{2}, \mathrm{SO}_{4}{ }^{2-}, \mathrm{HCO}_{3}{ }^{-}$, and $\mathrm{F}^{-}$concentrations. Some waters in the Portland Basin also have higher $\mathrm{Cl}^{-}, \mathrm{Na}^{+}$, and $\mathrm{K}^{+}$concentrations compared to eastern wells (Figure 2.3). As a result, some western Oregon wells have higher amounts of dissolved solids than wells east of the Cascades. The difference in groundwater composition between CRB aquifers east and west of the Cascades may be linked to the wetter climate west of the mountains and differing soil types in recharge 
zones through which recharge waters percolate. Differences in chemistry may also be influenced by mineral saturation states of the groundwaters.

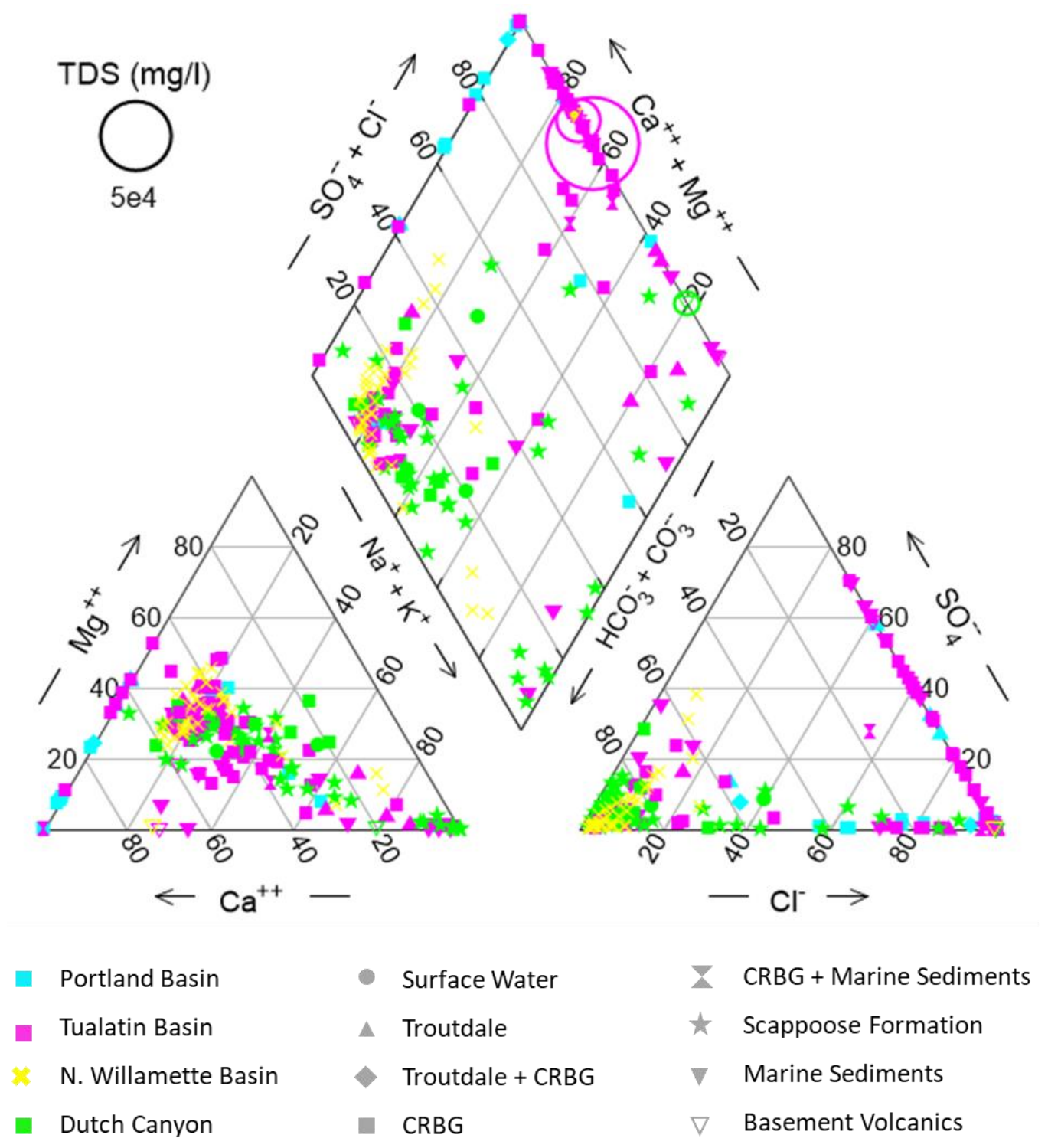

Figure 2.2. A piper plot of CRB groundwaters generated with data from this study. Colors indicate regional location, while shapes indicate the well's hydrogeologic unit. 

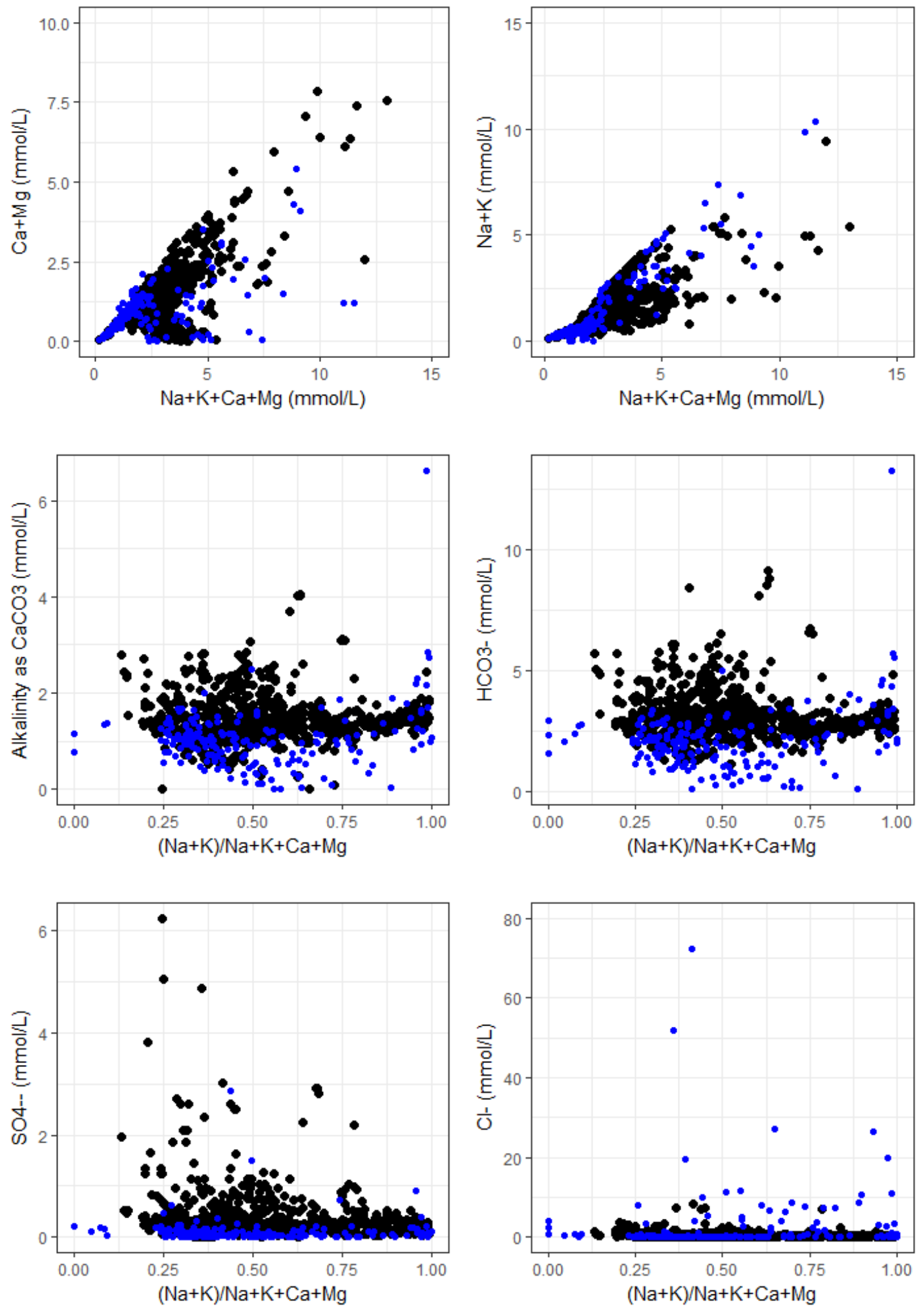

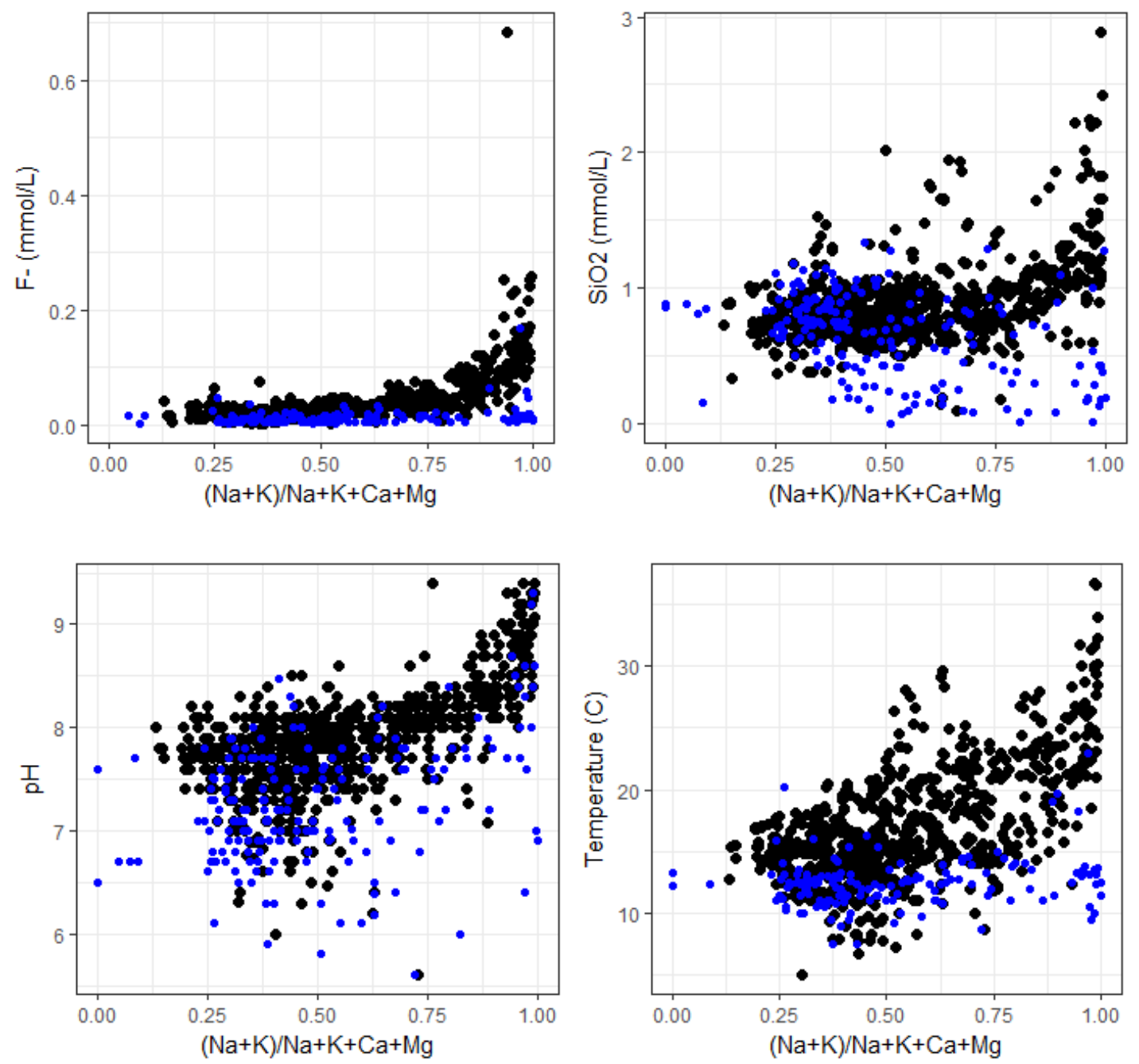

Figure 2.3. Comparison of groundwater chemistry of waters east of the Cascades (black) and west of the Cascades (blue) in $\mathrm{mmol} / \mathrm{L}$.

\section{Mineral Saturation States}

Calculated saturation indices (Figure 2.4) indicate that most CRB samples are undersaturated with respect to the primary basalt minerals plagioclase, pyroxene, and basaltic glass. Most CRB groundwaters east of the Cascades are in equilibrium with respect to calcite, while western Oregon $\mathrm{CRB}$ groundwaters are, on average, marginally 
undersaturated with respect to calcite. In both regions, waters are slightly undersaturated with respect to rhodochrosite, magnesite, and siderite, and slightly oversaturated with respect to witherite. CRB Groundwaters on both sides of the Cascades are on average oversaturated (saturation indices of 0.5 to 1.0) with respect to $\mathrm{SiO}_{2}$ phases, except for amorphous silica, with which waters are marginally undersaturated (mean saturation indices of -0.27 and -0.46$)$. CRB groundwaters also are oversaturated with respect to clay and zeolite phases, although some groundwaters in western Oregon are somewhat undersaturated with respect to certain smectites (Figure 2.4). Groundwaters on both sides of the Cascades are oversaturated with respect to goethite. However, waters east of the mountains are undersaturated with respect to $\mathrm{Fe}(\mathrm{OH})_{3}(\mathrm{ppd})$ and gibbsite, while waters west of the Cascades are oversaturated with respect to both (Figure 2.4, Appendix A).

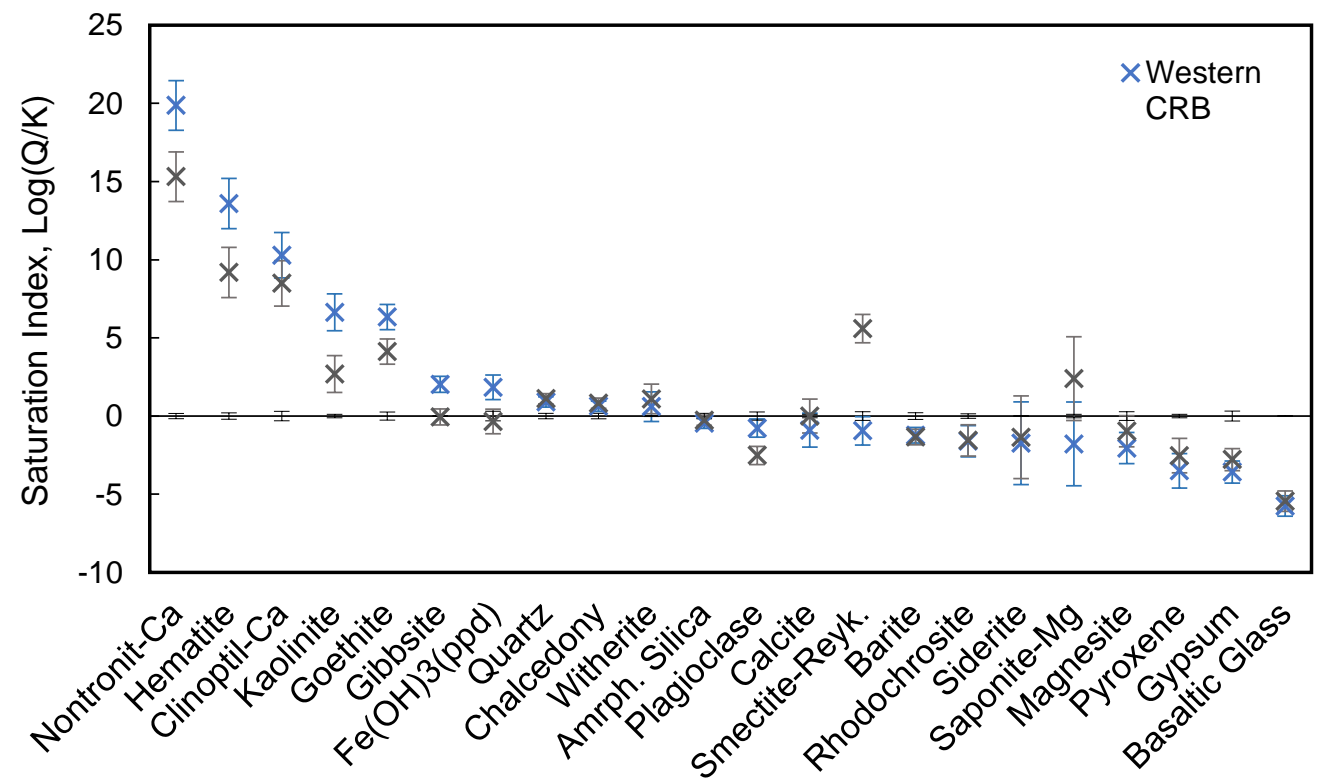

Figure 2.4. Average saturation indices of minerals with respect to $\mathrm{CRB}$ groundwater east (blue) and west (red) of the Cascades. Error bars are based on the standard deviation of the samples' average SI. Error bars about the origin provide the standard deviation of the SI calculation based on stoichiometry. 
The calculated saturation indices suggest that within the CRB carbonate minerals (particularly calcite), $\mathrm{Al}$ and $\mathrm{Fe}$ hydroxides, and silica phases are most likely to dissolve or precipitate in response to cycles of heating, injection, and extraction of a thermal energy storage system. Clay phases near saturation (saponite and Icelandic smectite) may also increase the rate at which they form or dissolve in response to elevated temperatures.

\section{Hierarchical Cluster Analysis}

Cluster analysis of the CRB groundwaters revealed three groups (summarized in Table 2.2). The first group (CRB1) consists of recharge waters with low TDS, which are undersaturated with respect to calcite. The second group (CRB2) represents more evolved waters that have higher cation and bicarbonate concentrations but are still below saturation with respect to calcite. The third group (CRB3) contains samples with the greatest range in compositions and comprises mature groundwaters, generally from deeper wells, that have high TDS, primarily because of elevated chloride concentrations. Most CRB3 samples are at equilibrium with respect to calcite (Figure 2.5). Calcite precipitation controls bicarbonate concentrations, preventing it from building up in the water, and raising the water's $\mathrm{pH}$. This may explain why CRB3 switches from a calcium-magnesium-bicarbonate type water (as in CRB1 and CRB2) to a water type where chloride is the dominant anion. 

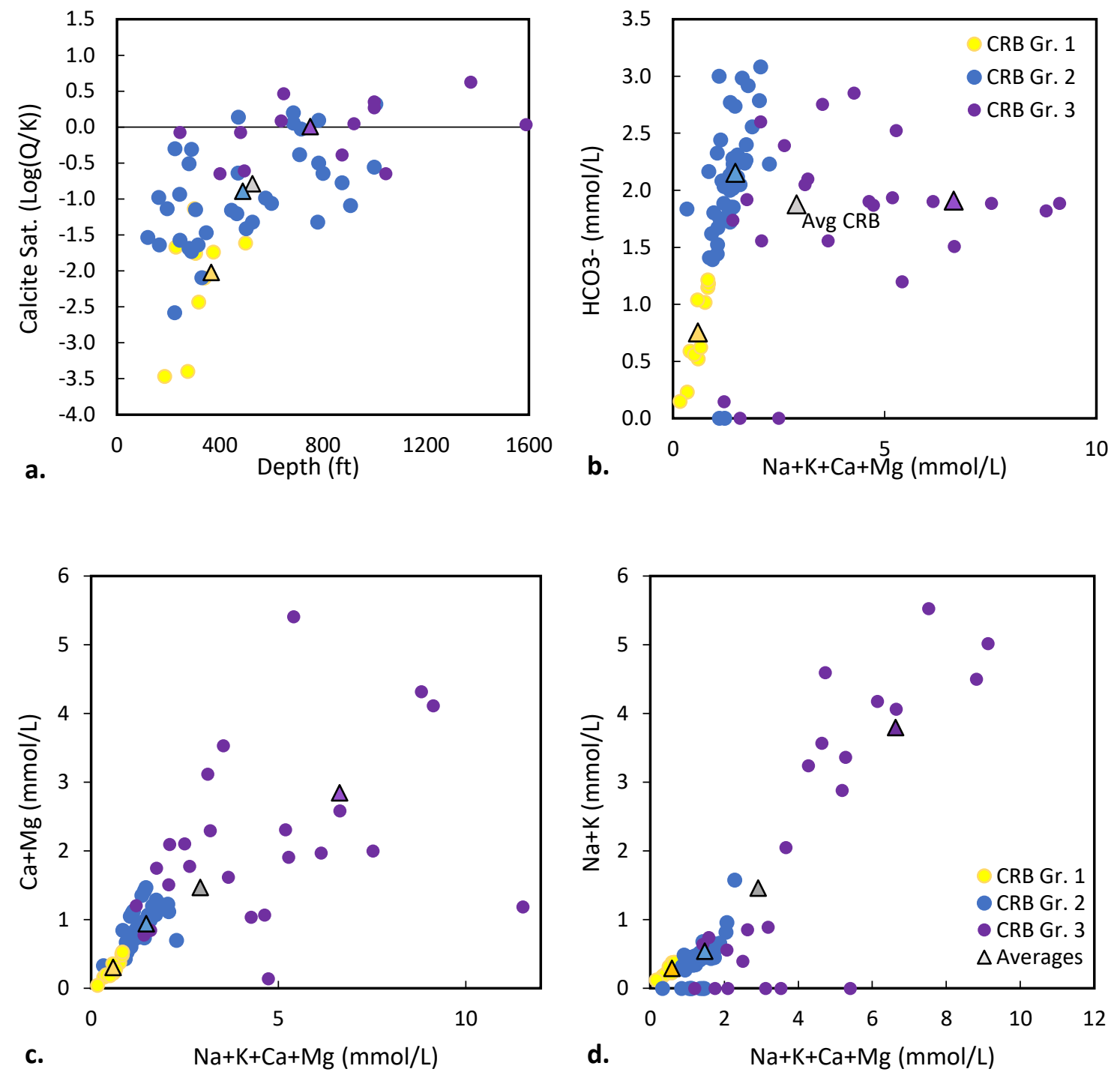

Figure 2.5. Calcite saturation by group with depth (a), bicarbonate concentration by the sum of major cations for clustered CRB wells (b), $\mathrm{Ca}$ and $\mathrm{Mg}$ versus the sum of major cations (c), and $\mathrm{Na}$ and $\mathrm{K}$ versus the sum of major cations (d) for $\mathrm{CRB}$ wells. Color indicates the groundwater group, with recharge waters plotting closest to the origin.

The basin wide HCA identified seven distinct groundwater groups, summarized in Table 2.2, below. Similar to the CRB cluster analysis, Group 1 of the basin wide HCA represents unevolved recharge waters. These occur primarily at wells that are shallow, at 
high elevation, near a fault, or that tap the Troutdale aquifer in addition to the CRB wells identified in the previously described HCA. Group 2 represents slightly more evolved waters (similar to $\mathrm{CRB} 2$ ), that have elevated levels of $\mathrm{Ca}$ and $\mathrm{Mg}$ from increased time spent in the aquifer, compared to Group 1. Group 3 has low TDS, similar to Group 1, but a greater amount of $\mathrm{Na}$ and $\mathrm{K}$ compared to $\mathrm{Ca}$ and $\mathrm{Mg}$ and varies more widely in composition. This is apparent in Figure 2.6. Group 4 has a similar composition to CRB group 3 and basin wide group 2, but has somewhat higher TDS and elevated $\mathrm{Na}$ and $\mathrm{K}$ compared to the increasing $\mathrm{Ca}$ and $\mathrm{Mg}$ trend in Groups 1 and 2. Group 6 consists of brackish waters with a TDS concentration greater than $1,000 \mathrm{mg} / \mathrm{L}$ and significantly higher Na compared to Ca concentrations. Group 5 has a concentration similar to Group 6, but with elevated $\mathrm{SO}^{2-}$ concentrations ( $>87 \mathrm{mg} / \mathrm{L}$ ). Group 7 comprises saline water (TDS >10,000 mg/L), sourced from Tertiary marine sediments, basement volcanic rocks, and certain CRBG wells.

Graphically evaluating the groups identified via HCA revealed that in some groups (e.g. 1 and 2), $\mathrm{Ca}$ and $\mathrm{Mg}$ concentrations increase linearly with total cation concentration (Figure 2.6a). Sampled wells in these groups are primarily calciummagnesium-bicarbonate waters. However, cation concentrations in groups 3 and 4 are widely scattered, and include samples with much higher sodium and potassium concentrations when compared to group 1 and 2 samples with similar calcium and magnesium concentrations (Figure 2.6a and b). Group 3 samples are mostly of sodiumbicarbonate waters, while Group 4 shifts to primarily $\mathrm{Ca}-\mathrm{Cl}$ waters. Groups 6 and 7 are further enriched in sodium and consist of $\mathrm{Na}-\mathrm{Cl}$ type waters. 
Table 2.2. Groups identified using HCA, ranging from recharge waters to deep saline waters.

\begin{tabular}{|c|c|c|}
\hline Group & Water Type & Description \\
\hline CRB1 & Recharge & $\begin{array}{l}\text { Low TDS recharge water, undersaturated with respect } \\
\text { to calcite. }\end{array}$ \\
\hline CRB2 & Evolving CRB & $\begin{array}{l}\text { More evolved CRB still undersaturated with respect to } \\
\text { calcite, but with elevated bicarbonate and cation } \\
\text { concentrations. }\end{array}$ \\
\hline CRB3 & Mature CRB & $\begin{array}{l}\text { Mature, high TDS deep CRB waters. At equilibrium with } \\
\text { respect to calcite. }\end{array}$ \\
\hline 1 & Recharge & $\begin{array}{l}\text { Recharge water, consisting of unevolved Troutdale and } \\
\text { CRBG. Characterized by low TDS }(<300 \mathrm{mg} / \mathrm{L})\end{array}$ \\
\hline $2 \bullet$ & $\begin{array}{l}\text { Evolving } \\
\text { recharge }\end{array}$ & $\begin{array}{l}\text { More evolved Troutdale and CRBG water that has not } \\
\text { experienced mixing with brackish water. Contains lower } \\
\text { Na:Ca ratios }\end{array}$ \\
\hline 3 & $\begin{array}{l}\text { Unevolved, } \\
\text { mixed waters }\end{array}$ & $\begin{array}{l}\text { Less evolved CRBG water that has been influenced by } \\
\text { mixing with brackish water. Low TDS, but increased } \mathrm{Na} \\
\text { to } \mathrm{Ca} \text { concentrations }\end{array}$ \\
\hline $4 \bullet$ & $\begin{array}{l}\text { Mature, some } \\
\text { mixing }\end{array}$ & $\begin{array}{l}\text { More evolved CRBG water that has mixed with brackish } \\
\text { water. Characterized by higher TDS and widely } \\
\text { scattered Na:Ca ratios }\end{array}$ \\
\hline $5 \bullet$ & High sulfate & $\begin{array}{l}\text { Older, evolved CRBG and tertiary marine sediment } \\
\text { waters, with high } \mathrm{SO}_{4} \text { concentrations (average of } 87 \\
\mathrm{mg} / \mathrm{L} \mathrm{SO}_{4} \text { ) }\end{array}$ \\
\hline $6 \circ$ & Brackish & $\begin{array}{l}\text { Brackish water that has migrated upwards, } \\
\text { characterized by high } \mathrm{Na} \text { :Ca and average TDS }>1,000 \\
\mathrm{mg} / \mathrm{L}\end{array}$ \\
\hline $7 \bullet$ & Saline & $\begin{array}{l}\text { Older, saline water from marine sediments and } \\
\text { basement volcanics. Contains very high TDS (average } \\
>10,000 \mathrm{mg} / \mathrm{L} \text { ) }\end{array}$ \\
\hline
\end{tabular}



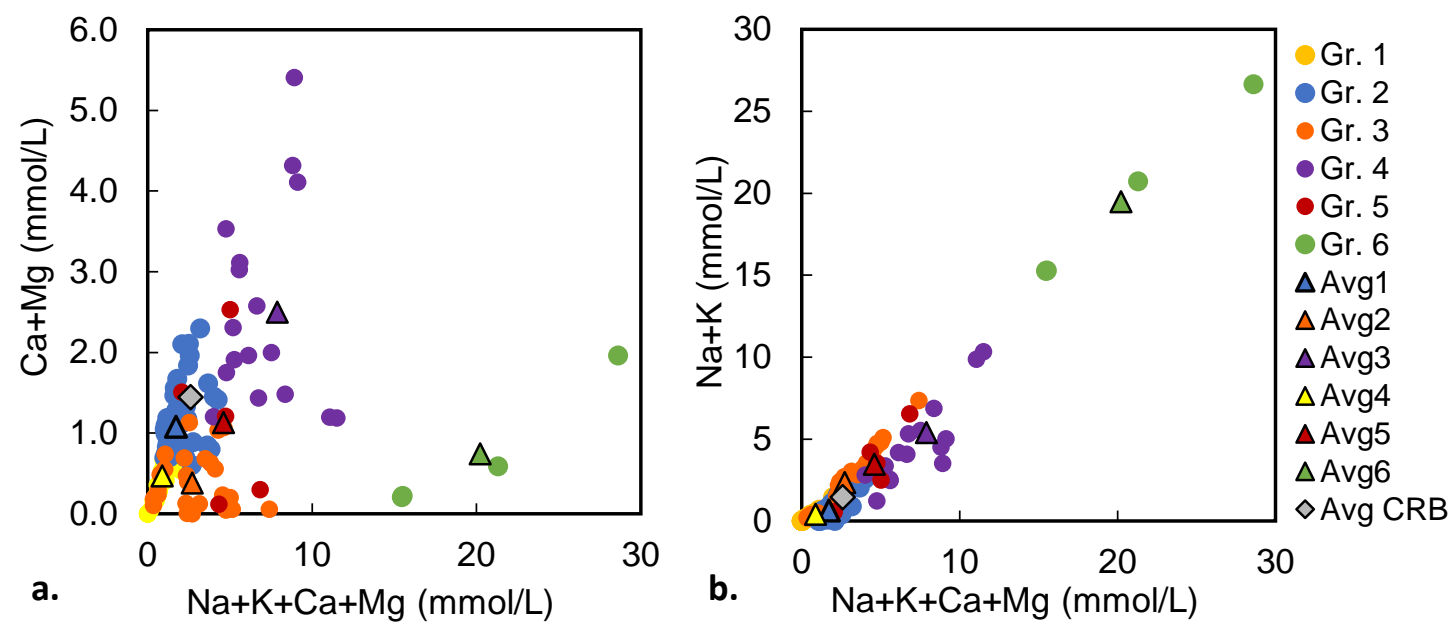

Figure 2.6. $\mathrm{Ca}$ and $\mathrm{Mg}$ versus the sum of major cations (a) and $\mathrm{Na}$ and $\mathrm{K}$ versus the sum of major cations (b). Color indicates groundwater type, with recharge waters plotting closest to the origin. Group 7 is not pictured, as it plots outside the bounds of the chart axes.

\section{Discussion}

\section{Groundwater Mixing}

The mixing of different groundwaters could explain how waters morph from Ca$\mathrm{HCO}_{3}{ }^{-}$type waters to $\mathrm{Na}-\mathrm{HCO}_{3}{ }^{-}$or $\mathrm{Na}-\mathrm{Cl}^{-}$type waters. For example, mixing $75 \%$ TBCRB-9 well water (representative of uninterrupted groundwater evolution within the CRB) with 25\% TB-M-3 well water (representative of high TDS water from underlying units) closely matches the composition of Portland Basin well PB-CRB-4 with regard to major cation and chloride compositions (see Appendix A Table A-5 for full results). These mixing models imply much of the scatter seen in Groups 3 and 4 in $\mathrm{Ca}+\mathrm{Mg}$ vs major cation plots can be attributed to mixing between CRB groundwaters and brackish waters from underlying units. Mixing between CRB waters and high TDS waters from underlying units can also explain elevated chloride concentrations in some CRB wells. 
However, identifying the true extent of mixing is complicated when considering there are multiple interflow zone aquifers at play, which all have a slightly different chemistry.

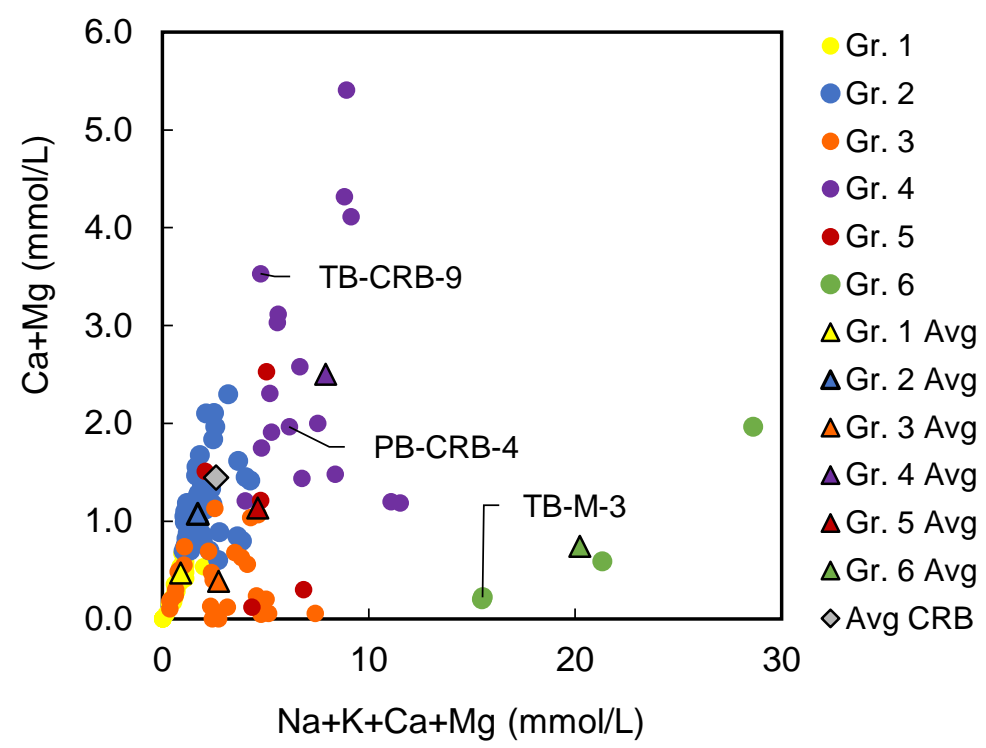

Figure 2.7. $\mathrm{Ca}$ and $\mathrm{Mg}$ versus the sum of major cations. The composition of well PBCRB-4 can be duplicated by mixing wells TB-CRB-9 and TB-M-3.

Given one third of wells in the compiled database show a potentially mixed composition implies a greater connectedness between the CRBG and underlying saline aquifer than previously suspected. Possible mixing mechanisms include upwelling along faults and migration along well bores screened over both aquifers. Mixing can also result from pumping and drawdown of the upper aquifers. As the upper aquifers are pumped and heads reduced, the vertical hydraulic gradients increase, and deeper saline water can up-well from the underlying strata. Hydraulic gradients can also be locally reversed, causing initially downward flow before pumping to become upward flow as a result of lower hydraulic head in the upper aquifer. The effects of pumping can be observed at 
Oregon Water Resources well CLAC 3033 (TB-CRB-56 in the western Oregon CRBG groundwater chemistry database, Appendix A Table A-2) where TDS increased from 175 to $550 \mathrm{mg} / \mathrm{L}$ between the years 1942 and 1949, after 7 years of pumping. Upwelling and mixing between waters in the CRBG and underlying units would also explain the higher chloride and total dissolved solids content of CRBG groundwater in western Oregon compared to CRBG groundwaters east of the Cascade Range. This widespread mixing and upwelling could be enabled by Holocene active faulting in the Portland Basin (Horst, 2019). Additionally, the CRB are thinner on the western side of the Cascades (farther from the eruption source) and marine sedimentary units reside in the near subsurface within the Portland Basin, possibly interfingering with the earliest CRB in some locations (Ketrenos, 1986; Aherna and Perkins, 2016).

The brackish water wells from group 6 (shown in green in Figure 2.8), plot amid many wells with less evolved groundwater (e.g. Groups 1 and 2). Group 6 wells are high in sodium, chloride, and other dissolved solids, and are located along a northwestsoutheast trend, between the Gales Creek Fault to the north and the Mount Angel Fault to the south. The Gales Creek and Mount Angel fault systems are connected by the Gales Creek-Mount Angel Structural Zone (Reidel et al. 1989). Deeper groundwater may be upwelling along the fault planes and mixing with shallow groundwaters in this location. Upwelling would explain why a well that taps the shallow Troutdale aquifer (TB-TR-2) contains such brackish water, and faulting provides an explanation for the presence of Tertiary marine sediments in relatively shallow wells (TB-M-3 and TB-M-10, see Appendix A). 


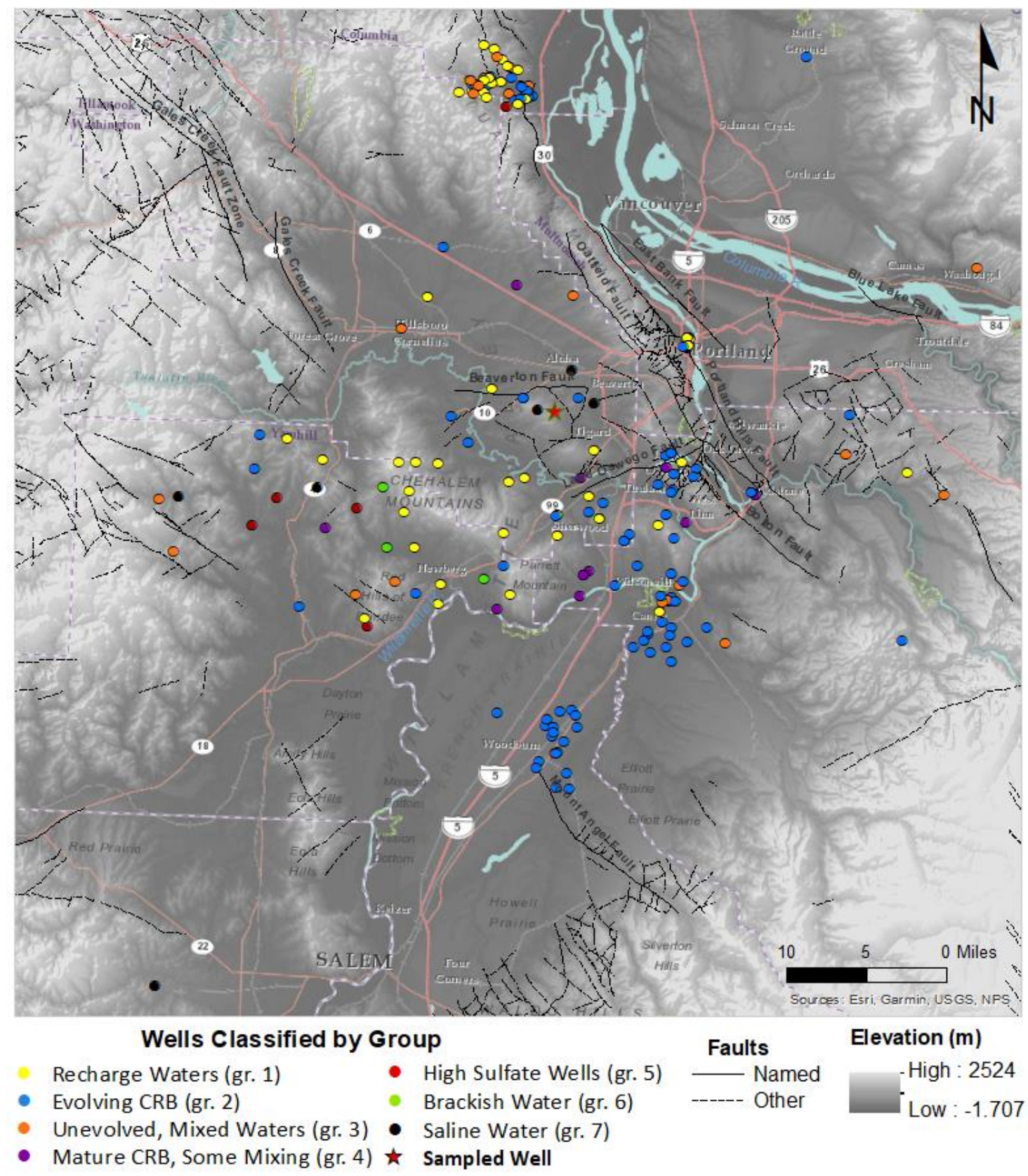

Figure 2.8. Western Oregon well locations, color coded by groundwater group. Lines represent faults. Note that group 6 wells (in green) are shallow wells with a brackish water chemistry that plot directly within the Gales Creek - Mount Angel Structural Zone.

Groundwater in the Portland and surrounding basins appears to evolve with increasing time spent in the aquifer, shown by approaching saturation with respect to 
calcite with increasing depth. However, while deeper waters are closer to saturation with respect to calcite, they do not show an increase in TDS at greater depths as we would expect. The lack of a correlation between depth and TDS could be due to more extensive secondary mineralization at depth. Groundwater mixing, promoted by the extensive faulting and folding the CRBG have undergone since inundating the area in the midMiocene, could also mask the expected correlation between increasing depth and increasing TDS. Lastly, the lack of correlation may also be a result of limitations imposed by relatively short groundwater flow paths between higher elevation recharge zones (e.g., the West Hills and Chehalem Mountains) and the furthest sampled points (e.g. the centers of the Portland and Tualatin Basins).

\section{Establishing Average Groundwater Composition}

Implementing a thermal energy storage system in the lower portion of the Portland Basin CRB aquifer requires some knowledge of the groundwater chemistry found in that zone. An average groundwater composition representative of water in the target zone was calculated by taking the $10 \%$ trimmed mean of all CRBG groundwater samples from western Oregon. Using a trimmed mean cut out the highest and lowest $10 \%$ of values used in the average, which removed any outliers and samples that were impacted by excessive mixing or that could be immature. The result of the calculation approximates the samples that fall at the end of the Ca-Mg linear trend in Figure 2.6a. It includes wells that may have undergone mixing and that exhibit a variety of $\mathrm{CaCO}_{3}$ saturation states. These variabilities were included in the average composition 
calculation because they appear widespread throughout the Portland and Tualatin Basins. This average was used as the basis for reaction modeling of TES operations in the Portland Basin's CRBG aquifer system. The average of each HCA identified CRB group, and the average of groups 6 and 7 from the basin wide HCA (the brackish and saline waters, respectively) were also used to model the system, to constrain the impact variable native groundwater compositions on TES processes (see CH. 4). 


\section{CHAPTER 3: THERMAL ROCK-WATER BATCH REACTIONS}

Implementing thermal energy storage in Portland Basin CRBG aquifers will

change the chemical equilibrium state of groundwaters with respect to aquifer minerals.

Laboratory scale reaction experiments between CRBG and synthetic CRBG groundwater are conducted to quantify changes in analyte concentrations. These changes in water chemistry are used to infer resultant mineral dissolution and precipitation reactions at elevated temperatures that could form scale, etc. and be detrimental to TES operations.

\section{Methodology}

The changes in groundwater chemistry that ensue thermal energy storage in a CRBG aquifer were simulated using batch reaction experiments with aquifer matrix samples together and simulated CRBG groundwater over a period of several months. CRB samples were obtained from an aquifer storage and recovery (ASR) well in Beaverton, OR (provided courtesy of GSI Water Solutions, Inc.) that penetrated several Grande Ronde basalt flows. These included the Ortley or Grouse Creek member of the Grande Ronde (basalt flow interior, sampled from a depth of 129-132 m), the Wapshilla Ridge member of the Grande Ronde (basalt flow interior, sampled from 210 to $216 \mathrm{~m}$ ), and the interflow zone between the two members (sample depth 160-161 m). Rock samples of the Sentinel Bluffs member of the Grande Ronde from a quarry in Scappoose Washington were also characterized. The water used in these simulations was collected from a well near Mosier, OR (WASC 52569) that extracts water from the lower Grande Ronde CRBG flow, analogous to the target zone for TES in the Portland Basin. WASC 52569 water was used to simulate TES because the well's water chemistry and lithology 
were well documented, and because this water could be chemically supplemented, rather than synthesized from scratch, to match the predicted average water composition in the Portland Basin CRBG aquifers.

\section{Sample and Water Preparation}

The ASR well rock samples from GSI came in the form of washed, crushed rock while the Scappoose Quarry sample came as a large block which was broken and crushed at PSU. Crushed samples were run through a splitter several times each. Half of the split sample was used for the experiment, and the other half was kept as reference material. Large chunks were put through a rock chipper and broken down to roughly centimetersize pieces. A few grams of each sample were ground down to powder for X-ray diffractometry. Samples were sieved and split into size fractions of $>4 \mathrm{~mm}, 2.00-4.00$ $\mathrm{mm}, 0.71-2.00 \mathrm{~mm}, 0.212-0.710 \mathrm{~mm}$, and $0.210 \mathrm{~mm}$.

For the first round of experiments, WASC 52569 well water was supplemented with $5.56 \times 10^{-4} \mathrm{M}_{\text {of }} \mathrm{CaCl}_{2}$ to match the average groundwater composition calculated for the CRB aquifer in the Portland Basin (Ch. 2). The final pH of this "synthesized groundwater" was 7.50. Subsequent rounds used groundwater from the WASC 52569 well. The variation in starting water compositions between experiments had some influence on overall $\mathrm{Ca}$ concentrations but made little difference to the $\mathrm{Ca}$ mass transfer.

\section{Rock Sample Characterization}

X-ray powder diffractometry was used to identify the mineralogy of the rock samples before the start of the experiment. Samples were first crushed to $<6 \mu \mathrm{m}$ size and 
loaded in a side-pack sample holder. The analyses were made using a Philips (now PANalytical) X'Pert MPD X-ray diffractometer (XRD) equipped with a copper anode Xray lamp $(\mathrm{K}-\mathrm{Alpha} 1=1.54060 \AA)$ and a $0.25^{\circ}$ fixed divergence slit size. Diffraction patterns were obtained at $40 \mathrm{kV}$ and $30 \mathrm{~mA}$ in continuous mode using a step size of 0.010 degrees two theta $\left({ }^{\circ} 2 \mathrm{Th}\right)$ and a scan step time of 1 second from 3 to $70{ }^{\circ} 2$ Theta. The interflow zone rock sample was rerun after solvation with ethylene glycol to identify fine (clay) fraction minerals.

The resulting XRD scans were viewed and interpreted using the software High Score Plus. High Score Plus identified relevant peaks, which were then checked manually and adjusted by adding and removing peaks as necessary to visually best fit the data. A multiphase search and match analyses identified mineral phases which best correlate to the d-spacing and count intensities of identified peaks and provided a score based on the strength of the correlation. Mineralogical composition was determined based on these scores and constrained by the mineralogy reported in published literature for the corresponding flow units. High Score Plus was then used to perform a Rietveld Refinement on the selected minerals. The refinement uses least squares to minimize the difference between the experimental diffraction pattern and the pattern created by the chosen mineralogy.

\section{Experiment Design}

Thermal rock-water batch reaction experiments were conducted in three rounds, ranging in duration from 4 to 9 weeks. Batch reactors were heated over this period to 
either $74^{\circ} \mathrm{C}$ or $35^{\circ} \mathrm{C} .74^{\circ} \mathrm{C}$ was chosen because at the start of the experiments, this temperature was considered to be near the high end of temperatures that the proposed TES system would use. A lower temperature of $35^{\circ} \mathrm{C}$ was chosen based on work by Burns et al. (2016) that indicates $35^{\circ} \mathrm{C}$ is the temperature above which hydrothermal alteration occurs in the CRBG. The $74^{\circ} \mathrm{C}$ experiments used either Parr bombs equipped with 25-ml PTFE reaction vessels or a Swagelok 400-mL double ended stainless steel cylinder (rated to $1800 \mathrm{PSIG}$ ) equipped with a pressure relief valve, in which water and rock samples were sealed and heated in an oven. For the $35^{\circ} \mathrm{C}$ experiments, water and rock samples were placed in 30 to $60 \mathrm{~mL}$ plastic bottles. These vials were then placed in a plastic tub that was suspended and insulated in a larger, insulated tub filled with water and heated to $\sim 35^{\circ} \mathrm{C}$ by an aquarium heater. Temperatures were monitored weekly. Low temperature experiments fluctuated between 34 and $35^{\circ} \mathrm{C}$, while high temperature experiments fluctuated between 72 and $75^{\circ} \mathrm{C}$. Samples were not mixed to mimic slow or no groundwater flow, as in the TES target zone during seasonal storage.

Water-rock ratios and grain sizes were varied in the first round of experiments to determine if water rock reactions were surface or equilibrium controlled. Subsequent rounds focused on periodic sampling in a time series to determine the rate at which water-rock reactions may occur. The contents of each batch reactor are summarized in Table 3.1, below. Basalt flow interior samples were examined, in addition to interflow zones, based on the assumption that less weathered flow interiors would be more reactive than previously weathered interflow zone. 


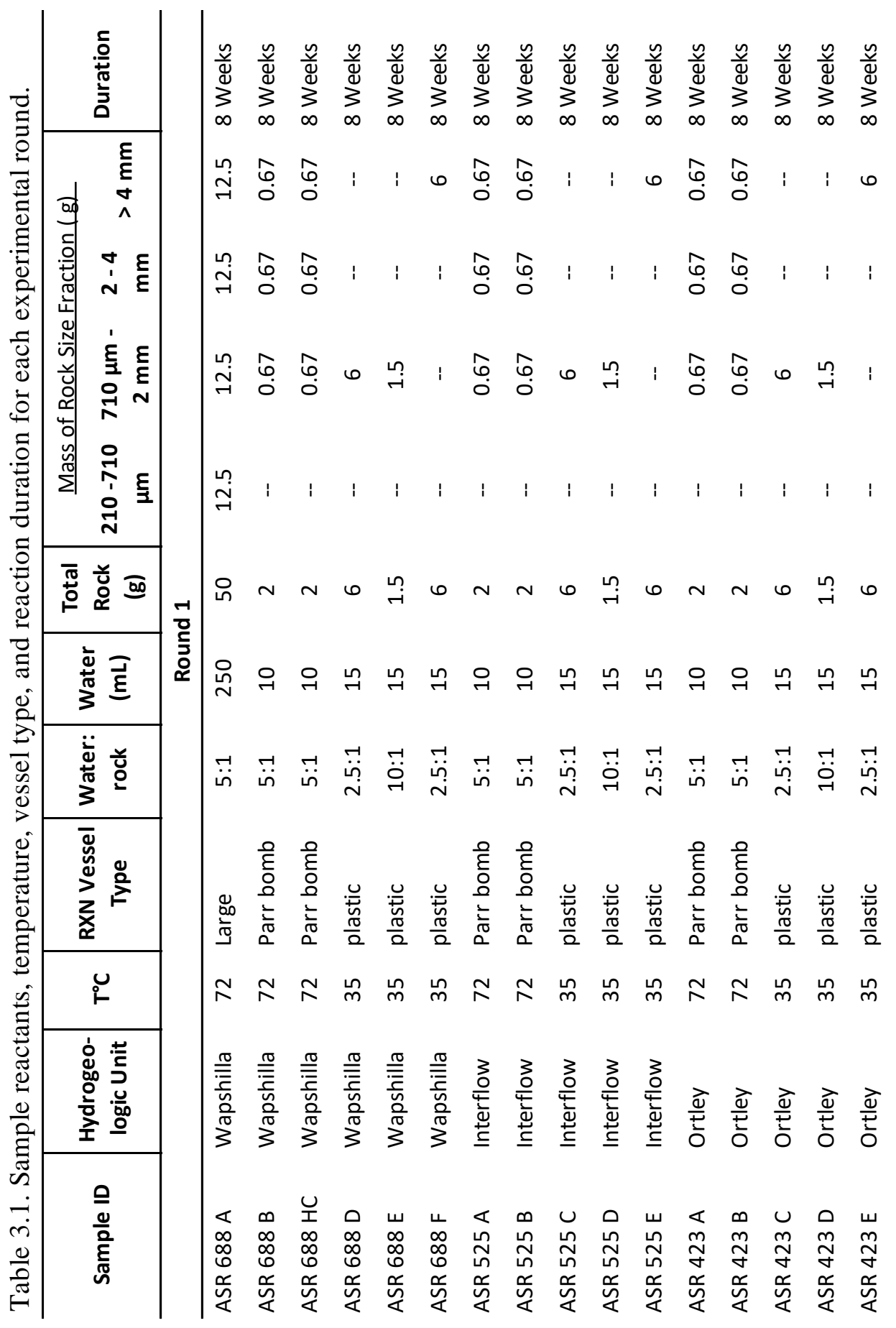




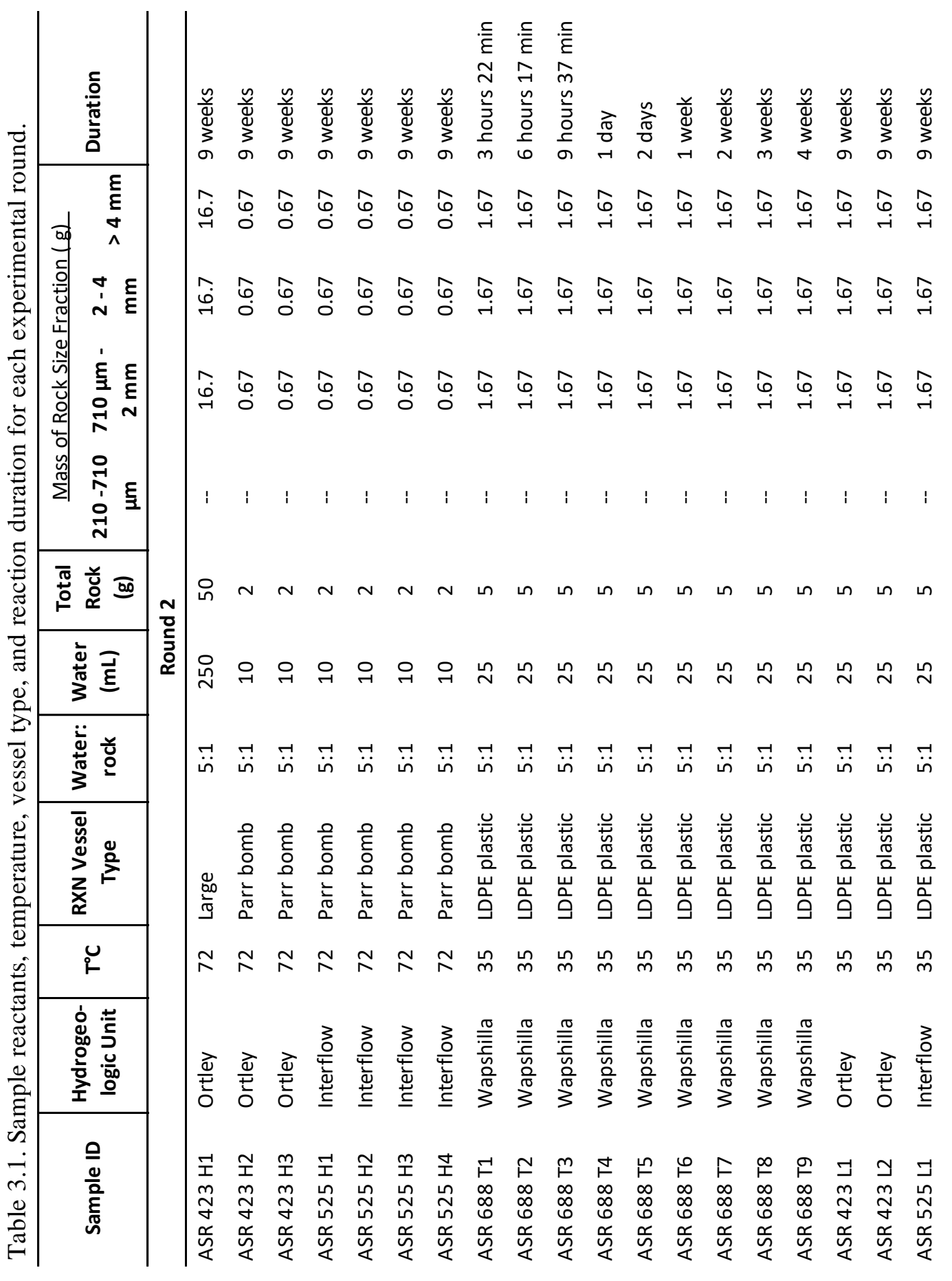




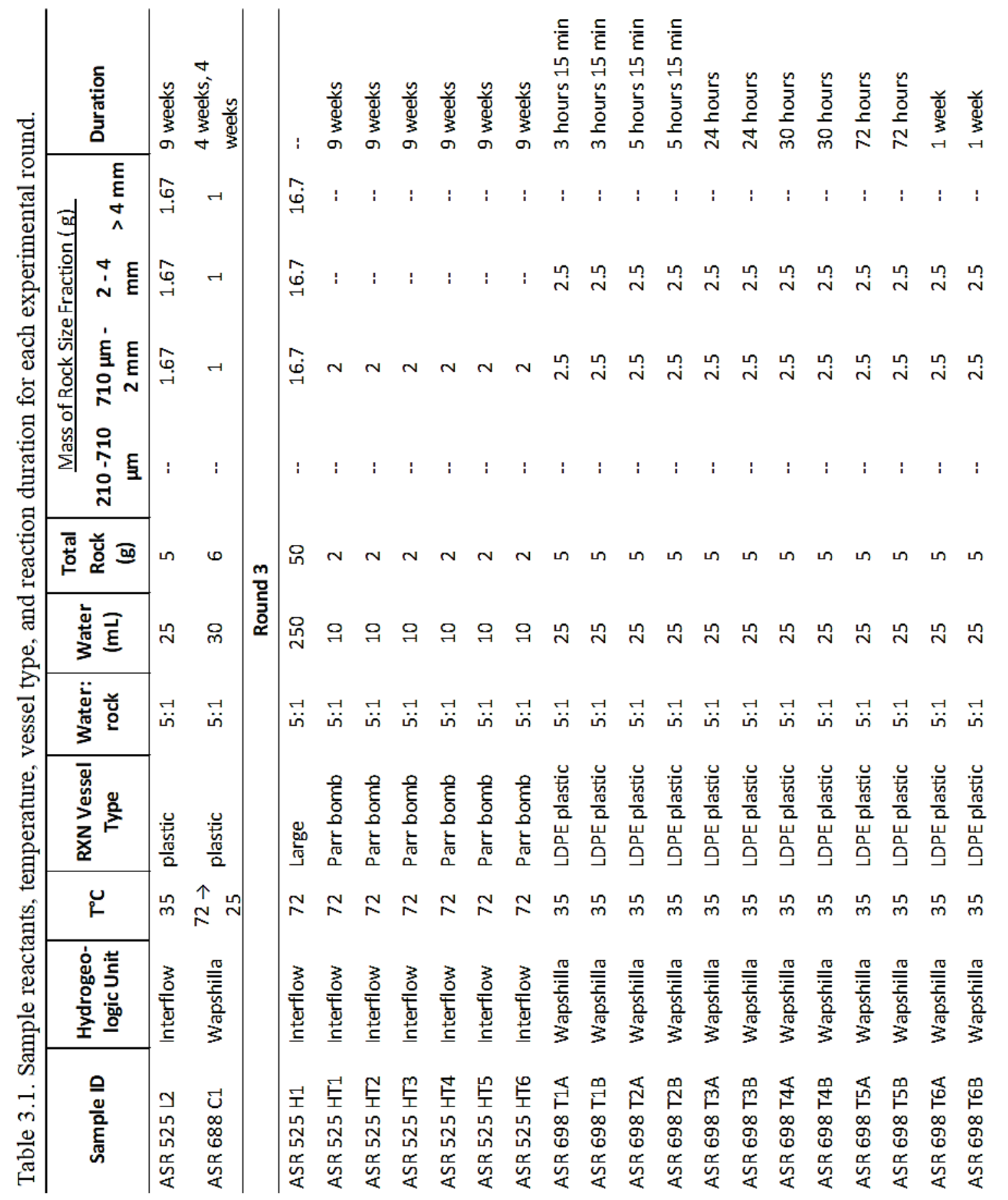




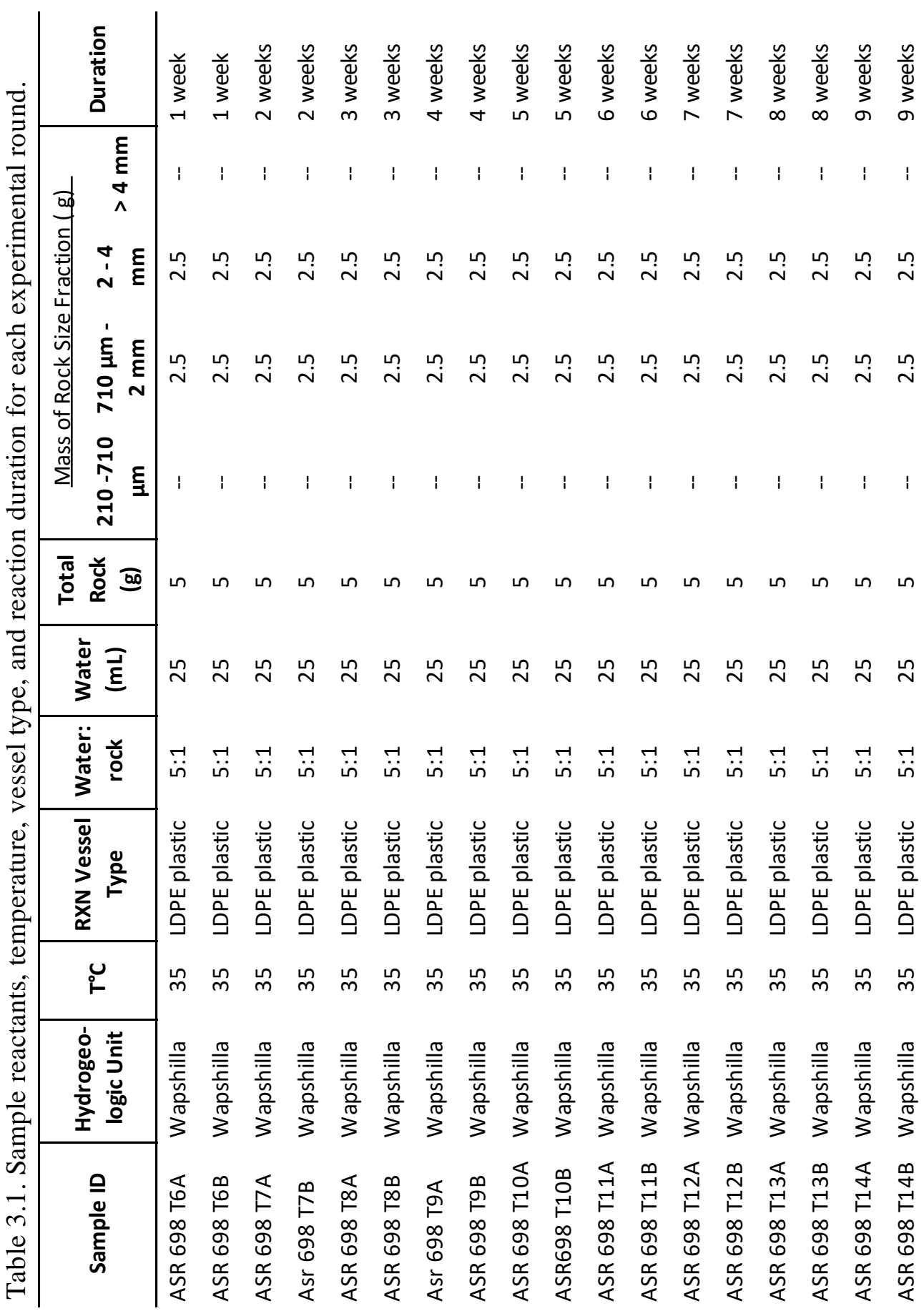

Upon sampling each reactor, water samples were immediately filtered with a $0.45 \mu \mathrm{m}$ or $0.1 \mu \mathrm{m}$ polyethersulfone filter (depending on availability) and acidified with 
$2 \%$ nitric acid for preservation for cation analysis. A subset of water from time series samples and samples from the large reaction vessel were filtered but left unacidified to measure $\mathrm{pH}$ and anion concentration. Alkalinity was also measured for the Ortley and Wapshilla Ridge samples that were reacted in the large vessel. Batch reacted rock grains were set aside to air dry before SEM analysis.

During the second round of reactions, $500 \mathrm{~mL}$ of water and $50 \mathrm{mg}$ of rock from the Wapshilla Ridge were heated together for four weeks. The rock was then removed, and the water cooled to room temperature for another four weeks. A subset of the cooled water was sampled, filtered, and acidified for ICP analysis. The remaining water was shaken, and vacuum filtered through a $0.45 \mu \mathrm{m}$ polyethersulfone filter. The filter was then preserved for identification of resulting minerals by SEM/EDX.

\section{Sample Analysis}

Water samples were analyzed using an Agilent 7900 inductively coupled plasma mass spectrometry (ICP-MS). Samples were analyzed for the major cations $\mathrm{Ca}, \mathrm{Mg}, \mathrm{Na}$, $\mathrm{K}, \mathrm{Al}$, and $\mathrm{Si}$ and the trace elements $\mathrm{Sr}, \mathrm{Mn}, \mathrm{Ti}, \mathrm{V}, \mathrm{Cu}, \mathrm{Rb}$, and $\mathrm{Ba}$. External calibration was performed using a range of standards all prepared from commercial NIST-traceable, multi-element stock standards (Inorganic Ventures Stock-3, Stock-27, and MSSi). Internal standards covering a wide mass range were used to account for any matrix differences between standards and samples and signal variations with time. One sample each from Wapshilla Ridge, Ortley, and the interflow zone experiments were also measured for the anions $\mathrm{F}^{-}, \mathrm{Cl}^{-}$, and $\mathrm{SO}_{4}{ }^{2-}$ using a Dionex 2500 ion chromatography (IC), 
calibrated with NIST-traceable external standards. These samples were also analyzed for alkalinity by titrating $0.1 \mathrm{M}$ hydrochloric acid into the water until it reached a $\mathrm{pH}$ of 4.5 or less. Alkalinity was calculated from the titration data using the Gran Function plot method.

A Zeiss Sigma VP FEG scanning electron microscope (SEM) was used to search for and identify signs of hydrothermal alteration in heated basalt that would indicate specific reaction pathways between the heated water and rock (SEM operating parameters reported in Table 3.2). SEM data was acquired for both reacted and unreacted Wapshilla Ridge samples, reacted and unreacted interflow zone samples, and precipitates from cooled water. Rock samples were investigated in two ways: by comparing unheated samples to those which had undergone experimentation, and by comparing pristine flow interior samples to already altered interflow zone samples. To prepare samples for analysis, rock shards were mounted in epoxy and polished down to the 0.3 micron level and coated with $18 \mathrm{~nm}$ of carbon coating. Filtered precipitates were examined both on the filter paper and on copper tape, which was used to pick up some of the larger precipitates. To minimize charging issues with the filter paper, these samples were given a 40-nm carbon coating.

SEM samples were viewed from a cross-sectional perspective to investigate the presence or absence of chemical alteration around the exterior of the rock chips. By viewing the grain cross-sections, rock chip interiors can be compared with exteriors, and signs of surficial weathering may be more apparent. Classic grain mounts were used as well, to examine surficial and topographic differences between samples, and to look for 
signs of surface pitting that are suggestive of dissolution. These consisted of rock fragments mounted on a stub using carbon tape or glue. A secondary electron detector was used to collect topographic information regarding rock morphology of mounted grains. A backscattered electron detector was used to search for compositional differences between rock interiors and edges in cross section. The X-ray detector was used to acquire both qualitative and quantitative compositional data of both sample types. Operating parameters for each scenario are summarized in Table 3.2.

Table 3.2. Summary of operating parameters for each SEM task. SE refers to secondary electron, BSE refers to backscattered electron.

\begin{tabular}{lccccc}
\hline \multicolumn{1}{c}{ Task } & Detector & $\begin{array}{c}\text { Accelerating } \\
\text { Voltage }\end{array}$ & Aperture & $\begin{array}{c}\text { Working } \\
\text { Distance }\end{array}$ & $\begin{array}{c}\text { High } \\
\text { Current } \\
\text { Mode }\end{array}$ \\
\hline $\begin{array}{l}\text { Topographic images } \\
\text { of grain mounts }\end{array}$ & SE & Low & Center & Long & Off \\
\hline $\begin{array}{l}\text { Z-contrast } \\
\text { compositional } \\
\text { images of plugs }\end{array}$ & BSE & $15 \mathrm{keV}$ & Center & Close & Off \\
\hline $\begin{array}{l}\text { Qualitative } \\
\text { elemental analysis of } \\
\text { grain mounts }\end{array}$ & X-ray & $20 \mathrm{keV}$ (High) & Large/Center & $\begin{array}{c}\text { Near analytical } \\
\text { (as close as } \\
\text { possible with } \\
\text { topography) }\end{array}$ & On \\
\hline $\begin{array}{l}\text { Quantitative } \\
\text { elemental analysis of } \\
\text { plugs }\end{array}$ & X-ray & $20 \mathrm{keV}$ (High) & Large/Center & $\begin{array}{l}\text { Analytical } \\
\text { (8.5mm) }\end{array}$ & On \\
\hline
\end{tabular}

\section{Results}

\section{Rock Characterization}

Basalt flow interior samples appear massive and dark gray in hand sample, with small amounts of red discoloration due to weathering. Microscopy reveals that rock chips are largely aphyric, though olivine phenocrysts that have weathered to iddingsite and relict plagioclase and pyroxene grains are observed. Interflow zone samples appear 
redder and more oxidized, suggesting greater alteration. Rock chips are often vesiculated, as is typical for some water bearing zones. Any glass present in interflow zone samples appears to have been either replaced or coated by secondary minerals.

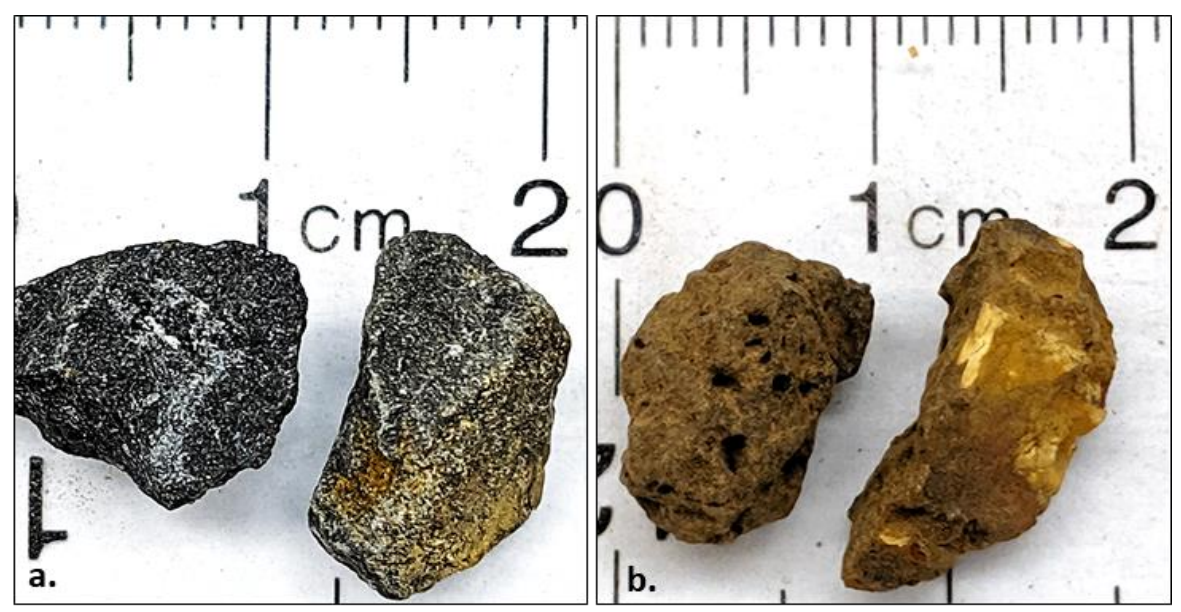

Figure 3.1. a) Basalt flow interior sample rock chips from the Wapshilla Ridge, and b) interflow zone sample rock chips.

The results of the XRD analysis are summarized in Table 3.3. XRD analysis reports are supplied in Appendix B. Basalt samples primarily comprised calcium-sodium bearing andesine feldspar (30-50\% anorthite) and calcium bearing augite (clinopyroxene) with trace amounts of clay.

Table 3.3. Basalt flow mineralogy identified via XRD analysis.

\begin{tabular}{|c|c|c|c|}
\hline Sentinel Bluffs & Ortley-Grouse Creek & Wapshilla Ridge & Interflow Zone \\
\hline $\begin{array}{l}\text { 68.6\% Andesine } \\
\text { 31.4\% Augite }\end{array}$ & $\begin{array}{l}\text { 69.7\% Anorthite } \\
\text { 27.9\% Clinopyroxene } \\
\text { 2.2\% Magnesioferrite } \\
0.2 \% \text { Montmorillonite }\end{array}$ & $\begin{array}{l}\text { 66.2\% Andesine } \\
33.8 \% \text { Augite }\end{array}$ & $\begin{array}{l}\text { 98.4\% Andesine } \\
\text { 1.6\% Montmorillonite }\end{array}$ \\
\hline
\end{tabular}




\section{Scanning Electron Microscopy}

Very little difference was visible between the mineralogy of batch reacted and unreacted basalt flow interior samples. Qualitative EDS data of both reacted and unreacted samples showed augite, andesine, and ilmenite; minerals consistent with previous studies of CRBG mineralogy. Low magnification surface imaging showed no obvious signs of recent mineral dissolution (surface pitting, etc.), and grains were still identifiable via Z-contrast imaging and qualitative EDS at this scale (Figure 3.2). Viewing rock chips in cross section also did not show any indication of alteration or mineral precipitation around the rim of rock grains. Evidence of previous weathering was apparent in the form of clay structures on the surface of unreacted flow interior grain mounts and rare vesicles filled with secondary minerals (Figure 3.3). As with the basalt flow interior samples, SEM imaging of the interflow zone samples showed no observable difference between reacted and unreacted samples. Zeolites and clays were found in both reacted and unreacted samples, as were vesicles filled with debris and/or secondary minerals with desiccation cracks indicative of dehydrated hydrous minerals, indicating some previous, in situ weathering. However, no surface pitting was observed that might have evidenced recent dissolution, nor were there any obvious signs of recent mineral precipitation. Some relict plagioclase and pyroxene minerals were identified in both reacted and unreacted interflow zone samples, although the surface of many mineral grains appeared primarily as a weathered clay groundmass (Figure 3.4). 


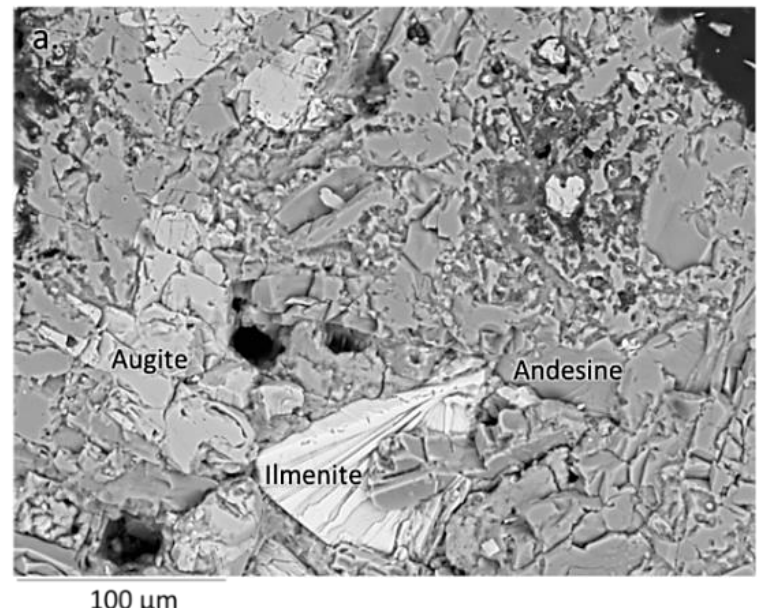

$100 \mu \mathrm{m}$

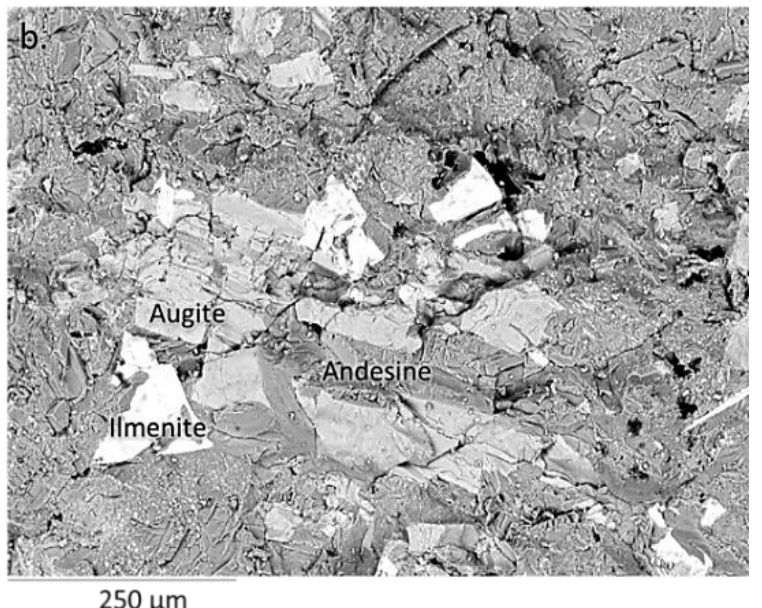

$250 \mu \mathrm{m}$

Figure 3.2. BSE images of both reacted and non-reacted Wapshilla ridge basalt from flow interiors, showing identical mineralogies; a) is a reacted epoxy plug, and b) is an unreacted grain mount.

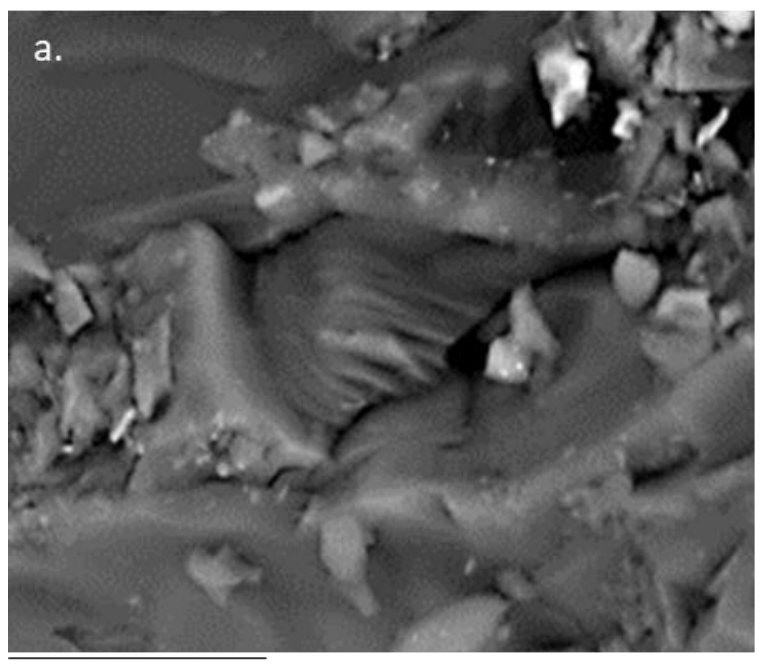

$10 \mu \mathrm{m}$

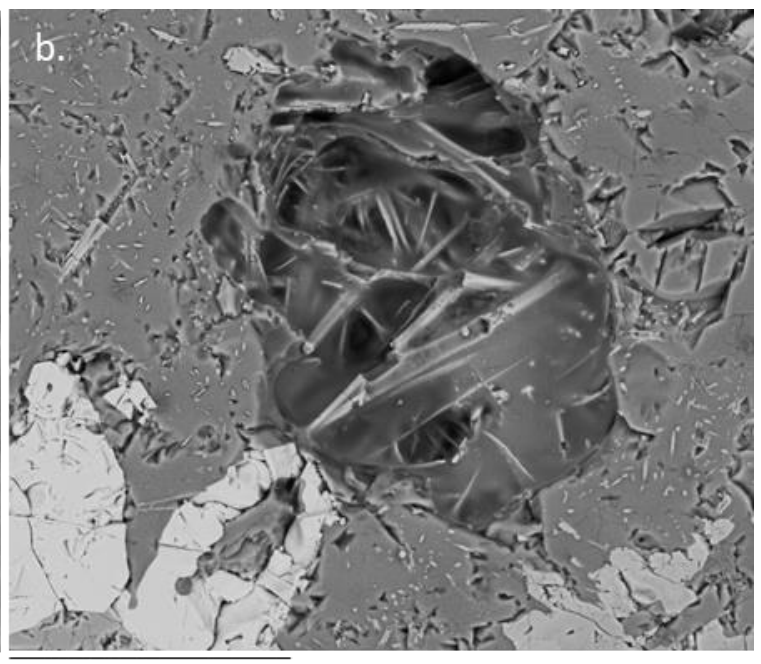

$100 \mu \mathrm{m}$

Figure 3.3. a) SE image of clay formation at the surface of an unreacted flow interior sample, and b) a BSE image of a reacted flow interior sample vesicle filled with secondary minerals. 


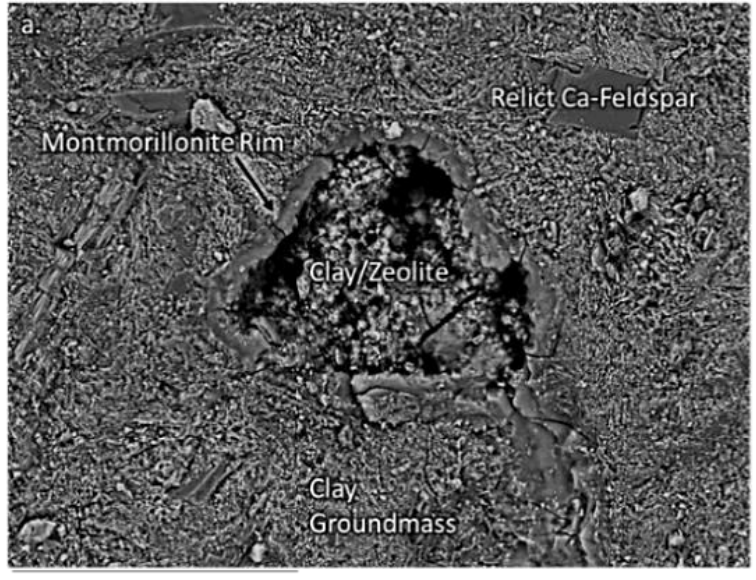

$100 \mu \mathrm{m}$

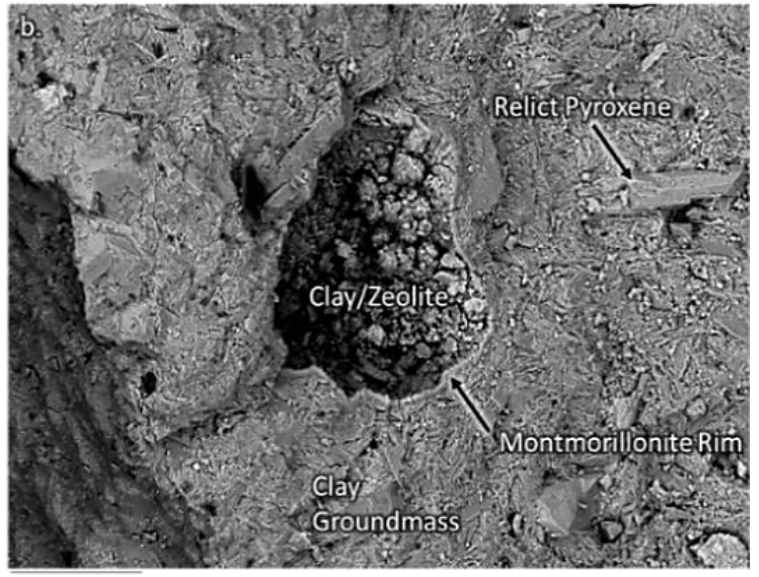

$100 \mu \mathrm{m}$

Figure 3.4. BSE images of both re-reacted and non-reacted interflow zone samples, showing similar mineralogies and surface textures; a) is a BSE micrograph of an epoxy plug, b) is a grain mount.

Precipitates that resulted from cooling the water were variable in composition. Analysis of the filter and copper tape revealed Al-hydroxide, Fe-hydroxide, and aluminosilicate minerals (likely clay particles). Only one calcium carbonate particle was detected. Some relict ilmenite and pyroxene appeared on both the tape and filter, likely dislodged from the original reacted rock chips and which were small enough to slip through the initial filtering process but were large enough to be retained by the filter paper later (perhaps because of their orientation). See Appendix B for all SEM result images and corresponding spectra. 


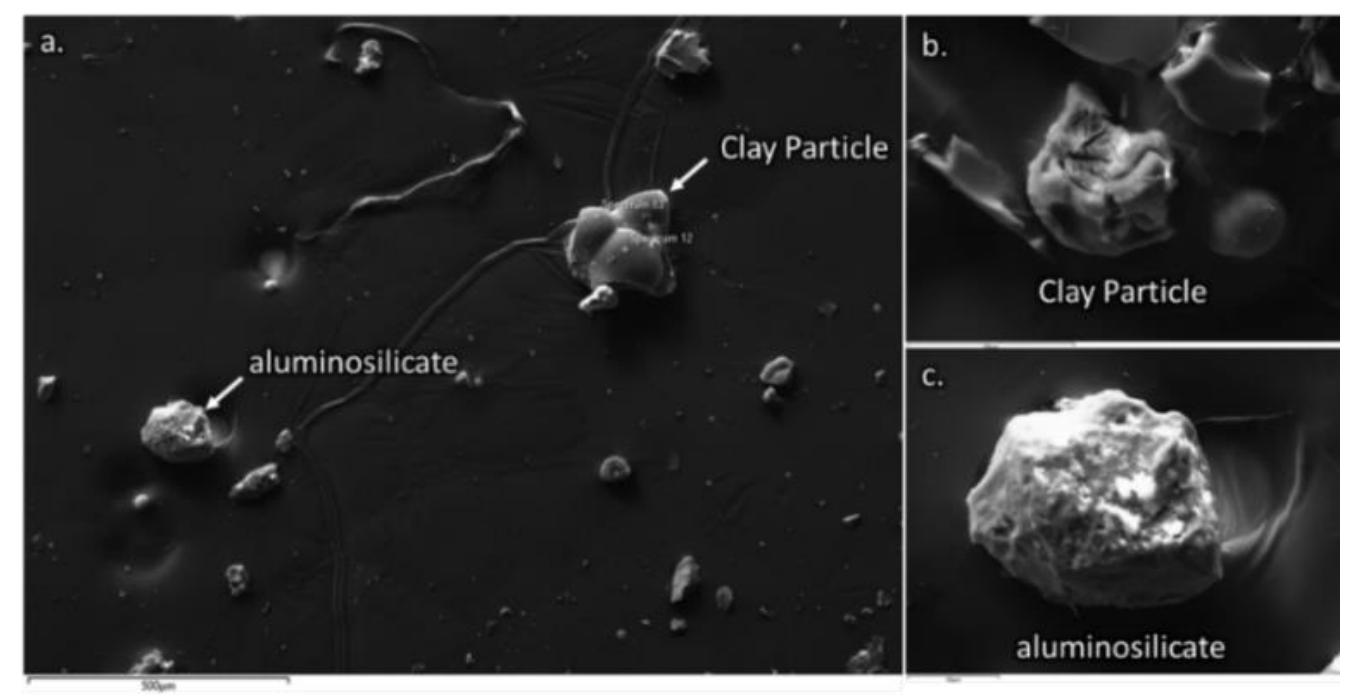

Figure 3.5. a) Lower magnification view of particles on filter paper collected during filtering of cooling water, b) higher magnification image of a possible clay structure, and c) higher magnification image of a clay (or another aluminosilicate) particle pictured in (a). All images were collected using the secondary electron detector. For corresponding EDS, see Appendix B.

\section{Changes in Water Chemistry}

\section{Long-term Batch Reactions}

Water chemistry analyses indicate that at $74^{\circ} \mathrm{C}$ there is a net increase in $\mathrm{Na}, \mathrm{Si}, \mathrm{K}$, $\mathrm{Al}, \mathrm{V}, \mathrm{Mn}, \mathrm{Fe}, \mathrm{Cu}, \mathrm{Rb}, \mathrm{Sr}$, and Ba concentrations, with a net decrease in $\mathrm{Ca}, \mathrm{Mg}$, and some $\mathrm{Mn}$ and $\mathrm{Sr}$ concentrations. Interflow zone heating results in $\mathrm{Si}, \mathrm{K}, \mathrm{Al}, \mathrm{V}, \mathrm{Cu}$, and $\mathrm{Rb}$ entering the water, while $\mathrm{Na}, \mathrm{Mg}, \mathrm{Ca}, \mathrm{Mn}, \mathrm{Fe}, \mathrm{Sr}$ and $\mathrm{Ba}$ exit the water (Figure 3.6a, b). At $35^{\circ} \mathrm{C}$, flow interior sample fluids gained $\mathrm{Na}, \mathrm{Mg}, \mathrm{K}, \mathrm{Al}, \mathrm{V}, \mathrm{Cu}, \mathrm{Rb}$, and $\mathrm{Sr}$ upon heating and lost $\mathrm{Ca}, \mathrm{Mn}, \mathrm{Fe}$, and $\mathrm{Ba}$. Interflow zone sample fluids at $35^{\circ} \mathrm{C}$ gained $\mathrm{Si}, \mathrm{Al}$, $\mathrm{Cu}, \mathrm{Rb}$, and $\mathrm{Sr}$ and lost $\mathrm{Na}, \mathrm{Mg}, \mathrm{K}, \mathrm{Ca}, \mathrm{Mn}, \mathrm{Fe}$, and Ba from the water (Figure 3.6c, d). The non-uniformity of these elemental transfers indicates incongruent mineral dissolution and precipitation. 

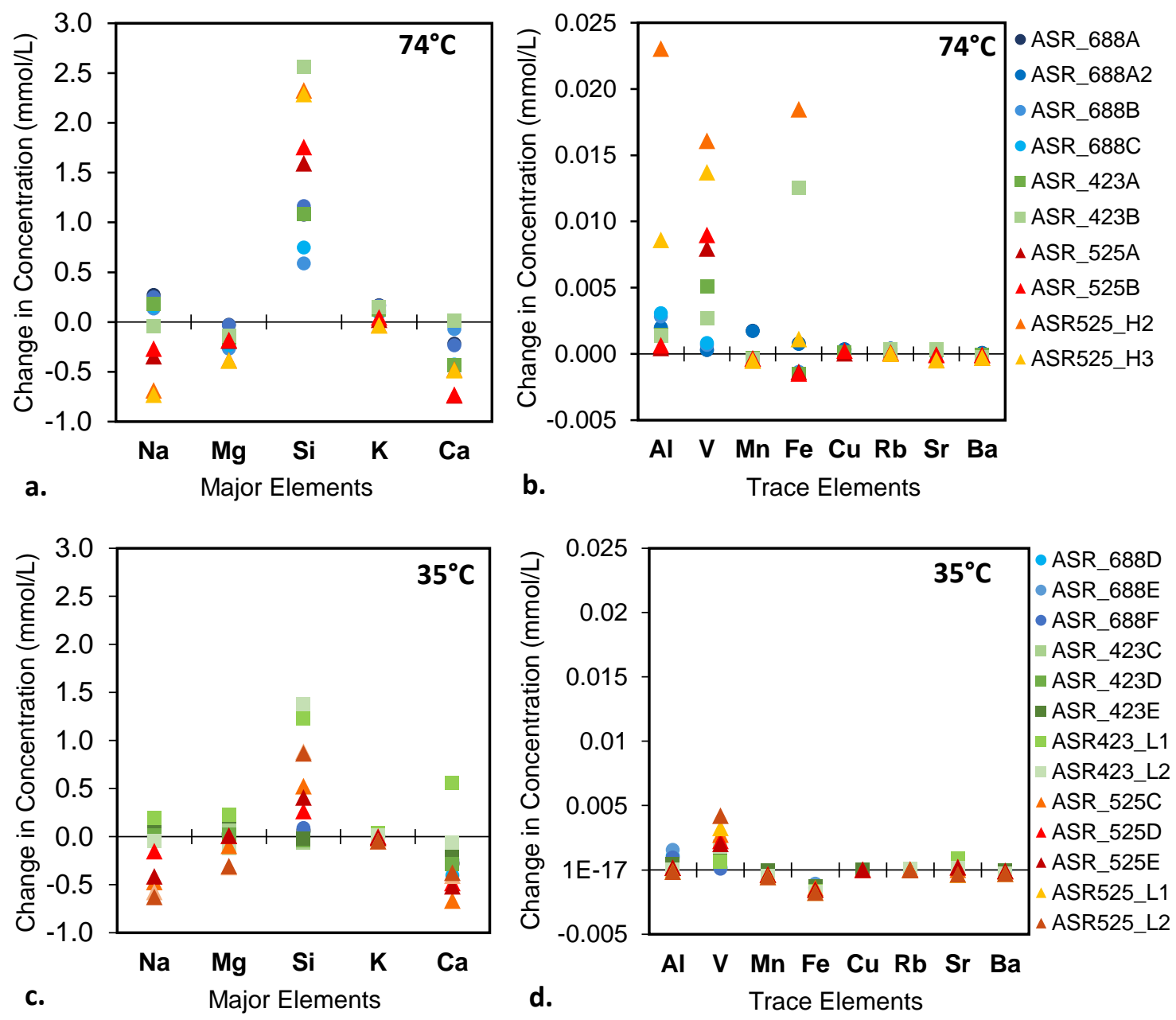

Figure 3.6. Elemental mass transfers resulting from batch reactions at $74^{\circ} \mathrm{C}$ for both major elements (a) and trace elements (b). Mass transfers resulting from batch reactions at $35^{\circ} \mathrm{C}$ for both major elements (c) and trace elements (d). Wapshilla Ridge samples are indicated by circles in shades of blue, Ortley as squares in shades of green, and the interflow zone as triangles in shades of red. Zero line represents the initial water composition.

Experimental results exhibited increasing elemental mass transfer with increasing water to rock ratios (Figure 3.7a). As grain size decreases and surface area increases, elemental mass transfer increases as well, with the exception of magnesium (Figure 
3.7b). These trends occur in both the major cations and trace elements, and in both basalt flow interiors and interflow zones. The increasing mass transfer with increasing waterrock ratio and surface area indicates that water chemistry is controlled by reactions at the minerals' surface rather than by equilibrium with the bulk solids.
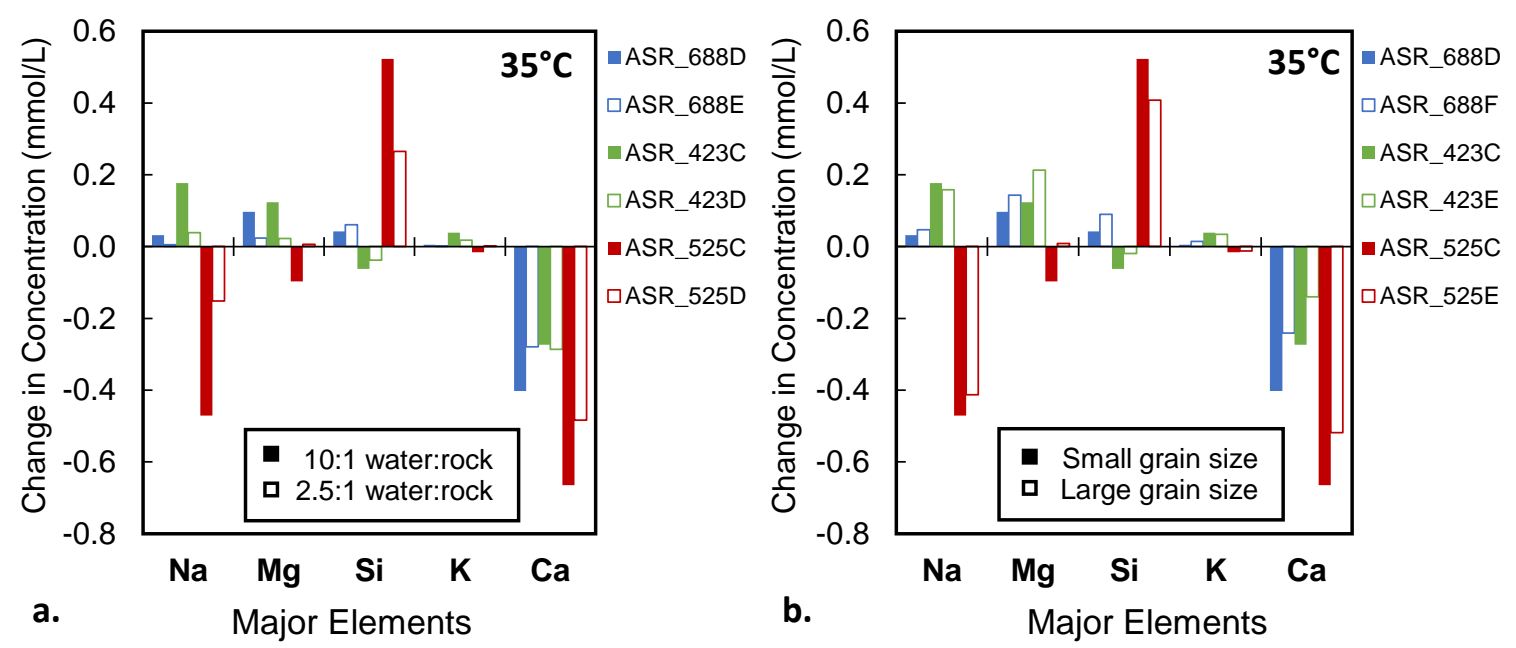

Figure 3.7. Mass transfer based on a) water:rock ratio, and b) grain size at $35^{\circ} \mathrm{C}$, for samples from the Wapshilla ridge (blue), Ortley (green), and interflow zone (red).

\section{Cooling Experiments}

Results from cooling batch reacted water were perplexing. Provided that with increasing temperature the solubility of silicate minerals increases while the solubility of carbonate minerals decreases, we would expect to see $\mathrm{Si}$ concentrations rise and fall with increasing and decreasing temperatures, while $\mathrm{Ca}$ concentrations (if controlled by $\mathrm{CaCO}_{3}$, as hypothesized) do the opposite. Si concentrations increase with temperature, but then do not decline much upon cooling, while Ca concentrations decrease upon heating but then continue to decrease upon cooling. Mg behaves similarly. $\mathrm{Na}, \mathrm{K}, \mathrm{Fe}, \mathrm{Rb}$, and $\mathrm{Sr}$ 
concentrations all increase with heating then decrease upon cooling. Al and V increase during both heating and cooling steps, while $\mathrm{Mn}$ and Ba appear to almost completely precipitate upon cooling (Figure 3.8).
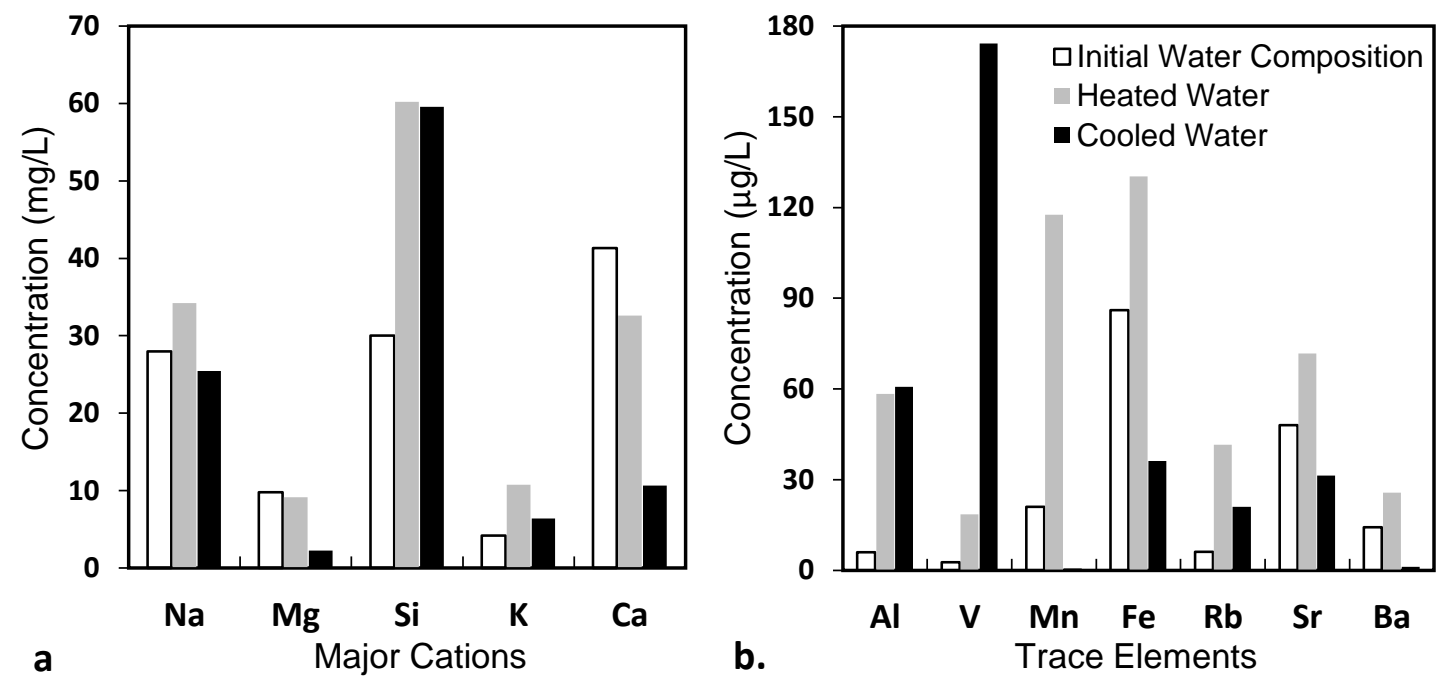

Figure 3.8. (a) Major cation concentrations in the initial water, water heated to $74^{\circ} \mathrm{C}$, and water cooled to room temperature, and (b) trace element concentrations in the same initial, heated, and cooled water (sample ASR 688 C1, Table 3.1).

\section{Time Series Results}

Time series results indicate that $\mathrm{Si}, \mathrm{Al}$, and $\mathrm{Fe}$ concentrations vary over time at elevated temperatures and could explain the range of $\mathrm{Al}$ values observed in single sample batch reaction experiments, which were sampled at different times for rounds 1 and 2. Concentrations of major cations ( $\mathrm{Ca}, \mathrm{Mg}, \mathrm{Na}$, and $\mathrm{K}$ ) decrease with time, as do concentrations of trace elements $\mathrm{Sr}, \mathrm{Mn}, \mathrm{Rb}$, and $\mathrm{Ba}$. In agreement with the long-term experiments, V concentrations increase with time. Conversely, $\mathrm{Si}, \mathrm{Na}, \mathrm{Mn}$, and $\mathrm{Sr}$ concentrations decrease, counter to previous heating experiments. 

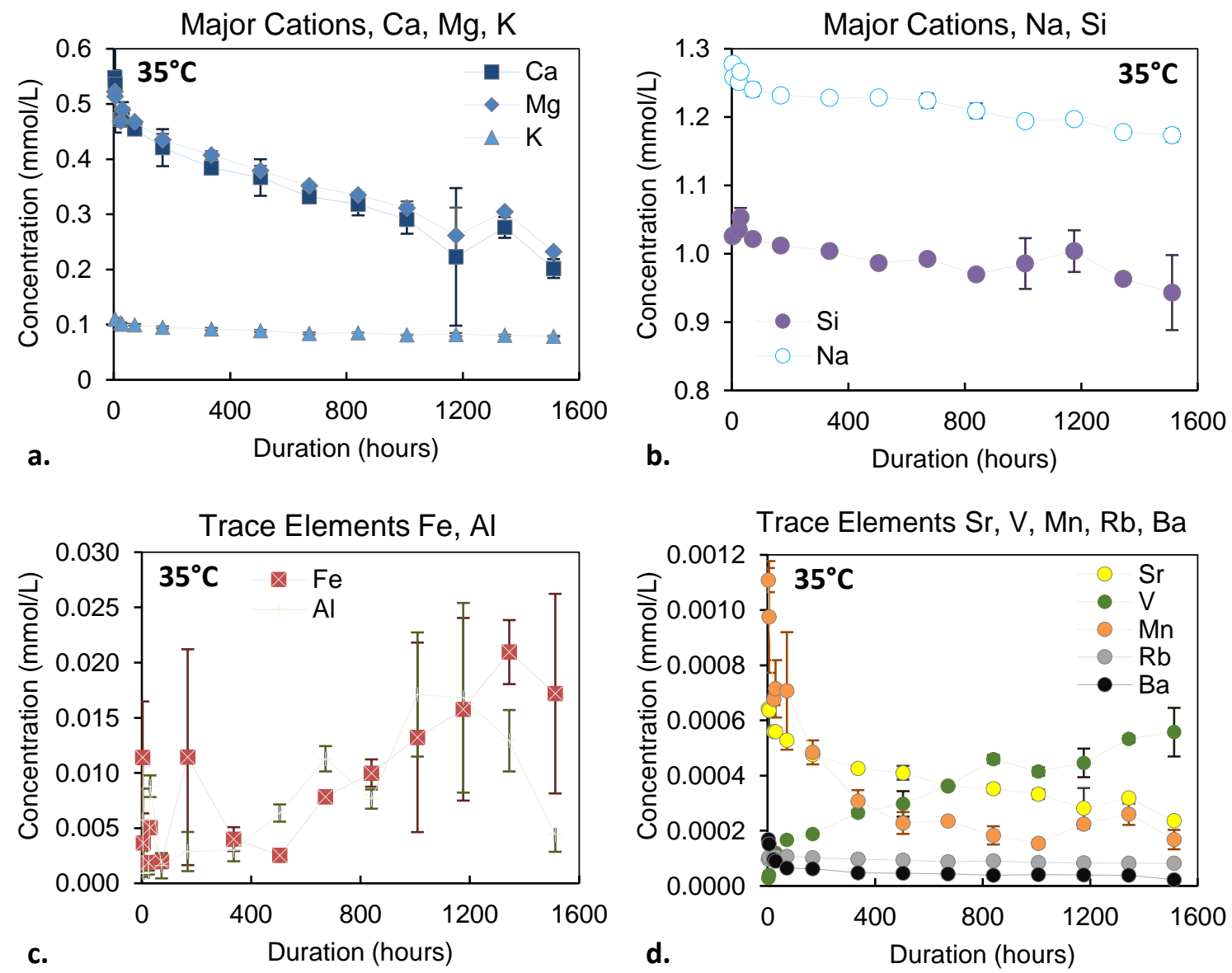

Figure 3.9. Average element concentration versus time for the time series samples 698 T1-T14. Error bars represent one standard deviation ( $n=2)$. After 840 hours, samples were filtered with a $0.1 \mu \mathrm{m}$ filter rather than a $0.45 \mu \mathrm{m}$ filter.

This decrease may be because of the lower temperature of time-series experiments or variations in rock chemistry within basalt flows. Results from experimental rounds two and three are in good agreement, although Si concentrations in the first round were higher while still following the same downward trend as Si concentrations measured during the second round (data included in Appendix B). Decreasing the filter size to $0.1 \mu \mathrm{m}$ after 
840 hours does not appear to have resulted in reduced ion concentrations, even for Fe and

Al.

Assuming that calcite precipitation controls Ca concentrations during heating, a zero-order rate constant for calcite precipitation can be calculated from plots of $\mathrm{Ca}$ concentration versus time (Figure 3.10). This is done by finding the slope of a trendline (using the points in red in Figure 3.10) and dividing by the surface area of the solid per unit volume of solution used in the experiments.

Converting $\mathrm{Ca}$ concentrations (in $\mathrm{mmol} / \mathrm{L}$ ) into equivalent $\mathrm{mol} / \mathrm{L}$ of calcite, and converting time to seconds, yields a calcite precipitation rate constant of $1.08 \times 10^{-10}$ $\mathrm{mol} / \mathrm{sec}$ when neglecting surface area. Surface area is often the greatest unknown when determining reaction rates. Surface area for time series samples was estimated as 2,428 $\mathrm{cm}^{2}$ per $0.025 \mathrm{~L}$ of water (further detail on estimating sample surface area can be found in section 3.2.5). Dividing by the surface area per unit volume of solution yields a rate constant of $1.12 \times 10^{-15} \mathrm{~mol} / \mathrm{cm}^{2} / \mathrm{sec}$. This is several orders of magnitude slower than calcite precipitation rate constants compiled by Sanjuan and Girard (1996), which are between $10^{-11}$ and $10^{-10} \mathrm{~mol} / \mathrm{cm}^{2} / \mathrm{s}$. This method of rate constant calculation does not account for the faster loss of $\mathrm{Ca}$ over the first 3 days of heating and implies that a zeroorder rate constant may not capture the behavior of precipitating calcite.

To account for the faster loss of Ca during the first 3 days, an exponential trendline was also fit to the data, which estimated a first-order rate constant of $-6 \times 10^{-4}$ $\mathrm{mmol} / \mathrm{L} / \mathrm{hr}$. Normalizing by surface area and converting to $\mathrm{mol} / \mathrm{cm}^{2} / \mathrm{s}$ results in a rate constant of $-1.7 \times 10^{-14}$, which is still slower than previously determined rates. However, 
most experimentally derived rates for calcite precipitation are determined from reacting grains of pure calcite, rather than calcite bearing whole rocks which may simultaneously supply Ca via dissolution of primary phases.

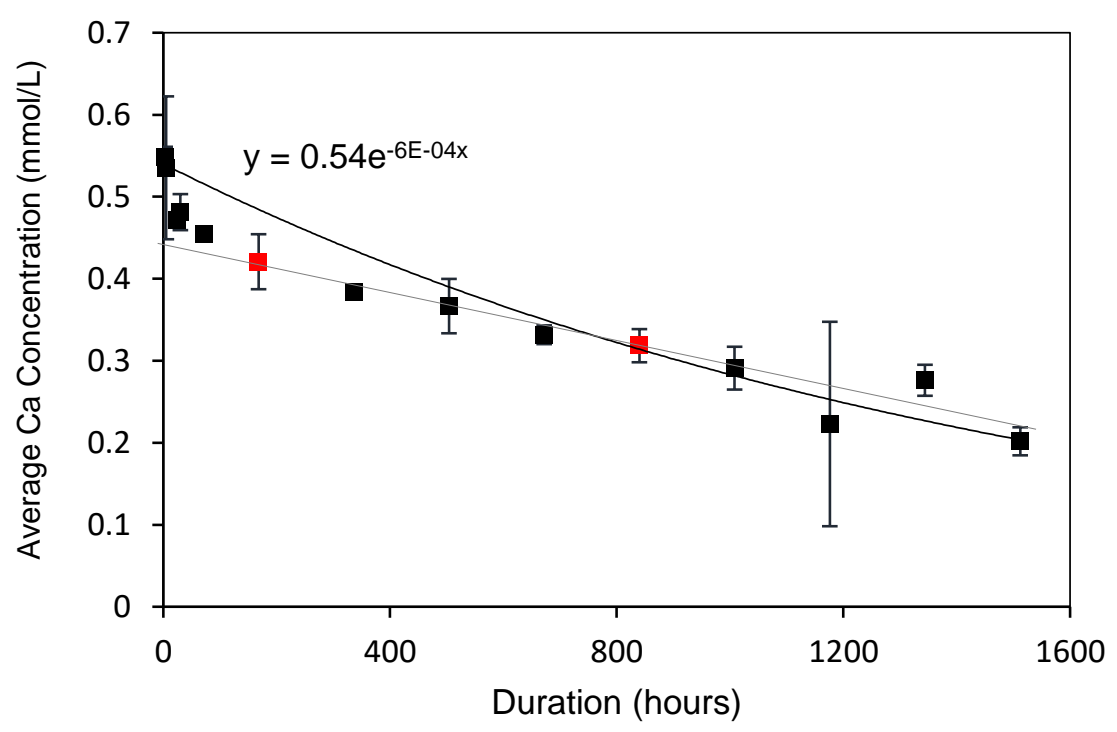

Figure 3.10. Time in hours vs. the average Ca concentration. Error bars show one standard deviation. The linear trendline used to calculate the zero-order rate constant is shown in gray, and the exponential trendline and accompanying equation used to calculate the first order rate constant is shown in black.

\section{Inverse Modeling of Experimental Results}

Experimental mass transfers were inversely modeled using both PhreeqC and Geochemist's Workbench (GWB) to quantify the mass of minerals needed to dissolve and/or precipitate in order to account for the experimentally observed changes in water chemistry. In PhreeqC, this requires assigning a set of primary minerals to dissolve and a suite of secondary minerals to precipitate when the initial water composition is heated. Then the program solves for the masses and mineral phases that would need to dissolve or precipitate to account for the chemical difference between the initial and final water 
compositions, using the LLNL thermodynamic database. Plagioclase and pyroxene are primary basalt minerals that are likely to weather, and with which the water is undersaturated, and so they were allowed to dissolve in the inverse model. Nontronite is a secondary clay mineral that forms early, then alters to other secondary mineral phases (Baker, 2016), and with which the water is also undersaturated, as is saponite. These or other smectite clay minerals are already present in interflow zones and may be dissolved or re-reacted upon heating, so they were permitted to dissolve or precipitate as necessary in inverse models. Calcite, gibbsite, chalcedony and amorphous silica are hypothesized secondary minerals, which were assigned to precipitate. Inverse modeling results for mineral mass transfer due to heating basalt flow interior sample 688A and interflow zone sample 525A are included in the table below.

Table 3.4. Mineral mass transfers (in moles) identified via inverse modeling of a basalt flow interior sample 688A and interflow zone sample 525A using phreeqC.

\begin{tabular}{|c|c|c|c|}
\hline \multirow{3}{*}{$\begin{array}{c}\text { Flow } \\
\text { Interior }\end{array}$} & \multirow{3}{*}{$\begin{array}{c}\text { Solution No. } \\
1\end{array}$} & \multicolumn{2}{|c|}{ Phase Transfers (mmol) } \\
\hline & & Anorthite & 0.0011 \\
\hline & & Enstatite & 0.0075 \\
\hline \multirow{2}{*}{ Interior } & \multirow{2}{*}{2} & Anorthite & 0.0007 \\
\hline & & Saponite-Mg & 0.0025 \\
\hline \multirow{2}{*}{ Interior } & \multirow{2}{*}{3} & Anorthite & 0.0087 \\
\hline & & Gibbsite & -0.0151 \\
\hline \multirow{6}{*}{ Interflow } & \multirow{6}{*}{1} & Calcite & -0.8730 \\
\hline & & $\mathrm{Fe}(\mathrm{OH}) 3$ & 0.0791 \\
\hline & & Gibbsite & 1.0150 \\
\hline & & Smectite-high-F & 1.0950 \\
\hline & & Smectite-low-Fe & -1.8890 \\
\hline & & $\mathrm{SiO} 2(\mathrm{am})$ & 5.0450 \\
\hline \multirow{5}{*}{ Interflow } & \multirow{5}{*}{2} & Anorthite & 0.3470 \\
\hline & & Calcite & -1.1450 \\
\hline & & $\mathrm{Fe}(\mathrm{OH}) 3$ & 0.0535 \\
\hline & & Smectite-high-F & 0.7582 \\
\hline & & Smectite-low-Fe & -1.3080 \\
\hline
\end{tabular}

*Positive phase transfers indicate mineral dissolution, negative indicates precipitation 
GWB was also used to simulate interflow zone cation mass transfers for sample 525A, with an emphasis on matching $\mathrm{Ca}$ and Si final concentrations. The GWB React module was used with the modified thermodynamic database (discussed in Ch. 2) to titrate primary minerals into the starting water, in the presence of secondary minerals. Secondary mineral precipitation was equilibrium controlled, while the mass of primary minerals dissolving was estimated. The simplest solution (the solution involving the fewest phases) found by inversely modeling with GWB indicated that $60 \mathrm{mg} / \mathrm{L}(0.22$ $\mathrm{mmol} / \mathrm{L})$ of plagioclase and $40 \mathrm{mg} / \mathrm{L}(0.4 \mathrm{mmol} / \mathrm{L})$ of pyroxene would need to dissolve, while calcite and gibbsite (or another Al-hydroxide phase) precipitate, to explain the largest mass transfers observed during interflow zone batch reaction experiments.

The primary issue with inverse modeling, particularly in a complex system such as the CRBG aquifers, is that of non-uniqueness. Both PhreeqC and GWB returned several possible reaction pathways, all with large errors, and varying degrees of feasibility based on what we know about the aquifer system. Modeling scripts are included in Appendix B.

\section{Quantifying Mineral Precipitation and Dissolution}

Assuming a loss of $\mathrm{Ca}$ from solutions during heating is due to calcite precipitation, then the mass of calcite precipitated exceeded that of any other precipitates. Using the amount of $\mathrm{Ca}$ as $\mathrm{CaCO}_{3}$ precipitated over the course of the experiment, and the total surface area of the rock chips reacted with the water, the maximum thickness of the amount of $\mathrm{CaCO}_{3}$ precipitated over the surface of the rock grains over the course of the 
experiments can be calculated. Total sample surface area was estimated as by summing the surface area of each size fraction included in the sample. Surface area for each size fraction was approximated as the surface area of a sphere (which is more conservative than approximating rock grains as cubes) with a radius equivalent to the average radius for the size fraction in question, multiplied by the number of rock grains of that size fraction. The average number of grains was calculated as the total mass of rock of that size fraction divided by the average rock grain mass for that size. Average grain mass for each size fraction was determined by taking the mean weight of 10 randomly selected grains from each size fraction. Once the total sample surface area has been established, the expected thickness $(\mathrm{T}$, in $\mathrm{cm}$ ) of an even calcite coating over rock grains can be calculated for each sample by dividing the mass of $\mathrm{Ca}$ as an equivalent mass of $\mathrm{CaCO}_{3}$ in $\mathrm{mg}\left(\mathrm{M}_{\mathrm{CaCO} 3}\right)$, by the total surface area $\left(\mathrm{A}_{\mathrm{s}}\right.$ in $\left.\mathrm{cm}^{2}\right)$ multiplied by the density of calcite $\left(\rho_{\text {calcite }}\right.$ in $\left.\mathrm{mg} / \mathrm{cm}^{3}\right)$ :

$$
T_{\text {calcite }}=\frac{M_{\mathrm{CaCO} 3}}{A_{s} * \rho_{\text {calcite }}}
$$

Using the maximum observed calcium mass transfer $(9.4 \mathrm{mg} / \mathrm{L}$ from Wapshilla Ridge sample 688A and $29.3 \mathrm{mg} / \mathrm{L}$ from interflow zone sample 525B) yields a maximum calcite coating that is $0.01 \mu \mathrm{m}$ thick in the Wapshilla Ridge sample, and $0.264 \mu \mathrm{m}$ thick in the interflow zone sample. As this is the maximum amount of secondary mineralization expected for any precipitating mineral phase, it explains why no visible difference between reacted and control sample mineralogy and surface texture were observed during SEM analysis. 
Based on the mass per volume precipitated over the course of these experiments, we can calculate the change in porosity that results from mineral precipitation and dissolution using the equation:

$$
\Delta \mathrm{n}=\frac{\delta_{m} * n_{0}}{1000 * \rho_{m}}
$$

after the methods of Palmer and Cherry (1984), where $\Delta \mathrm{n}$ is the change in porosity, $\delta_{\mathrm{m}}$ is the change in mineral mass in $\mathrm{mg} / \mathrm{L}, \mathrm{n}_{0}$ is initial porosity, and $\rho_{\mathrm{m}}$ is the density of the dissolving/precipitating mineral in $\mathrm{mg} / \mathrm{cm}^{3}$. Using this equation, an assumed initial porosity of 0.2 , a $\rho_{\mathrm{m}}=2710 \mathrm{mg} / \mathrm{cm}^{3}$ (density of calcite), and the Ca mass transfer from Wapshilla Ridge sample 688A (9.4 mg/L) and interflow zone sample 525A (29.3 mg/L), returns a porosity reduction of $1.7 \times 10^{-6}$ and $5.4 \times 10^{-6}$, respectively. This is equivalent to a $0.001 \%$ reduction in porosity in the flow interior and a $0.003 \%$ reduction in porosity in the interflow zone per pore volume due to calcite precipitation. In this scenario, a pore volume is the volume required to hold $1 \mathrm{~L}$ of water in an aquifer with a porosity of 0.2 (e.g. $1000 \mathrm{~cm}^{3}$ pore volume out of $5000 \mathrm{~cm}^{3}$ total volume of aquifer). As heated water is pumped, flowing through an increasing number of pore volumes, the resulting change in porosity is multiplied by the number of pore volumes the water passes through. Over time, this can lead to significant porosity gains or losses.

Changes in porosity can be related to permeability using the Carman-Kozeny equation given below (Palmer and Cherry 1984), where $\mathrm{k}=$ permeability, $\mathrm{C}$ is a constant of value $0.2, \mathrm{n}$ is porosity, and $\mathrm{S}$ is surface area in $\mathrm{cm}^{2}$.

$$
k=\left(C n^{3}\right) /(1-n)^{2} S^{2}
$$


The aquifer modeled in permeability calculations contains one liter of water and has the dimensions $50 \mathrm{~cm} \times 10 \mathrm{~cm} \times 10 \mathrm{~cm}$, and is characterized by 10 fractures with a width and length of $50 \mathrm{~cm} \times 10 \mathrm{~cm}$ (which yields a total aquifer volume of $5000 \mathrm{~cm}^{3}$, a pore volume of $1000 \mathrm{~cm}^{3}$, and a porosity of 0.2 ). Assuming an aquifer with a surface area of 10,000 $\mathrm{cm}^{2}$ and an initial porosity of 0.2 for an increasing number of pore volumes (where pore volume $=1000 \mathrm{~cm}^{3}$ for $5000 \mathrm{~cm}^{3}$ of aquifer) yields the permeability values in Table 3.5 .

Table 3.5. Changes in porosity and permeability determined using equations 2 and 3 for an aquifer with a surface area of $10000 \mathrm{~cm}^{2}$, an initial porosity of 0.2 , and an increasing number of pore volumes through which water has flowed (where pore volume $=1000$ $\left.\mathrm{cm}^{3}\right)$

\begin{tabular}{cccc}
\hline $\begin{array}{c}\text { Number of } \\
\text { Pore Volumes }\end{array}$ & Porosity & $\begin{array}{c}\text { \% Change in } \\
\text { Porosity }\end{array}$ & $\begin{array}{c}\text { Permeability } \\
\left(\mathbf{c m}^{\mathbf{2}}\right)\end{array}$ \\
\hline $\mathbf{0}$ & 0.200 & $0 \%$ & $2.500 \mathrm{E}-11$ \\
1 & 0.200 & $0.00 \%$ & $2.500 \mathrm{E}-11$ \\
10 & 0.200 & $0.03 \%$ & $2.498 \mathrm{E}-11$ \\
100 & 0.199 & $0.27 \%$ & $2.476 \mathrm{E}-11$ \\
1000 & 0.195 & $3 \%$ & $2.272 \mathrm{E}-11$ \\
2000 & 0.189 & $5 \%$ & $2.061 \mathrm{E}-11$ \\
5000 & 0.173 & $13 \%$ & $1.514 \mathrm{E}-11$ \\
10000 & 0.146 & $27 \%$ & $8.536 \mathrm{E}-12$ \\
18500 & 0.100 & $50 \%$ & $2.478 \mathrm{E}-12$ \\
\hline
\end{tabular}

The new porosity, after water has moved through a number of pore volumes, is found by multiplying the change in porosity due to calcite precipitation (determined for sample $525 \mathrm{~A}$ from equation 2 , above) times the total number of pore volumes through which water has passed, and subtracting the resulting total change in porosity from the initial porosity. The percent change in porosity is shown for comparison, and permeability is calculated using equation 3 . By the time porosity has been reduced by $50 \%$, permeability has decreased by almost an order of magnitude. This calculation shows that as water 
flows through an increasing number of pore volumes, the potential impacts of secondary mineralization on porosity and permeability increase as well.

\section{Discussion}

Laboratory scale TES simulations revealed that interflow zone samples experienced a greater mass transfer upon heating than did basalt flow interiors. This result counters previous assumptions that less weathered flow interior samples would be more reactive. The greater reactivity of interflow zone samples could be due to faster dissolution kinetics and/or greater temperature dependencies of secondary minerals compared to the remaining basaltic glass and primary minerals in unweathered basalt flow interiors.

Dissolving phases from the flow interiors likely comprise andesine, augite, trace amounts of ilmenite or magnetite, and any remaining basaltic glass. Dissolving phases in interflow zones are likely to be relict plagioclase, pyroxene and glass, and re-reacted clay and zeolite minerals whose solubilities have increased with increasing temperature. SEM analysis suggests that basaltic glass may have altered to clay, since emplacement of the basalts in the Miocene. Precipitating phases in both zones likely include calcite, Fe or Al oxides and hydroxides, and clay minerals that have lower solubilities at higher temperatures. The relatively high concentrations of dissolved vanadium likely result from dissolution of ilmenite in flow interiors and possibly from clays in the interflow zones (Winter, 2001). Compared to the starting water, both flow interior and interflow zone waters become further undersaturated with respect to amorphous silica and become less oversaturated with respect to chalcedony upon heating. Inverse modeling suggests 
that plagioclase and pyroxene dissolution, and precipitation of calcite and aluminosilicates can explain the mass transfers observed in heating experiments.

The results from cooling the previously heated water are more difficult to interpret. The rates of most mineral dissolution and precipitation reactions are greater at higher temperatures, and the solubilities of most minerals, including quartz, chalcedony and amorphous silica, increase with temperature (carbonate minerals, and some clays being an important exception). Therefore, upon cooling, Ca concentrations, if controlled by carbonates, should increase (or at least remain the same) while $\mathrm{Si}$ concentrations, if controlled by mono-silica phases, should decrease. Instead, $\mathrm{Ca}$ and $\mathrm{Mg}$ concentrations decrease upon heating but then continue to decrease upon cooling, while $\mathrm{Si}$ concentrations increase with temperature but do not decline much upon cooling. Explanations for the unexpected behavior of $\mathrm{Ca}$ and $\mathrm{Mg}$ include carbonate exsolution upon sampling and exposure to the atmosphere post reaction, or incorporation into other phases- although the most likely phases would be clays or zeolites that should also remove $\mathrm{Si}$. If a kinetic barrier was crossed at higher temperatures, once there is a surface template or nucleation site, minerals may continue to precipitate at lower temperatures. The lack of a measurable Si response to cooling is likely because of the slow precipitation kinetics of $\mathrm{SiO}_{2}$ minerals (Rimstidt and Barnes 1980). For TES, this slow rate implies $\mathrm{SiO}_{2}$ precipitation may not be a concern in the short term but could build up in the system over time. SEM analysis of filtered precipitates from the cooled water showed gibbsite, Fe-hydroxides, and indeterminate aluminosilicate precipitates present, and rare calcite crystals. Because solutions were filtered before they cooled, there was no 
solid substrate present to promote mineral nucleation and precipitation in the cooling water. If the water had not been filtered before cooling, a greater amount of precipitation might have occurred, particularly in the presence of colloidal $\mathrm{SiO}_{2}$ and $\mathrm{Fe}$ and $\mathrm{Al}$ oxyhydroxides. However, without filtering it would have been difficult to determine whether or not minerals were the result of cooling.

The bulk of the experimental analysis focuses on calcite precipitation because 1) Ca concentrations in groundwater are primarily controlled by calcite solubility (see $\mathrm{Ch}$. 2), whereas other cations ( $\mathrm{Na}, \mathrm{Si}, \mathrm{Al})$ may be distributed into several secondary mineral phases common to the CRBG, and 2) because calcite has a relatively fast precipitation rate, and is the most likely mineral to react in the time frame of interest for thermal energy storage (e.g. several months for one storage cycle). Given that $\mathrm{Si}$ and $\mathrm{Al}$ are controlled by incongruent reactions, generalizing their concentrations as controlled only by amorphous silica or an Al-oxyhydroxide like gibbsite may be a poor assumption, especially as both published literature and our SEM analysis shows that the CRB have a tendency to form clay and zeolite minerals upon weathering (Ames and McGarrah, 1980; Benson and Teague, 1982; Hearn et al., 1985, 1990).

Several processes could occur with rising temperatures in the aquifer system. Dissolution of any remaining glass may be accelerated, the rate of clay precipitation may increase, or existing clays may dissolve and release ions into the water. Chapter 4 discusses the use of geochemical reaction modeling to further explore which water-rock reactions are occurring over the period of interest, and where in the TES system mineral precipitation may be of greatest concern. 
Extrapolating porosity reductions that result from calcite precipitation (Section 3.2.4) from flow through 100s or 1000s of pore volumes indicates that there could be significant loss of porosity over time. The extent of precipitation would be exacerbated if the native groundwater is already at saturation with respect to calcium carbonate. Furthermore, any reduction in porosity can significantly reduce permeability within the aquifer, limiting the efficiency of hot water injection and extraction. Even if more mass were to dissolve ( $\mathrm{Si}$ or $\mathrm{Al}$ from aluminosilicates) than precipitate (e.g. carbonate minerals and exothermic clays) in the aquifer at elevated temperatures, this dissolved mass may precipitate out when water is brought to the surface and put through a heat exchanger, increasing the risks for scale formation at the surface. The hydrogeochemical modeling discussed in Ch. 4 further explores this problem. 


\section{CHAPTER 4: GEOCHEMICAL REACTION MODELING OF TES CYCLES}

Geochemical reaction modeling is used to simulate thermal energy storage in the Columbia River Basalt aquifer system and provide some idea of the potential problems and long-term effects of employing TES in the Portland Basin. Equilibrium modeling is used here to bracket the maximum extent of mineralization (scale formation) that can be expected at the surface and within a heat exchange system due to the circulation of heated waters. Both equilibrium and kinetic transport modeling are used to estimate and compare the water-rock interactions that may occur once heated water is injected into the CRBG aquifer. Modeling results provide insight as to which system design parameters and geochemical processes are most likely to impact TES.

\subsection{Methods}

\subsubsection{Equilibrium modeling of TES}

The changes in water chemistry and the volume of minerals that can be dissolved or precipitated in the thermal energy storage system can be simulated with geochemical reaction models. The program Geochemist's Workbench (Bethke, 2008) and the modified thermodynamic database (described in section 2.1.2) were used to simulate the mass transfers and potential changes to water quality that result from cyclical heating and cooling of native groundwater, and to constrain the impacts of mineral assemblage, temperature, atmospheric pressure, flow rate, and water composition on results. The impact TES processes may have on a heat exchanger and on the porosity of the aquifer 
system can be estimated from the mass transfers and changes to water quality identified by geochemical reaction modeling.

Table 4.1. Average water compositions for cluster groups used in geochemical reaction models.

\begin{tabular}{|c|c|c|c|c|c|c|c|}
\hline Cluster Group: & Unit & CRB 1 & CRB 2 & CRB 3 & Avg CRB & Avg. 6 & Avg. 7 \\
\hline Count & -- & 11 & 43 & 24 & 78 & 4 & 7 \\
\hline Well Depth & $\mathrm{ft}$. & 370 & 490 & 750 & 530 & 200 & 3080 \\
\hline Temperature & ${ }^{\circ} \mathrm{C}$ & 11.3 & 11.2 & 14.4 & 12.5 & 12.3 & 14.7 \\
\hline $\mathrm{pH}$ & -- & 6.88 & 7.11 & 7.69 & 7.24 & 8.30 & 7.97 \\
\hline $\mathrm{SiO}_{2}$ & $\mathrm{mmol} / \mathrm{L}$ & 0.647 & 0.865 & 0.759 & 0.816 & 0.222 & 0.353 \\
\hline $\mathrm{Na}^{+}$ & $\mathrm{mmol} / \mathrm{L}$ & 0.252 & 0.449 & 3.68 & 1.33 & 19.4 & 143 \\
\hline $\mathrm{K}^{+}$ & $\mathrm{mmol} / \mathrm{L}$ & 0.036 & 0.089 & 0.276 & 0.125 & 0.121 & 3.06 \\
\hline $\mathrm{Ca}^{++}$ & $\mathrm{mmol} / \mathrm{L}$ & 0.168 & 0.560 & 2.29 & 1.05 & 0.647 & 86.4 \\
\hline $\mathrm{Mg}^{++}$ & $\mathrm{mmol} / \mathrm{L}$ & 0.135 & 0.376 & 0.596 & 0.412 & 0.098 & 1.87 \\
\hline $\mathrm{HCO}_{3}^{-}$ & $\mathrm{mmol} / \mathrm{L}$ & 0.751 & 2.15 & 1.89 & 1.87 & 6.07 & 0.950 \\
\hline $\mathrm{Cl}^{-}$ & $\mathrm{mmol} / \mathrm{L}$ & 0.065 & 0.490 & 9.19 & 3.18 & 14.5 & 288 \\
\hline SO4-- & $\mathrm{mmol} / \mathrm{L}$ & 0.012 & 0.055 & 0.067 & 0.043 & 0.064 & 0.606 \\
\hline $\mathrm{F}^{-}$ & $\mathrm{mmol} / \mathrm{L}$ & 0.0059 & 0.010 & 0.028 & 0.015 & 0.033 & 0.012 \\
\hline $\mathrm{NO}_{3}{ }^{-}$ & $\mathrm{mmol} / \mathrm{L}$ & 0.011 & 0.0051 & 0.0034 & 0.0054 & 0.0005 & 0.0024 \\
\hline Total Fe & $\mathrm{mmol} / \mathrm{L}$ & 0.002 & 0.017 & 0.012 & 0.014 & 0.077 & 0.018 \\
\hline Total Mn & $\mathrm{mmol} / \mathrm{L}$ & 0.0001 & 0.0014 & 0.042 & 0.014 & 0.0013 & 0.0096 \\
\hline${ }^{1} \mathrm{Al}^{+++}$ & $\mathrm{mmol} / \mathrm{L}$ & -- & -- & 0.0024 & 0.0024 & -- & -- \\
\hline $\mathrm{Ba}^{++}$ & $\mathrm{mmol} / \mathrm{L}$ & $2.2 \mathrm{E}-05$ & -- & 0.0004 & 0.0003 & -- & 0.0002 \\
\hline${ }^{2} \mathrm{Eh}$ & $\mathrm{mV}$ & -- & -- & -- & 150 & -88 & -160 \\
\hline \multicolumn{8}{|c|}{ Calculated Parameters } \\
\hline $\mathrm{CO}_{2}$ Fugacity & bar & 0.0037 & 0.0068 & 0.0018 & 0.0046 & 0.0014 & 0.00025 \\
\hline TDS & $\mathrm{mg} / \mathrm{kg}$ & 100 & 240 & 670 & 400 & 1350 & 16300 \\
\hline \multicolumn{8}{|c|}{ Select Mineral Saturation Indices $(\log Q / K)$} \\
\hline Amorph. Silica & & -0.41 & -0.21 & -0.31 & -0.24 & -0.82 & -0.61 \\
\hline Calcite & & -2.1 & -0.96 & 0.15 & -0.64 & 0.62 & 0.95 \\
\hline
\end{tabular}

TES will likely source its water from deeper CRBG aquifers present in the Portland Basin. Because there is little published data regarding water composition in the lower $\mathrm{CRBG}$, and because groundwater compositions may vary depending on depth, 
proximity to structures, and location within the basin, a range of potential native groundwater compositions were utilized in the geochemical reaction models. Water compositions are based on the means of groups identified via the HCA in Chapter 2 (reported in Table 4.1) and include: shallow/minimally evolved CRB waters (CRB1), evolved CRB waters (CRB2), mature/mixed CRB waters that are at or near saturation with respect to calcite (CRB3), sedimentary waters (basin-wide Avg 6), and brackish to saline Na-Cl-type marine sedimentary or volcanic ("basement") waters (basin-wide Avg 7). Water compositions representative of the underlying units, represented by HCA Groups 6 and 7 ( $\operatorname{vvg} 6$ and $A v g$ 7), are included because there is interest in using these units as storage sites in addition to the CRB aquifers. An "average" CRB groundwater composition (CRB_Avg) was also calculated from all CRB groundwater data.

Table 4.2. Primary and secondary minerals considered during modeling of the TES system.

\begin{tabular}{l|lll}
\hline \hline Primary Minerals & \multicolumn{3}{|l}{ Secondary Minerals } \\
\hline Plagioclase & Amorphous Silica & Calcite & Saponite-Mg \\
Pyroxene & Chalcedony & Magnesite & Smectite-Reykjanes \\
Basaltic Glass & Gibbsite & Rhodochrosite & Smectite-high-Fe-Mg \\
& Fe(OH)3 $(\mathrm{ppd})$ & Witherite & Smectite-low-Fe-Mg \\
& Goethite & Siderite & Clinoptilolite \\
\hline \hline
\end{tabular}

Mineral phases utilized in the geochemical models (Table 4.2) include those which are: 1) identified in pertinent literature, 2) major primary minerals within the CRBG or secondary minerals at or near equilibrium with CRBG groundwaters (Figure 2.4) and 3) those with precipitation rates fast enough to potentially impact the TES cycle. Literature recognizes both chalcedony (cryptocrystalline silica) and amorphous silica as 
potential secondary silica phases within the CRB (Deutsch et al., 1982; Cummings et al., 1989; Gannett and Caldwell, 1998; Vlassopoulos et al., 2009). Modeling of clay phase stabilities for the CRB Avg water composition over a range of relevant temperatures and $\mathrm{pHs}$ indicates that saponite (a smectite) should be the dominant clay phase above $50{ }^{\circ} \mathrm{C}$ (Figure 4.1). The Avg 6 cluster waters, with a pH of 8.3 at measured temperatures of $\sim 12$ ${ }^{\circ} \mathrm{C}$ are at or near saturation with respect to both Saponite-K and Saponite-Mg (mean SI values of -0.08 and +0.17 , respectively), while modeled waters are highly supersaturated (SI values 2 to $5+$ ) with respect to other clay phases included in the thermodynamic database, including nontronites and smectites. One exception is the $C R B 1$ mean water, which appears at or near saturation with respect to Smectite-high-Fe-Mg $(\mathrm{SI}=0.19)$. As a result, saponite-Mg was the primary clay phase included in models. The most commonly reported zeolites are clinoptilolite and heulandite (Ames, 1980 and Vlassopoulos et al., 2009) which may also be found in CRBG interflow zones (i.e the target zone).

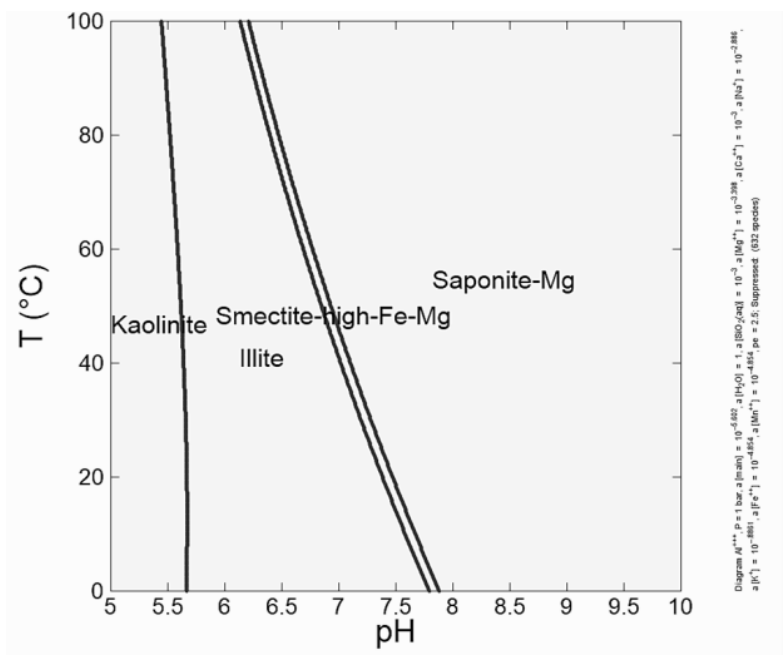

Figure 4.1. Temperature-activity $(\mathrm{pH})$ diagram showing stability fields for various clay phases assuming the Avg CRB water composition. (Nontronites and smectite-low-Fe-Mg and smectite-Reykjanes were permitted to form in this model). 
Equilibrium models were run both with and without gibbsite, and with and without clinoptilolite (a zeolite phase). Because clay and zeolite reaction rates are four to five orders of magnitude slower than reaction rates for amorphous silica, and because zeolites generally form after clays, clinoptilolite was only examined using equilibrium modeling to capture the "most extreme" case. Gibbsite was initially included, but as it has a higher solubility than clays, was subsequently excluded. Equilibrium modeling was also used to compare the effects of heating to $70^{\circ} \mathrm{C}$ versus $50^{\circ} \mathrm{C}$, and heating under open versus closed system conditions.

Table 4.3. Example water-rock reactions that may cause mineral dissolution, precipitation, or buffering (modified from Rattray and Ginsbach, 2014).

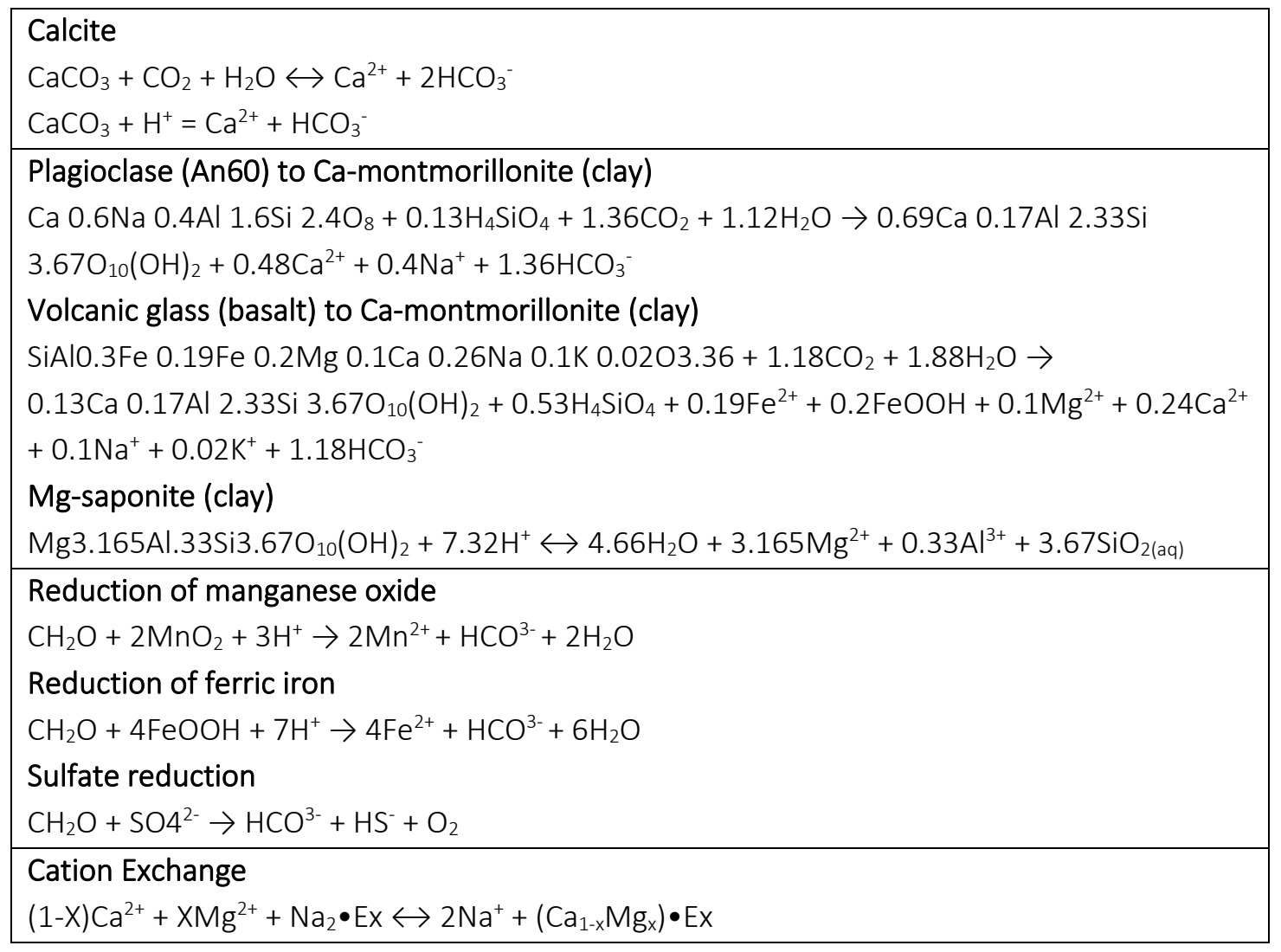




\subsubsection{Heating at the Surface}

Initial heating of native groundwaters was modeled as an equilibrium process using a polythermal reaction path to simulate heating $1 \mathrm{~kg}$ of extracted groundwater from the ambient aquifer temperature $\left(\sim 12^{\circ} \mathrm{C} \pm 2{ }^{\circ} \mathrm{C}\right.$, depending on the compositional group $)$ to a maximum temperature of $70^{\circ} \mathrm{C}$ (near the upper temperature threshold of the proposed TES system). The polythermal reaction path was modeled both with and without the addition of a sliding fugacity path. Sliding the fugacity to atmospheric levels simulates opening the system and allowing gas exchange with the atmosphere, resulting in gas loss from higher $\mathrm{f}_{\mathrm{CO} 2}$ waters to the atmosphere, and the addition of $\mathrm{O}_{2}$ into reduced groundwaters. Without sliding fugacity, the models simulate a closed system with no gas exchange. In the sliding fugacity models, both $\mathrm{CO}_{2}$ and $\mathrm{O}_{2}$ slide from their initial estimated fugacities within the confined basalt aquifer (Table 4.1) to their fugacities under atmospheric pressure $\left(\mathrm{CO}_{2}\right.$ fugacity of 0.0004 and $\mathrm{O}_{2}$ fugacity of 0.206$)$. To simulate extracting water from the aquifer, then heating it under open system conditions, the sliding fugacity path was first applied and fugacities fixed to atmospheric levels, then the polythermal reaction model was run. Fixing fugacity first simulates heating while maintaining equilibrium with atmospheric gasses.

Mineral saturation states are calculated for each step of the reaction path. Oversaturated minerals are allowed to precipitate in some cases to simulate scale formation in the heat exchange system and associated piping; in other cases, mineral precipitation is suppressed until the second modeling step (re-injection into the aquifer), 
to simulate slow kinetics or transfer of mineral mass as suspended solids. The minerals that precipitate during surface heating are potential pipe-scale forming minerals.

The redox state of groundwaters in the western Oregon CRBG aquifers are poorly constrained. The pe of waters in the compiled western Oregon CRBG groundwater database, which modeled waters are based on, ranges from -4 to 13 , with a median of 4.5 and an average of 1 (calculated from reported Eh values, Table 4.1). This median value was used for open system modeling of all water compositions and was adjusted upwards by the minimum amount possible when convergence errors occurred at the lower pe value. Excluding redox in closed system models limits formation of $\mathrm{Fe}(\mathrm{OH})_{3}$, goethite and FeIII-bearing smectites in most waters, providing a conservative estimate.

\subsubsection{Equilibrium modeling of Subsurface Processes}

The next modeling step simulates injecting $1 \mathrm{~kg}$ of heated water (from which mineral mass had been removed during the previous heating step) into the aquifer, with an assumed porosity of 0.2 . Undersaturated primary basalt minerals (plagioclase and pyroxene) are modeled as dissolving into the water in response to undersaturation with respect to these minerals at higher temperatures. Non-equilibrium dissolution of primary minerals at higher temperatures was modeled by titrating a set amount of mineral mass into the water because unsuppressing the primary minerals and allowing them to dissolve enough to reach equilibrium would have added more mass to the water than was deemed kinetically reasonable for the duration of the TES storage period. The mass of minerals reacted was determined by inversely modeling the batch reaction experiments in Ch. 3 . 
This result suggests that $60 \mathrm{mg} / \mathrm{L}(0.22 \mathrm{mmol} / \mathrm{L})$ of plagioclase, and $40 \mathrm{mg} / \mathrm{L}(0.4$ $\mathrm{mmol} / \mathrm{L}$ ) of pyroxene would need to dissolve and calcite, chalcedony, and gibbsite precipitate to explain the mass transfers obtained from batch experiments $525 \mathrm{~A}$ and 688A. The minerals the water becomes oversaturated with in this step could precipitate and decrease aquifer porosity, if the volume of minerals precipitating exceeds the volume of minerals dissolving. Differences in bulk mineral volumes are due to net mass transfers from dissolution and precipitation of specific minerals, which may entail density differences between primary and secondary minerals resulting from incorporation of dissolved ions or water in secondary mineral phases (e.g., dissolved carbonate in calcite or waters of hydration in clays), and ion substitution in the idealized mineral formulas.

The last step in the equilibrium model simulated mixing between injected and native groundwaters via a flash model which incrementally mixes native groundwater with the injected fluid (from 0 to $100 \%$ ). While this modeling step is revealing in terms of the impacts of mixing on mineral solubilities, the true extent of mixing is unknown. The additional use of transport modeling (section 4.1.2) attempts to constrain the amount of mixing that is expected to occur between injected and native waters within the aquifer.

\subsubsection{Kinetic Transport Model}

\subsubsection{First Cycle}

1D kinetic transport models simulate water-rock reactions within the aquifer over a 180-day injection-storage-extraction period. Use of a kinetic transport model accounts for both reaction rates and flow dynamics and so may provide more realistic estimates of 
mass transfers between minerals and water, and the extent of mixing between injected and native groundwaters during injection and storage. Modeled system parameters are provided in Table 4.4. Domain lengths of 20 to $200 \mathrm{~m}$ were used to investigate the impacts of rock-water interactions and mixing in the near-well and distal regions of the system. The impact of varying flow rates on porosity near the injection point was explored using a radial model domain. The radial domain accounts for increasing crosssectional area and a corresponding decrease in specific discharge away from the injection site. This enables modeling of high flow rates that are expected in the first few meters where cross-sectional flow-through areas are minimal.

A 2D kinetic transport model was also used to simulate the injection and storage period at high flow rates and to explore long-range spatial variations of mineral precipitates. This simulated injecting water for 120 days at $13.9 \mathrm{~L} / \mathrm{s}$, followed by ambient flow for another 80 days, assuming a permeability of 1 darcy and a hydraulic gradient of 0.005 ( $1 \mathrm{~m}$ head drop over $200 \mathrm{~m}$ length). 2D transport model parameters are included in Table 4. The modeled injection well location was at $x=20 \mathrm{~m}, \mathrm{y}=60 \mathrm{~m}$ within the $200 \mathrm{~m}$ by $120 \mathrm{~m}$ domain. Minerals in the $2 \mathrm{D}$ model were incorporated the same way as the $1 \mathrm{D}$ model.

All minerals in kinetic transport models were suppressed, except for those allowed to kinetically react (kinetic parameters summarized in Table 4.5) and carbonate minerals. For most models, carbonate minerals are assumed to react on fast enough time scales to be controlled by equilibrium (Bethke, 2008), an assumption supported by nearly identical results obtained in initial modeling efforts using both kinetically and 
equilibrium-controlled carbonate precipitation. Secondary minerals were assumed to form as a result of kinetically controlled dissolution and precipitation reactions, so were not assigned an initial mass unless otherwise noted.

Table 4.4. Kinetic transport modeling parameters

\begin{tabular}{|c|c|c|}
\hline Modeled Parameters & Values & References \\
\hline \multicolumn{3}{|l|}{ 1D Models } \\
\hline \multicolumn{3}{|l|}{ Linear Domain } \\
\hline Distance & 20 to $200 \mathrm{~m}$ & \\
\hline Nodal spacing & $0.5-1.0 \mathrm{~m}$ & \\
\hline Node Cross-Sectional Area & $1.0 \mathrm{~m} \mathrm{(y)} \times 1.0 \mathrm{~m}(\mathrm{z})$ & \\
\hline \multirow[t]{2}{*}{ Flow Rate } & $0.1-100 \mathrm{~m}^{3} / \mathrm{m}^{2} / \mathrm{d}$ & Tolan et al., 2009a \\
\hline & & Burns et al., 2015; Jayne and \\
\hline Permeability & 1 darcy & Pollyea, 2018 \\
\hline Longitudinal Dispersivity & $2 \mathrm{~m}$ & Schulze-Makuch, 2005 \\
\hline Diffusion Coefficient & $1 \times 10^{-6} \mathrm{~cm}^{2} / \mathrm{s}$ & \\
\hline Heat Capacity & $840 \mathrm{~J} / \mathrm{kg} /{ }^{\circ} \mathrm{C}$ & Burns et al., 2015 \\
\hline Thermal Conductivity & $1.6 \mathrm{~W} / \mathrm{m} /{ }^{\circ} \mathrm{C}$ & Burns et al., 2015 \\
\hline Radial Domain (near-well) & \multicolumn{2}{|c|}{ Parameters not listed below are same as above } \\
\hline Radius 1 (well interface) & \multicolumn{2}{|c|}{$0.20 \mathrm{~m}$} \\
\hline Radius 2 (domain length) & \multicolumn{2}{|l|}{$20 \mathrm{~m}$} \\
\hline Nodes & \multicolumn{2}{|l|}{10} \\
\hline Angle & \multicolumn{2}{|l|}{$1 \mathrm{rad}$} \\
\hline Flow Rate at Radius 1 & \multicolumn{2}{|c|}{1 to $400 \mathrm{~m}^{3} / \mathrm{m}^{2} / \mathrm{d}$ (declines sharply with radius) } \\
\hline 2D Models & \multicolumn{2}{|c|}{ Parameters not listed below are same as above } \\
\hline Distance $(\mathrm{X})$ & \multicolumn{2}{|l|}{$200 \mathrm{~m}$} \\
\hline Distance (y) & \multicolumn{2}{|l|}{$160 \mathrm{~m}$} \\
\hline Nodes (X) & \multicolumn{2}{|l|}{50} \\
\hline Nodes (Y) & \multicolumn{2}{|l|}{40} \\
\hline Height (Z) & \multicolumn{2}{|l|}{$3 \mathrm{~m}$} \\
\hline Well Location & \multicolumn{2}{|l|}{$(20 \mathrm{~m}, 80 \mathrm{~m})$} \\
\hline Transverse Dispersivity & \multicolumn{2}{|l|}{$1 \mathrm{~m}$} \\
\hline Initial Hydraulic Gradient & \multicolumn{2}{|l|}{0.005} \\
\hline Pumping Rate & \multicolumn{2}{|l|}{$13.9 \mathrm{~L} / \mathrm{s}$} \\
\hline
\end{tabular}


As most reaction rate constants reported in literature are for $25^{\circ} \mathrm{C}$, rate constants were calculated for higher temperatures in GWB using the Arrhenius equation and the activation energy and pre-exponential factor (Table 4.5), rather than the rate constant (with the exception of basaltic glass). A rate constant for $70^{\circ} \mathrm{C}$ was determined for basaltic glass via a linear regression from values reported by Gislason and Oelkers (2003) for glass dissolution at $50^{\circ} \mathrm{C}$ and $100^{\circ} \mathrm{C}$ and neutral $\mathrm{pH}$. Due to limited kinetic data for precipitation reactions, dissolution reaction data was used for some secondary phases (e.g., smectites). Specific surface areas were compiled from literature. Nucleation area was set at $1000 \mathrm{~cm}^{2} / \mathrm{cm}^{3}$ for all phases. Nucleation areas can vary by mineral, and seed particles can take a long time to form sufficient mass to initiate mineral nucleation (Van Pham et al., 2012; Hellevang et al., 2013).

An inherent problem with kinetic modeling is the uncertainty with respect to available reactive surface areas of modeled solids. This is compounded in complex natural systems by uncertainties as to what types of solid phases are even present. A series of models were constructed to investigate the impact of varying solids and reactive surface areas. The initial models assumed only the two primary basalt minerals plagioclase and pyroxene to be present. Their percent volumes (relative to the modeled aquifer domain) were varied from $45 \%$ and $35 \%$ respectively (the entire solid volume) to 0.45 and $0.35 \%$, assuming only $1 \%$ of the solid was available to react (the rest of the solid is unavailable or "inert"). 
Table 4.5. Dissolution rate constants $(\log (\mathrm{k}))$, activation energies $\left(\mathrm{E}_{\mathrm{a}}\right)$, pre-exponential factors $\left(\log \left(\mathrm{A}_{\mathrm{w}}\right)\right)$ and specific surface areas $(\mathrm{SA})$ at $25^{\circ} \mathrm{C}$ and neutral $\mathrm{pH}$ for primary and secondary minerals utilized in kinetic modeling. (Assuming dissolution rates approximate precipitation rates for secondary precipitates due to lack of available precipitation data).

\begin{tabular}{|c|c|c|c|c|c|}
\hline Mineral* & $\begin{array}{c}\log (\mathbf{k}) \\
\mathrm{mol} / \mathrm{m}^{2} / \mathrm{s}\end{array}$ & $\begin{array}{c}\mathbf{E}_{\mathrm{a}} \\
\mathrm{KJ} / \mathrm{mol}\end{array}$ & $\begin{array}{l}\log \left(A_{\mathrm{w}}\right) \\
\mathrm{mol} / \mathrm{m}^{2} / \mathrm{s}\end{array}$ & $\begin{array}{c}\text { SA } \\
\mathrm{m}^{2} / \mathrm{g}\end{array}$ & Reference \\
\hline $\begin{array}{l}\text { Pyroxene } \\
\text { (Augite) }\end{array}$ & -11.97 & 78.0 & 1.69 & 0.125 & Palandri and Kharaka, 2004 \\
\hline $\begin{array}{l}\text { Plagioclase } \\
\text { (Andesine) }\end{array}$ & -11.47 & 57.4 & -1.41 & 0.16 & $\begin{array}{c}\text { Stillings et al., 1996; Palandri } \\
\text { and Kharaka, } 2004\end{array}$ \\
\hline Basaltic Glass ${ }^{1}$ & -12.23 & -- & -- & 23 & Gislason and Oelkers, 2003 \\
\hline Calcite $^{2}$ & -5.81 & 23.5 & -1.7 & 0.21 & $\begin{array}{l}\text { Palandri and Kharaka, 2004; } \\
\text { Hellevang et al., } 2013\end{array}$ \\
\hline Siderite $^{2}$ & -6.9 & -- & -- & 0.21 & Hellevang et al., 2013 \\
\hline $\begin{array}{l}\text { Smectite } \\
\text { (Saponite-Mg) }\end{array}$ & -12.78 & 35.0 & -6.65 & 10 & $\begin{array}{l}\text { Palandri and Kharaka, 2004; } \\
\text { Hellevang et al., } 2013\end{array}$ \\
\hline $\begin{array}{l}\text { Amorphous } \\
\text { Silica }^{3}\end{array}$ & -9.42 & 49.8 & -0.66 & 10 & Palandri and Kharaka, 2004 \\
\hline
\end{tabular}

${ }^{1}$ Basaltic glass dissolution rate constant at $70^{\circ} \mathrm{C}$

${ }^{2}$ Carbonate minerals are assumed to be equilibrium controlled for most models due to relatively fast reaction rates (Bethke, 2008). Calcite kinetic parameters used in simulations of calcite-lined pore space. ${ }^{3}$ Reported for precipitation, not dissolution

The potential for basaltic glass as a matrix component was explored using $45 \%$ plagioclase, $30 \%$ pyroxene, and $5 \%$ basaltic glass. A final scenario assumed reactive volumes of $3 \%$ calcite, and $0.5 \%$ each plagioclase and pyroxene to simulate calcite coated fracture surfaces; this scenario was used only for water types that are at saturation with respect to calcite under ambient conditions. Saponite clays and amorphous silica were allowed to precipitate kinetically; carbonate minerals (calcite, siderite, magnesite, rhodochrosite, and witherite) were allowed to precipitate via equilibrium control, except 
for the last scenario where calcite was kinetically controlled. Injection of both $A v g C R B$ and $C R B 3$ waters at $70^{\circ} \mathrm{C}$ were simulated at a specific discharge of $1 \mathrm{~m}^{3} / \mathrm{m}^{2} /$ day (for simplicity) through a linear aquifer domain initially containing ambient-temperature native groundwater.

\subsubsection{Successive cycles}

Successive cycles were modeled using the Avg CRB water composition and a transport model wherein heated water is injected for 180 days at a rate of $1 \mathrm{~m}^{3} / \mathrm{m}^{2} / \mathrm{d}$, then recovered for another 120 days at the same rate. This simulation is accomplished in GWB by reversing the direction of flow and the hydraulic gradient at the end of the injection period. $1 \mathrm{~m}^{3} / \mathrm{m}^{2} / \mathrm{d}$ was chosen for simplicity. The recovery cycle is shorter than the injection cycle to 1) ensure recovered water is as close as possible to its injection temperature, and 2) to leave some heated water in place to minimize cooling in the aquifer and increase long-term system efficiency. The first cycle begins by heating water to $70^{\circ} \mathrm{C}$ (using a polythermal equilibrium model) and injecting and recovering it from the aquifer using the transport model, building a $70^{\circ} \mathrm{C}$ reservoir within the aquifer. Transport model parameters and rates are the same as those included in Table 4.4 and Table 4.5 (using a linear domain).

Recovered water is cooled to $40^{\circ} \mathrm{C}$ using a polythermal equilibrium model, to simulate extracting heat from the water during the winter period. This cooled water is then injected into a different zone of the same aquifer system (building a cooler $40^{\circ} \mathrm{C}$ reservoir), modeled using a transport model with the same parameters and reactant phases 
as the transport model used to model the initial $70^{\circ} \mathrm{C}$ reservoir. The $40^{\circ} \mathrm{C}$ water recovered from this model is then reheated upon extraction to $70^{\circ} \mathrm{C}$, using an equilibrium model and polythermal reaction path. This simulates reheating water during the summer period, prior to injection back into the original $70^{\circ} \mathrm{C}$ reservoir. Injection of $70^{\circ} \mathrm{C}$ reheated water marks the start of the next cycle. The resulting modeled system has two pumping regimes: the first occurs during the summer when water from the cooler reservoir is extracted, heated (via solar energy or another method), and injected into the hotter reservoir. The second occurs during the winter period, where water is pumped from the hotter reservoir, its heat extracted, and the resulting cool water is pumped into the cooler reservoir. As in previous models, minerals can precipitate as needed after each modeling step. "Waste" water $\left(40^{\circ} \mathrm{C}\right.$ water $)$ is stored and later reheated because it would require more energy to continuously heat native groundwater with a temperature of $\sim 12^{\circ} \mathrm{C}$ than recycled water with a presumed temperature of $\sim 40^{\circ} \mathrm{C}$.

\subsection{Results}

\subsubsection{Equilibrium Modeling}

\subsubsection{Effects of Different Mineral Assemblages}

The initial secondary mineral assemblage considered in equilibrium models consists of amorphous silica, calcite, chalcedony, $\mathrm{Fe}(\mathrm{OH})_{3}(\mathrm{ppd})$, gibbsite, goethite, magnesite, rhodochrosite, siderite, and witherite. However, later models excluded gibbsite and chalcedony. Chalcedony was excluded because it is less likely to form than amorphous silica, while gibbsite was excluded because, though it forms rapidly, it is less 
stable than clays and has a higher solubility (so is less likely to be a long-term concern). For this reason, saponite- $\mathrm{Mg}$ and $\mathrm{Fe}, \mathrm{Mg}$, and $\mathrm{Mn}$ bearing smectite clays were included in place of chalcedony and gibbsite. These clays were chosen because they are the clay phases nearest to saturation. Heating the average $\mathrm{CRB}$ water to $70^{\circ} \mathrm{C}$ under closed system conditions revealed that siderite precipitation does not occur until temperatures exceed $61^{\circ} \mathrm{C}$, but that saponite-Mg precipitation begins at $39^{\circ} \mathrm{C}$ and deposits up to 0.0061 $\mathrm{mmol} / \mathrm{L}$ of clay. While slightly more mass is precipitated by including clays in this step, the slower kinetics of clay minerals compared to carbonates make it unlikely that clays will precipitate at the surface upon heating. Injecting this heated water into the aquifer, saponite- $\mathrm{Mg}$ and siderite begin to precipitate, followed by calcite, then amorphous silica. Mixing injected and native waters results in precipitation of saponite-Mg, followed by carbonate minerals (Figure 4.2). Peak mineral precipitation occurs with a mixture containing 93\% native groundwater and $7 \%$ injected water, and porosity is predicted to be reduced from 0.2 to 0.1977 (total change) as the mixing fraction approaches one. Running the same model with barite included in the secondary mineral assemblage has no impact on the mineral phases and masses precipitated. 

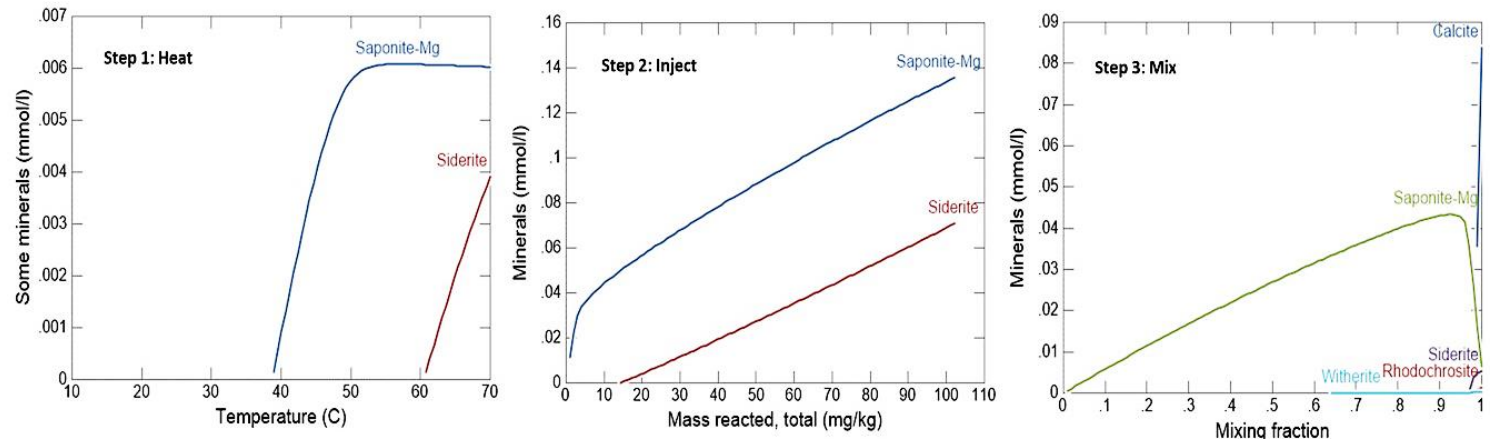

Figure 4.2. Concentration of minerals precipitated from $1 \mathrm{~kg}$ of water after each equilibrium modeling step, when excluding gibbsite and chalcedony and including clay minerals in the mineral assemblage.

Clinoptilolite has been identified as a common secondary mineral in the CRBG (Benson and Teague, 1982; Cummings et al., 1989) and so it was added to the mineral assemblage next. As in the previous model, saponite and siderite precipitate out upon heating. In this model scenario, minerals dissolve and precipitate equal molar amounts, so changes in porosity are due to density and volume differences between primary and secondary mineral phases. Mineral precipitates include clinoptilolite, saponite, and siderite (Figure 4.3). Mixing injected and native ground waters reveals that calcite precipitation peaks near $100 \%$ mixing, clinoptilolite at $58 \%$ mixing, and saponite at $93 \%$ mixing with native groundwater. As in the previous model, porosity is reduced from 0.2 to 0.1977 as the mixing fraction approaches one, for the volume necessary to contain $1 \mathrm{~kg}$ of water. Clinoptilolite precipitation is most likely to occur after the TES system has been running for some time, as Hearn et al., (1990) and others have determined clays form as a precursor to zeolites within the CRBG. 

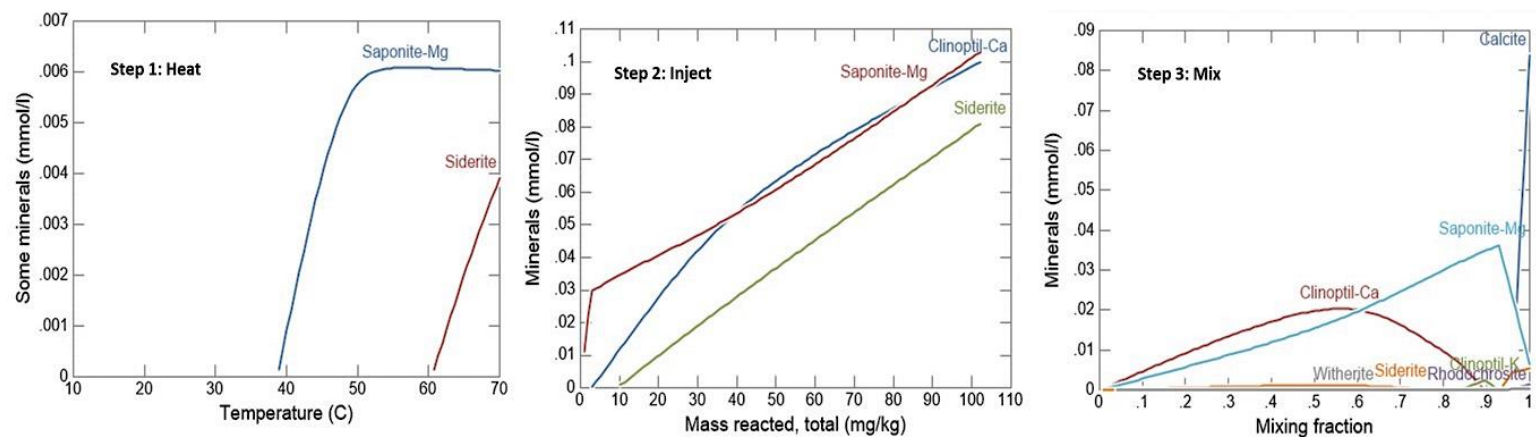

Figure 4.3. Concentration of minerals precipitated from $1 \mathrm{~kg}$ of water after each equilibrium modeling step, when including clinoptilolite in the mineral assemblage.

Most likely, the TES system will induce carbonate mineral precipitation at the surface followed by further carbonate, clay, and amorphous silica precipitation within the aquifer upon reaction of injected water with aquifer rock (though the amount of precipitates will depend on both the flow rate and chemical reaction rate). At the mixing front between injected and native waters, models show carbonate precipitation occurs as a result of heating of native ground waters, while $\mathrm{Si}$ - and $\mathrm{Al}$ - based minerals precipitate because of cooling injected water.

The mineral assemblage used in subsequent models consists of amorphous silica, calcite, $\mathrm{Fe}(\mathrm{OH})_{3}(\mathrm{ppd})$, magnesite, rhodochrosite, siderite, and witherite during surface heating; and amorphous silica, calcite, $\mathrm{Fe}(\mathrm{OH})_{3}(\mathrm{ppd})$, magnesite, rhodochrosite, siderite, witherite, saponite-Mg, smectite-high-Fe-Mg, smectite-low-Fe-Mg, and Mn-bearing smectite-Reykjanes during model steps simulating processes within the aquifer. Clays are not permitted to precipitate at the surface due to their slower kinetics. 


\subsubsection{Effect of Varying initial water composition}

To determine the impact of starting water chemistry on the mineral phases and masses precipitated, equilibrium models were run using average water chemistries from the groups identified via cluster analysis (Chapter 2) as a variety of initial groundwater compositions. Because many CRBG groundwaters are near saturation with respect to calcite, and because the solubilities of calcite and other carbonates, like siderite, decrease with temperature and with loss of $\mathrm{CO}_{2}(\mathrm{~g})$, carbonate scaling is of primary concern during heating of groundwaters. The greatest amount of precipitation observed in response to heating at the surface was found in groups that are saturated or oversaturated with respect to calcium carbonate prior to heating (CRB3, basin-wide Avg 6 and $A v g$ 7). These are the groups that represent the deepest, most mature CRBG groundwater (CRB3), and saline water found in underlying sediments and basement volcanics (Avg 6 and Avg 7). However, groundwaters near saturation may actually be at equilibrium if the calculated solubility product is within the error associated with its calculation. Saturated to oversaturated waters begin to precipitate calcite (or siderite) right away with the addition of heat, while calcite only reaches saturation and begins to precipitate from water compositions that are initially undersaturated once temperatures exceed $\sim 55^{\circ} \mathrm{C}$. Model results suggest that undersaturated waters form significantly less calcite upon heating, if any. The temperatures at which different waters reach saturation with calcite, siderite, and $\mathrm{Mg}$-saponite are shown in Figure 4.4. 

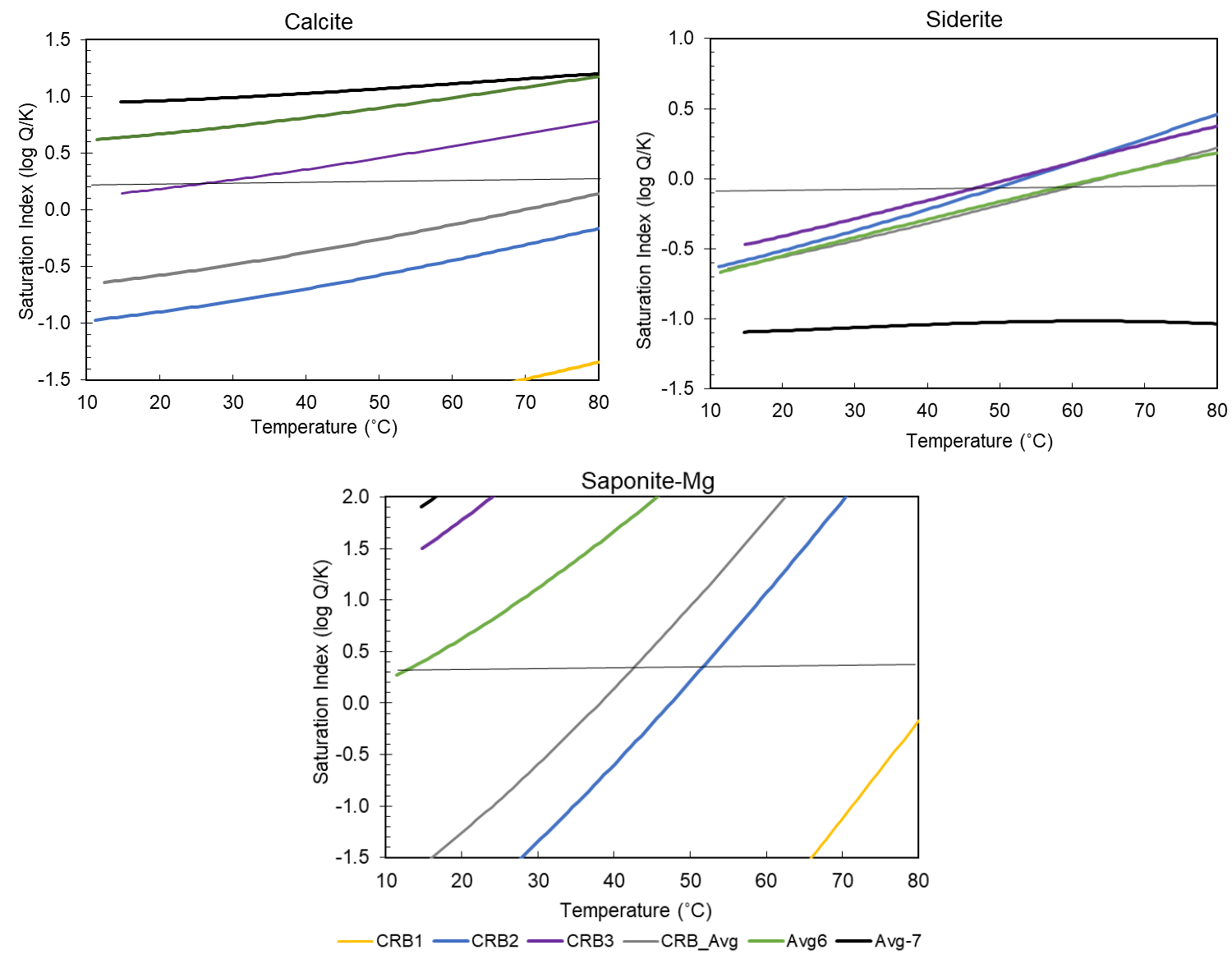

Figure 4.4. Saturation indices for calcite, siderite, and saponite-Mg with respect to temperature for different initial water compositions (from Table 4.1). A saturation index of 0 represents equilibrium; SI values $>0$ indicate the potential for mineral precipitation.

These models portray the maximum extent of mineral precipitation that can be expected at the surface (Figure 4.5). However, kinetic constraints may inhibit short-term precipitation in the heat exchange system, particularly for clays (calcite reaction rates are orders of magnitudes higher, so carbonate scale build up is of greatest concern). If flowthrough times are short enough (e.g., $<1$ day), calcite precipitates may be carried into the aquifer as suspended colloids. Filtration of suspended solids by the aquifer can result in significant decreases in aquifer porosity and permeability near the injection well. 


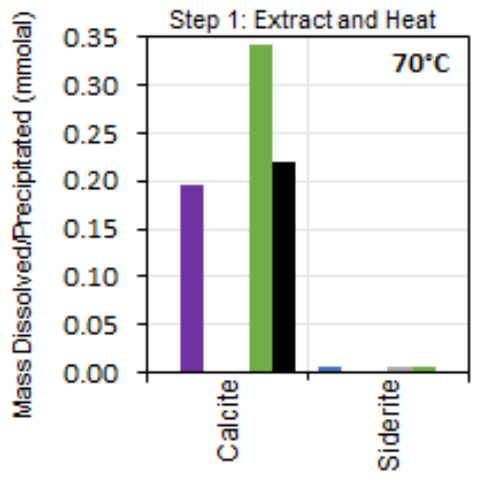

a.

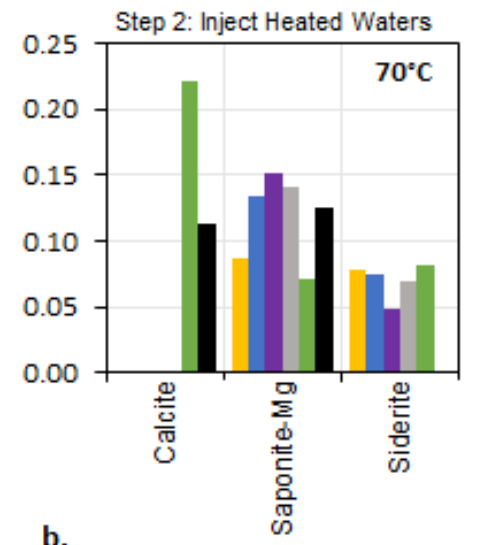

b.

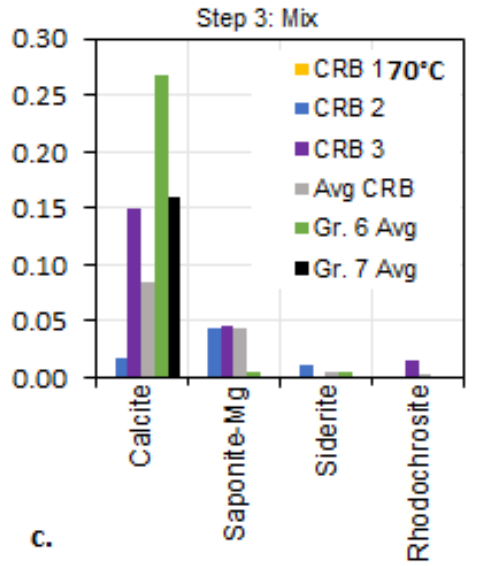

Figure 4.5. Amount of minerals precipitated per kilogram of water due to a) extraction and heating at the surface, b) injection and reaction with aquifer rock, and c) mixing between injected and native groundwaters. Colors represent varying ground water compositions that may be present in the TES target zone (see Ch. 2).

Inputting extracted and heated waters into subsurface equilibrium model reveals that only water compositions associated with units underlying the CRBG continue to precipitate calcite upon injection and reaction with aquifer rock. The upwelled mixed brackish water type (Avg 6, green) precipitates the greatest mineral amount (Figure 4.5). All waters but the saline water also precipitated siderite, and all waters precipitated $\mathrm{Mg}$ saponite. Mineral precipitation during this modeling step is enabled by the dissolution of primary minerals, which supplies the $\mathrm{Ca}, \mathrm{Mg}, \mathrm{Fe}, \mathrm{Si}$, and $\mathrm{Al}$ necessary for mineral precipitation.

Models predict that saline water and mature CRBG water types precipitate the most mineral mass in response to mixing between injected and native groundwaters (in addition to precipitating the most mineral mass at the surface). These are also the two water types that have the highest TDS. The precipitation of calcite and other carbonates 
in this step is linked to changes in $\mathrm{pH}$ and differences in the $\mathrm{f}_{\mathrm{CO} 2}$ of injected and native groundwaters. Carbonate solubility increases at lower pH's and lower fugacity of $\mathrm{CO}_{2}$.

\subsubsection{Varying Temperature}

Heating Avg $C R B$ groundwater to $70^{\circ} \mathrm{C}$ results in precipitation of siderite above $\sim 55^{\circ} \mathrm{C}$. Thus, when the same water is heated to only $50^{\circ} \mathrm{C}$, the water does not reach saturation and no surface mineral precipitation occurs (Figure 4.4). Injecting $50^{\circ} \mathrm{C}$ water into the aquifer and reacting in primary minerals results in an identical mass of precipitated siderite, but less saponite than is produced by injection of $70^{\circ} \mathrm{C}$ water (Figure 4.6). The $70^{\circ} \mathrm{C}$ water may precipitate an equivalent amount of siderite as $50^{\circ} \mathrm{C}$ water because the amount of $\mathrm{Fe}$ added to the water from dissolving minerals is enough to saturate the water with respect to siderite at both temperatures.

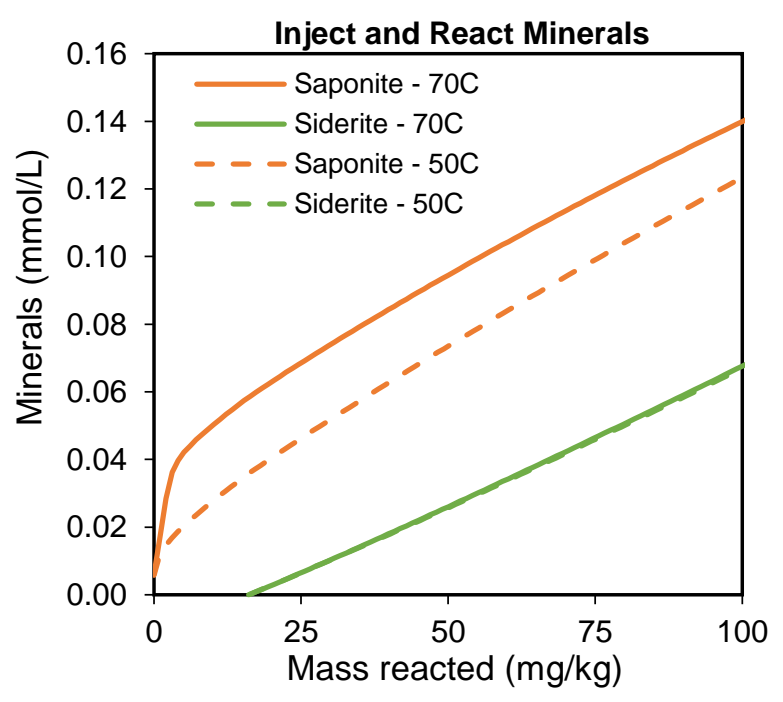

Figure 4.6.Concentration of precipitated minerals and resulting porosity per kilogram of injected water, in response to reaction of $40 \mathrm{mg} / \mathrm{L}$ of pyroxene and $60 \mathrm{mg} / \mathrm{L}$ of plagioclase. 
Mixing injected water with native groundwater results in saponite precipitation at both $70^{\circ} \mathrm{C}$ and $50^{\circ} \mathrm{C}$, but at $50^{\circ} \mathrm{C}$ the mixture precipitates less clay than at $70^{\circ} \mathrm{C}$. As the mixing fraction approaches unity, small amounts of carbonate minerals begin to form, corresponding to a $\mathrm{pH}$ increase in both cases. Porosity also decreases as waters mix, though to a greater extent when mixing with $70^{\circ} \mathrm{C}$ water than with $50^{\circ} \mathrm{C}$ water (Figure 4.7).

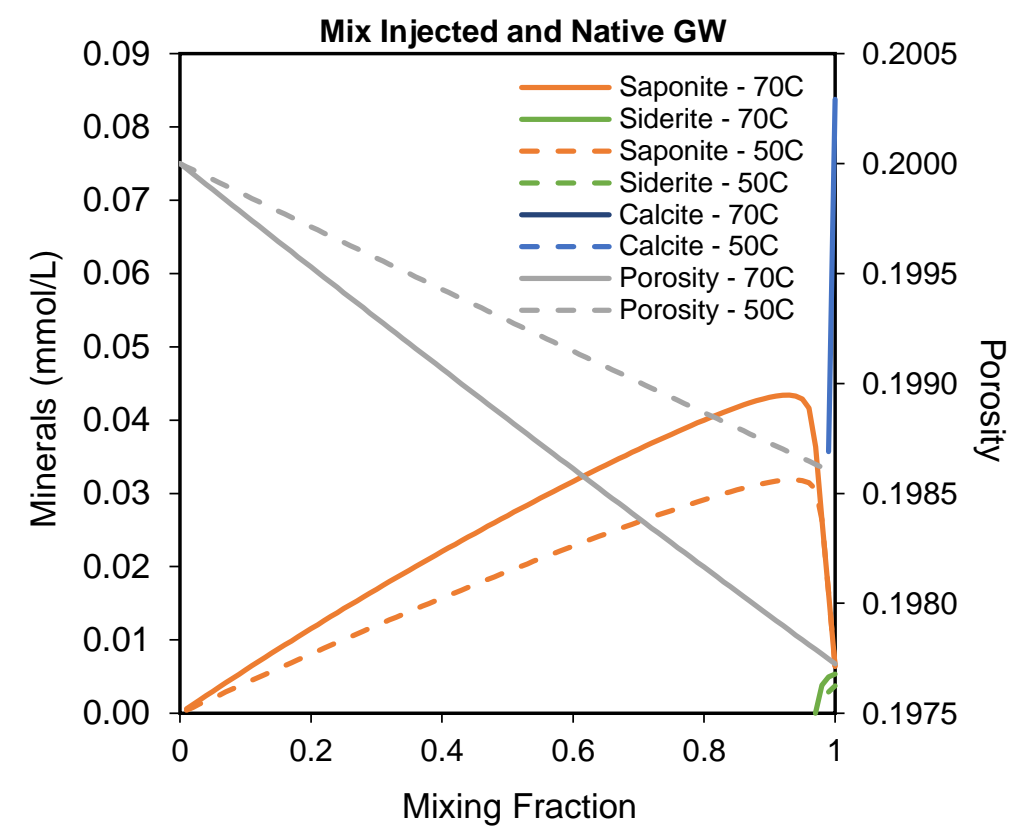

Figure 4.7. Concentrations of precipitated minerals and resulting porosity, as injected and native groundwaters mix. Solid lines indicate $70^{\circ} \mathrm{C}$ results, dashed lines indicate $50^{\circ} \mathrm{C}$ results.

\subsubsection{Open vs. closed system}

Model results indicate that when $1 \mathrm{~kg}$ of $A v g C R B$ groundwater is brought to the surface and allowed to equilibrate with the atmosphere, calcite, $\mathrm{Fe}(\mathrm{OH})_{3}(\mathrm{ppd})$, and rhodochrosite precipitate. $\mathrm{Fe}(\mathrm{OH})_{3}(\mathrm{ppd})$ is able to precipitate in this model because 
atmospheric $\mathrm{O}_{2}$ enters the (reduced) groundwater, and oxidizes the iron. Heating this water to $70^{\circ} \mathrm{C}$ while still in contact with the atmosphere results in $0.32 \mathrm{mmol} / \mathrm{l}$ of calcite precipitation. Heating to only $50^{\circ} \mathrm{C}$ results in $0.25 \mathrm{mmol} / \mathrm{l}$ of calcite precipitation. This amount of calcite is significantly more than the $0.0053 \mathrm{mmol} / 1$ precipitated upon heating the same water to $70^{\circ} \mathrm{C}$ under closed system conditions and is due to the greater $\mathrm{f}_{\mathrm{CO} 2}$ of groundwater compared to the $\mathrm{f}_{\mathrm{CO} 2}$ of the atmosphere.

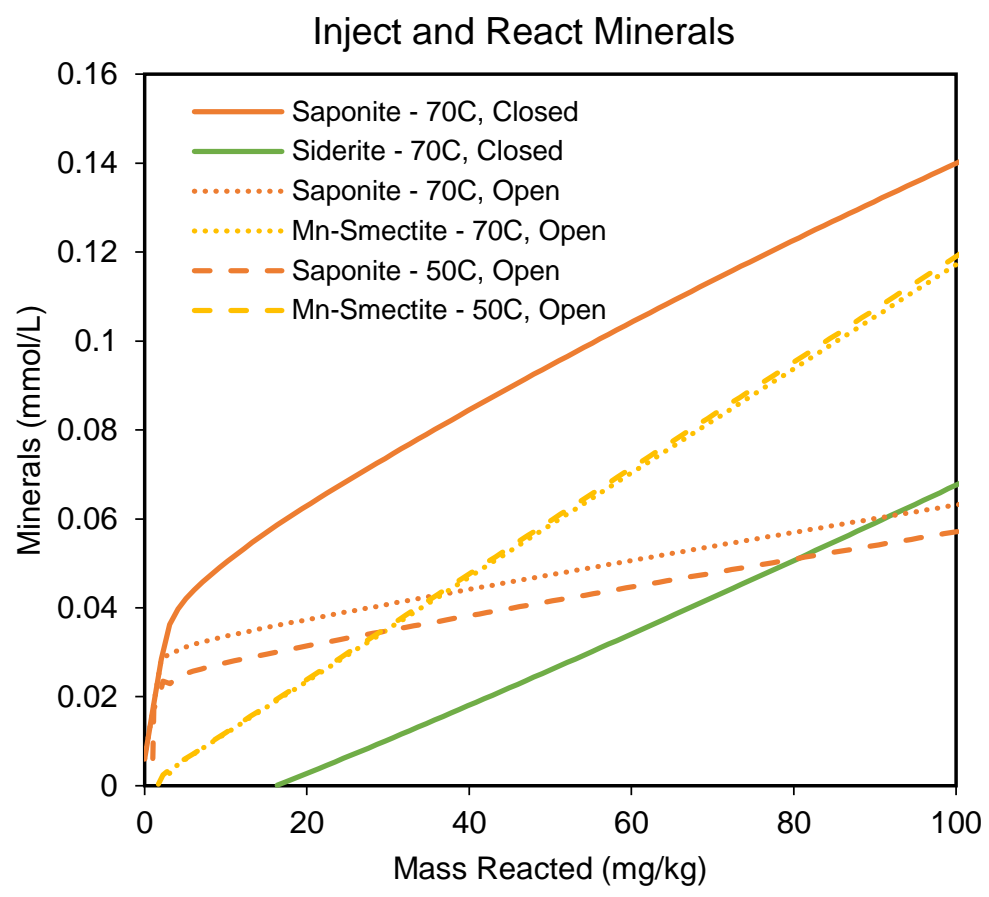

Figure 4.8. Concentrations of precipitated minerals and resulting porosity, per kilogram of injected water in response to reaction of $40 \mathrm{mg} / \mathrm{L}$ of pyroxene and $60 \mathrm{mg} / . \mathrm{L}$ of plagioclase under both open and closed system conditions, and at 50 and $70^{\circ} \mathrm{C}$.

Simulations of injecting $70^{\circ} \mathrm{C}$ heated and atmospherically equilibrated water into the aquifer results in precipitation of smectite-Reykjanes (an Mn-bearing clay), saponite$\mathrm{Mg}$, and trace amounts of carbonate minerals and $\mathrm{Fe}(\mathrm{OH})_{3}(\mathrm{ppd})$. Injection of $50^{\circ} \mathrm{C}$ 
atmospherically equilibrated water results in comparable amounts of smectite-Reykjanes precipitation, but less Mg-saponite precipitation (Figure 4.8). Comparing the results of injection with open and closed systems, the closed system model precipitates significantly more saponite, as well as siderite. Atmospherically equilibrated waters are depleted with respect to carbonate and bicarbonate, so cations released by mineral dissolution or that had remained in solution after heating speciate into clays upon injection, rather than carbonate minerals.

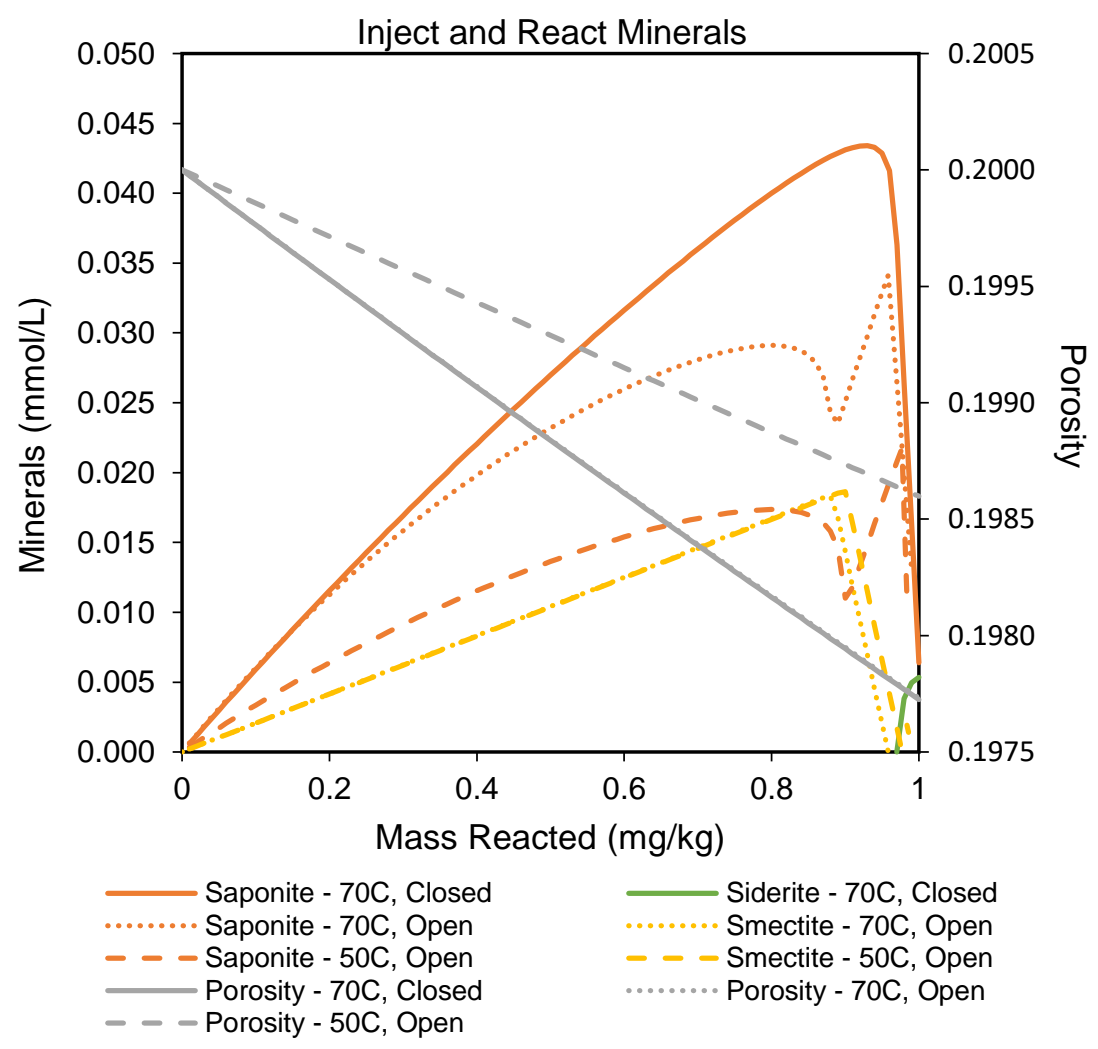

Figure 4.9. Concentrations of precipitated minerals and resulting porosity, as injected and native groundwaters mix. Injected waters have been heated to 50 and $70^{\circ} \mathrm{C}$, under both open and closed system conditions. 
Mixing injected and native groundwaters after open system heating and injection results in saponite-Mg, smectite-Reykjanes, and trace amounts of carbonate precipitation (Figure 4.9). Minerals precipitate to a lesser amount at $50^{\circ} \mathrm{C}$ compared to $70^{\circ} \mathrm{C}$ during this modeling step. Closed system models did not precipitate smectite clay during mixing, but did precipitate a small amount of siderite as the mixing fraction approached one. Injection and mixing of $70^{\circ} \mathrm{C}$ water resulted in the same amount of porosity loss, regardless of whether water had equilibrated with the atmosphere. Less porosity was lost in the $50^{\circ} \mathrm{C}$ open system scenario.

As the redox state of groundwaters in the CRBG is poorly constrained, and as this will particularly impact open system heating, open system equilibrium models were run using a pe of 4.5 (base case), -1 , and 10. Very little difference was detected between model runs using different pe values. However, impacts may become detectable as the volume of water moved through the system increases, and, upon injection, if iron oxidizing bacteria are present (Economides et al., 1996).

\subsubsection{Kinetic Transport Modeling}

\subsubsection{Varying Reactive Surfaces}

Kinetic transport modeling included kinetically controlled plagioclase, pyroxene, saponite clay, and amorphous silica, and equilibrium-controlled carbonate minerals and assumed $100 \%$ of the solid volume was available to react for the initial "base case" model. If hot water is simulated to flow through this aquifer at $1 \mathrm{~m}^{3} / \mathrm{m}^{2} /$ day (for simplicity) for 180 days (the maximum potential storage period), during that time 
saponite and siderite precipitate at the injection well site. As the amount of siderite and saponite precipitation decreases away from the well, calcite begins to precipitate instead (beginning about $4 \mathrm{~m}$ away, Figure 4.10). Trace amounts of witherite and rhodochrosite also precipitate, and a trace amount of amorphous silica precipitates where injected water is cooled by mixing with native groundwater. Overall, porosity increases near the well in response to injection of heated water, as primary minerals dissolve, and are more slowly re-precipitated as secondary minerals (Figure 4.10).
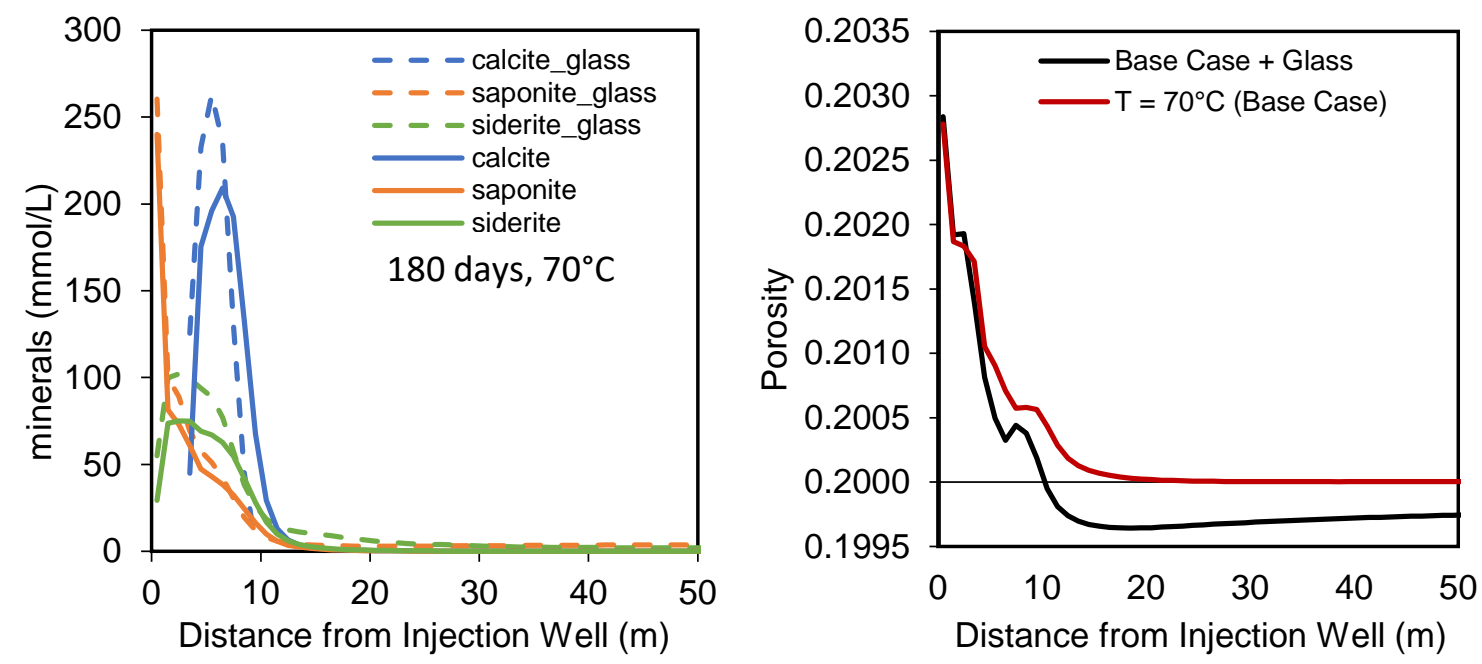

Figure 4.10. The concentration of minerals precipitated from $1 \mathrm{~kg}$ of water moving between 0 and $100 \mathrm{~m}$ from the injection well for the base case (solid lines) and when glass is included in the model (dashed lines) after 180 days and a flow rate of 1 $\mathrm{m}^{3} / \mathrm{m}^{2} /$ day (left). Aquifer porosity after 180 days of injection of $70^{\circ} \mathrm{C}$ water, as a result of excluding vs including basaltic glass (right).

Including kinetically controlled basaltic glass in the transport model leads to oversaturation of plagioclase, pyroxene, and saponite-clays. Saponite and basalt saturation indices appear strongly correlated. They approach equilibrium together, while as saponite becomes oversaturated, glass becomes undersaturated in response. As water is 
initially much more undersaturated with respect to basaltic glass than saponite, glass (and plagioclase and pyroxene) dissolution provides the necessary components for saponite and other secondary minerals to precipitate and the water to reach equilibrium. Similar amounts of clay precipitate when glass is included in the model, while the amount of calcite and siderite precipitated increases. This results in a greater amount of secondary mineral precipitation, and an overall loss in porosity (Figure 4.10).

Varying the amount and composition of reactive mineral mass can have significant impacts on results. Using the Avg $C R B$ water composition, and assuming the full volume of aquifer matrix is available to react (as in the base case), there is a net increase in aquifer porosity near the injection site and essentially no change further away. Inclusion of a small amount of basaltic glass yields very similar results near the injection site, but a slight reduction in aquifer porosity downgradient. However, such volumes of reactive material are likely only approached in the case of very fine-grained granular aquifers and are unlikely to reflect the fractured, brecciated and vesiculated nature of the basaltic flow zones. A reactive volume of only $10 \%$ of the matrix (4.5\% plagioclase and $3.5 \%$ pyroxene) yields a net decrease in porosity $(<5 \%$, from 0.200 to 0.191$)$ near the injection site, and a slight increase in porosity immediately downgradient. A reactive volume of only $1 \%$ of the matrix ( $0.45 \%$ plagioclase and $0.35 \%$ pyroxene) yields a similar decline in porosity near the injection site and little change downgradient (Figure 4.11). Because any carbonates are assumed to have been removed at the surface during heating, the porosity differences are largely due to the volume of primary silicates dissolved in the injected fluid, and the volume of saponite precipitated. Although there is 
less saponite precipitated in the case of a $1 \%$ reactive matrix when compared to fully a reactive matrix, there is also less dissolution of primary silicates.

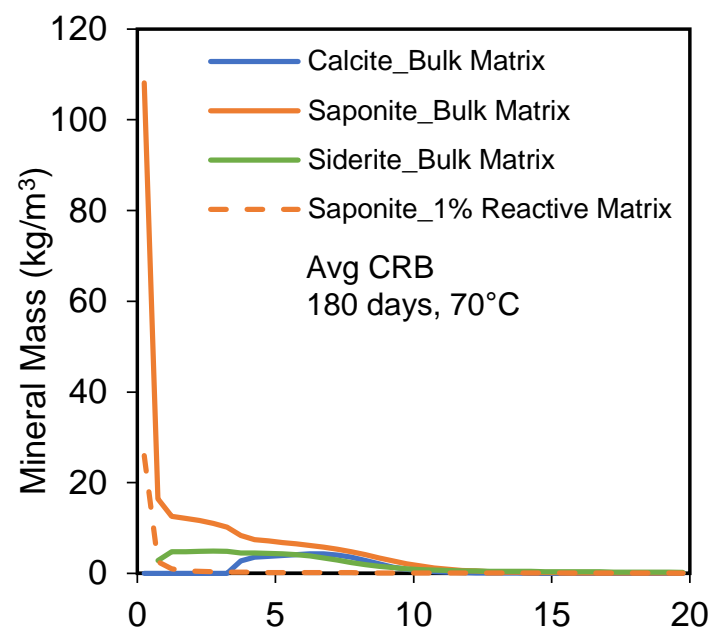

a. Distance from Injection Well (m)

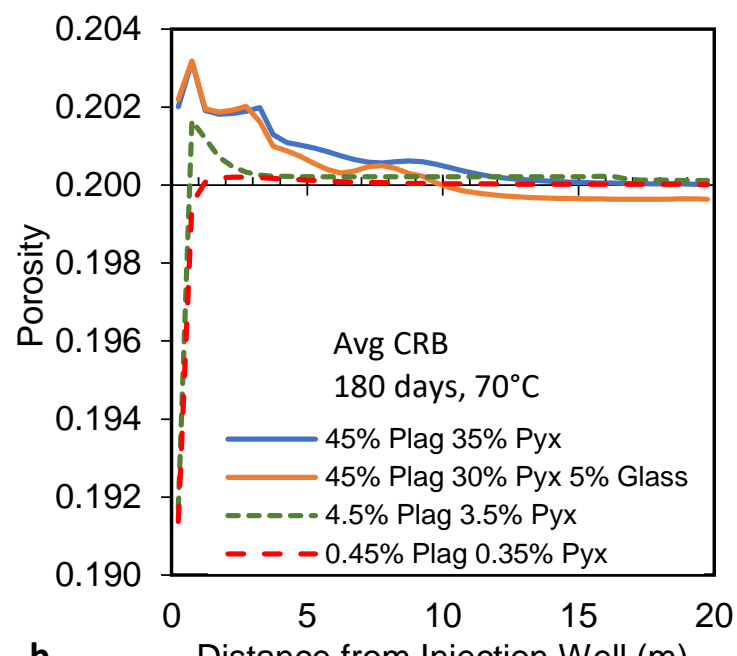

b. Distance from Injection Well $(\mathrm{m})$

Figure 4.11. a) The concentration of minerals precipitated from $1 \mathrm{~kg}$ of water moving between 0 and $100 \mathrm{~m}$ from the injection well for the base case (solid lines) and with reactive surface area reduced to $1 \%$ matrix. b) Aquifer porosity after 180 days of injection of $70^{\circ} \mathrm{C}$ water, with varying reactive solid volumes.

If calcite is considered the primary reactive surface within the aquifer, model results predict extensive secondary mineralization can occur. In such a scenario, (using the $C R B 3$ /“mature" groundwater composition average, and $3 \%$ calcite and $0.5 \%$ reactive solid volume each of plagioclase and pyroxene) calcite scale forms extensively, reducing porosity and continuing to do so over time (Figure 4.12). This could greatly reduce the operability of TES by reducing permeability, and well efficiency if scaling is occurring in close proximity to the well. This suggests scale may cause problems both in the aquifer and during surface heating and circulation. 

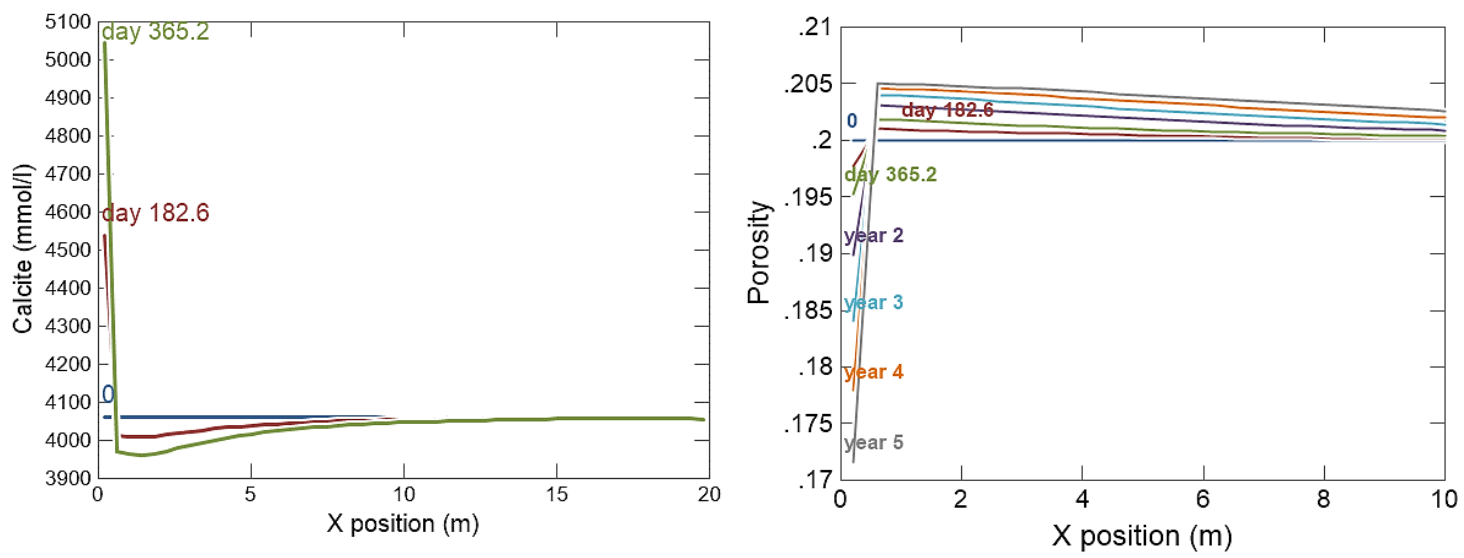

Figure 4.12. Calcite precipitated after 0,180 , and 365 days of injection of $70^{\circ} \mathrm{C}$ heated $C R B 3$ water (left) and the resulting changes in porosity each year for the first five years (right). Reactive solid volumes are $3 \%$ calcite, and $0.5 \%$ each plagioclase and pyroxene.

\subsubsection{Varying temperature}

Heating the $A v g C R B$ water to $50^{\circ} \mathrm{C}$, rather than $70^{\circ} \mathrm{C}$, and injecting it into the aquifer (assuming reactive volumes of $45 \%$ plagioclase and $35 \%$ pyroxene) both reduces and delays the amount of secondary mineral precipitation. As at $70^{\circ} \mathrm{C}$, siderite and clay minerals are the first to form. However, at $50^{\circ} \mathrm{C}$ calcite precipitation does not begin until $13 \mathrm{~m}$ from the injection well, and then exceeds the amount of siderite and clay precipitation. As $\mathrm{pH}$ decreases in the first $10 \mathrm{~m}$, in response to initial water-rock reactions (including alteration of primary minerals to clay, Table 4.3), calcite precipitation is delayed until $\mathrm{pH}$ rises. The resulting total porosity increase is less than at $70^{\circ} \mathrm{C}$ but extends farther from the well (Figure 4.13). 

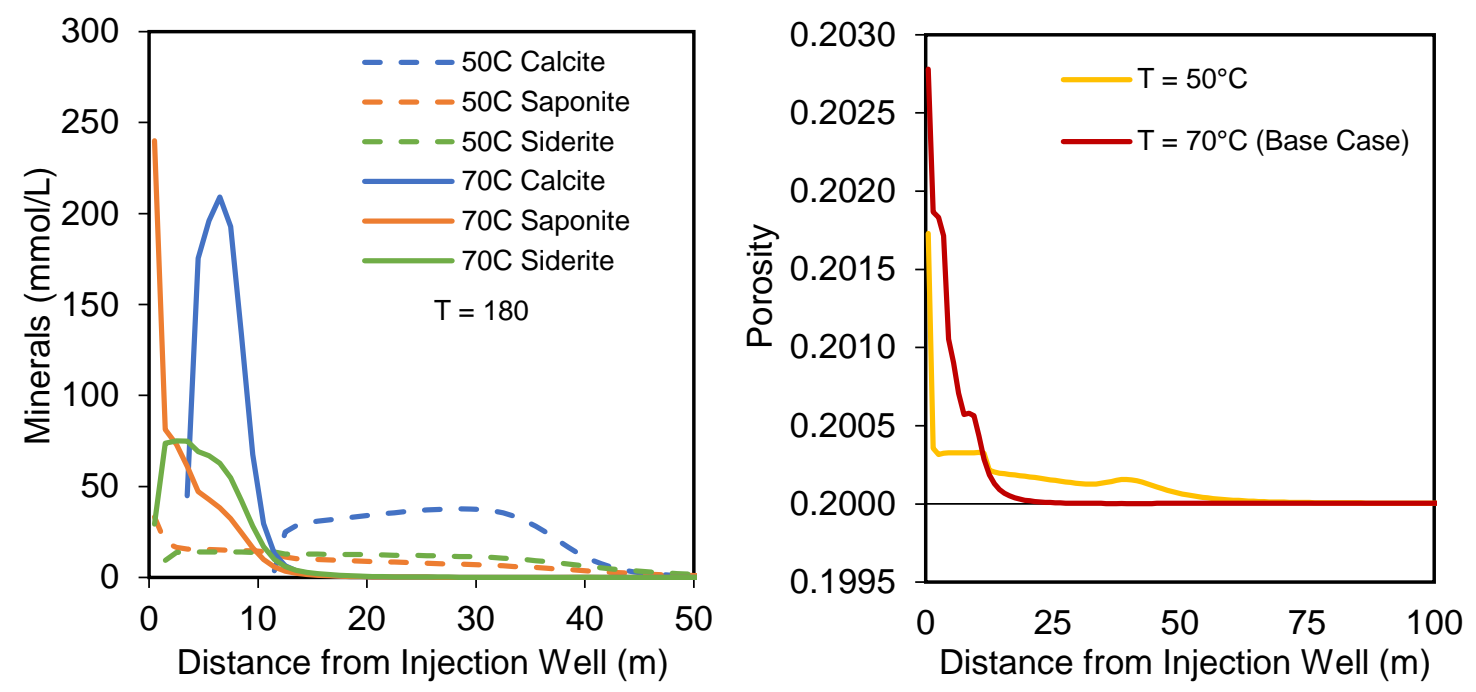

Figure 4.13. a) The concentration of minerals precipitated from $1 \mathrm{~kg}$ of water moving between 0 and $50 \mathrm{~m}$ from the injection well for the base case, when water is heated to $70^{\circ} \mathrm{C}$ prior to injection (solid lines) and when water is only heated to $50^{\circ} \mathrm{C}$ (dashed lines). Flow rate is $1 \mathrm{~m}$ /day shown after 180 days, and reactive solid volumes are $45 \%$ plagioclase and $35 \%$ pyroxene. b) Aquifer porosity after 180 days of injection of $70^{\circ} \mathrm{C}$ and $50^{\circ} \mathrm{C}$ water (initial porosity was 0.2 ).

\subsubsection{Open system conditions}

Simulating heating water to $70^{\circ} \mathrm{C}$ under open system conditions, then injecting it into the aquifer, yields greater amounts of saponite and siderite precipitation near the injection well than is estimated for water heated in a closed system. Models considered here assume reactive solid volumes of $45 \%$ plagioclase and $35 \%$ pyroxene. Atmospherically equilibrated and heated water precipitates far less calcite upon injection than waters heated under closed system conditions, because more calcite precipitates at the surface under open system conditions. Most mineral precipitation occurs within the first $10 \mathrm{~m}$ of the injection well when using open system heating, rather than being distributed across the first $17 \mathrm{~m}$ when using closed system heating (Figure 4.14). This difference in distance results in a greater initial increase in porosity compared to closed 
system heating, though porosity impacts are similar to previous model runs outside the first meter (Figure 4.14). Fe-hydroxide minerals precipitated in equilibrium models of the open system, but not in transport models of the same system (though they were included as an equilibrium controlled mineral phase in the transport model).
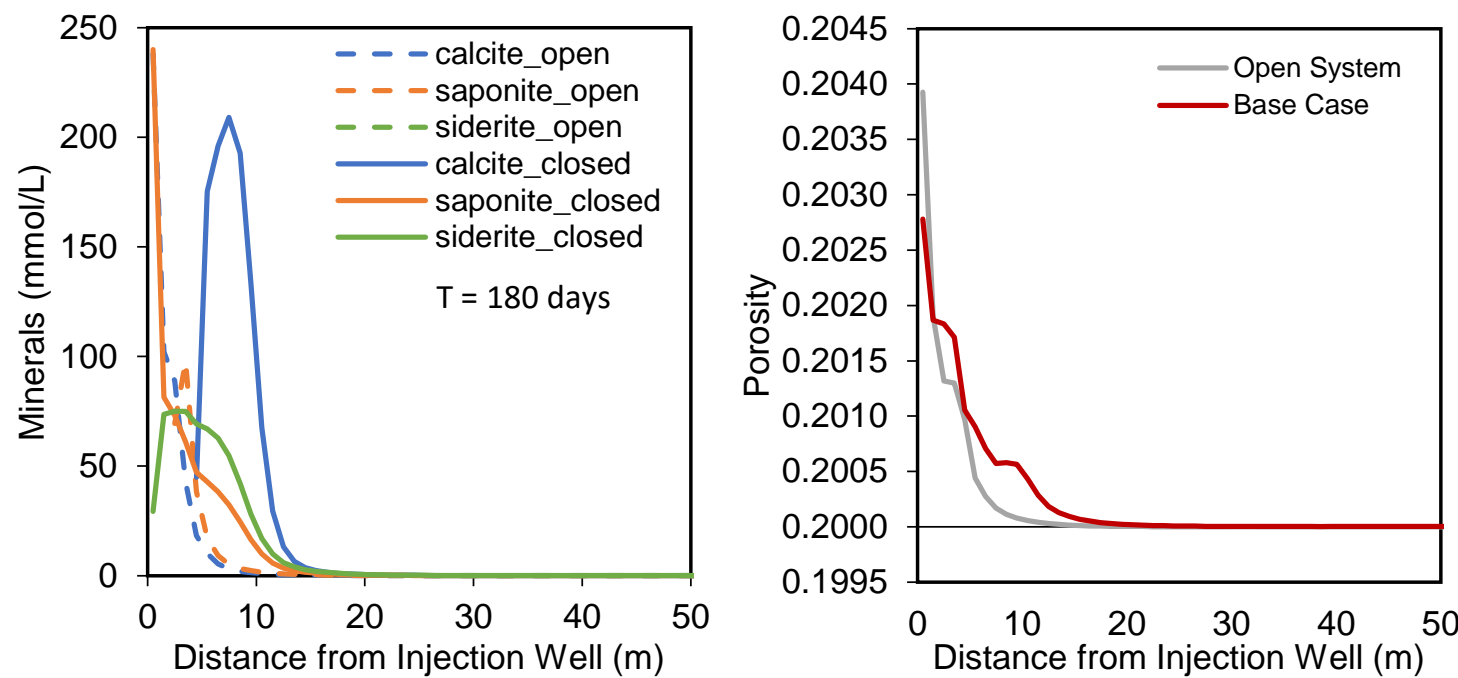

Figure 4.14. a) The concentration of minerals precipitated from $1 \mathrm{~kg}$ of $70^{\circ} \mathrm{C}$ water moving between 0 and $50 \mathrm{~m}$ from the injection well. Closed system heating is shown by solid lines and open system heating by dashed lines. b) Aquifer porosity after 180 days of injection of $70^{\circ} \mathrm{C}$ water heated under closed and open system conditions. Reactive solid volumes are $45 \%$ plagioclase and $35 \%$ pyroxene for all cases.

\subsubsection{Varying flow rate}

Increasing the flow rate (the number of pore volumes per unit time) produces a greater mass of secondary minerals and enhances dissolution of primary silicates by maintaining significant undersaturation. Increasing the flow rate in a $1 \mathrm{D}$ radial domain transport model with $10 \%$ solid volume reactive surfaces yields increasing and dispersed masses of precipitated minerals (Figure 4.15). Saponite precipitates significantly more 
than amorphous silica and carbonates included in the models and is primarily responsible for observed losses in porosity. As flow rates increase, the greater degree of secondary mineral precipitation results in greater losses of porosity near the injection site.
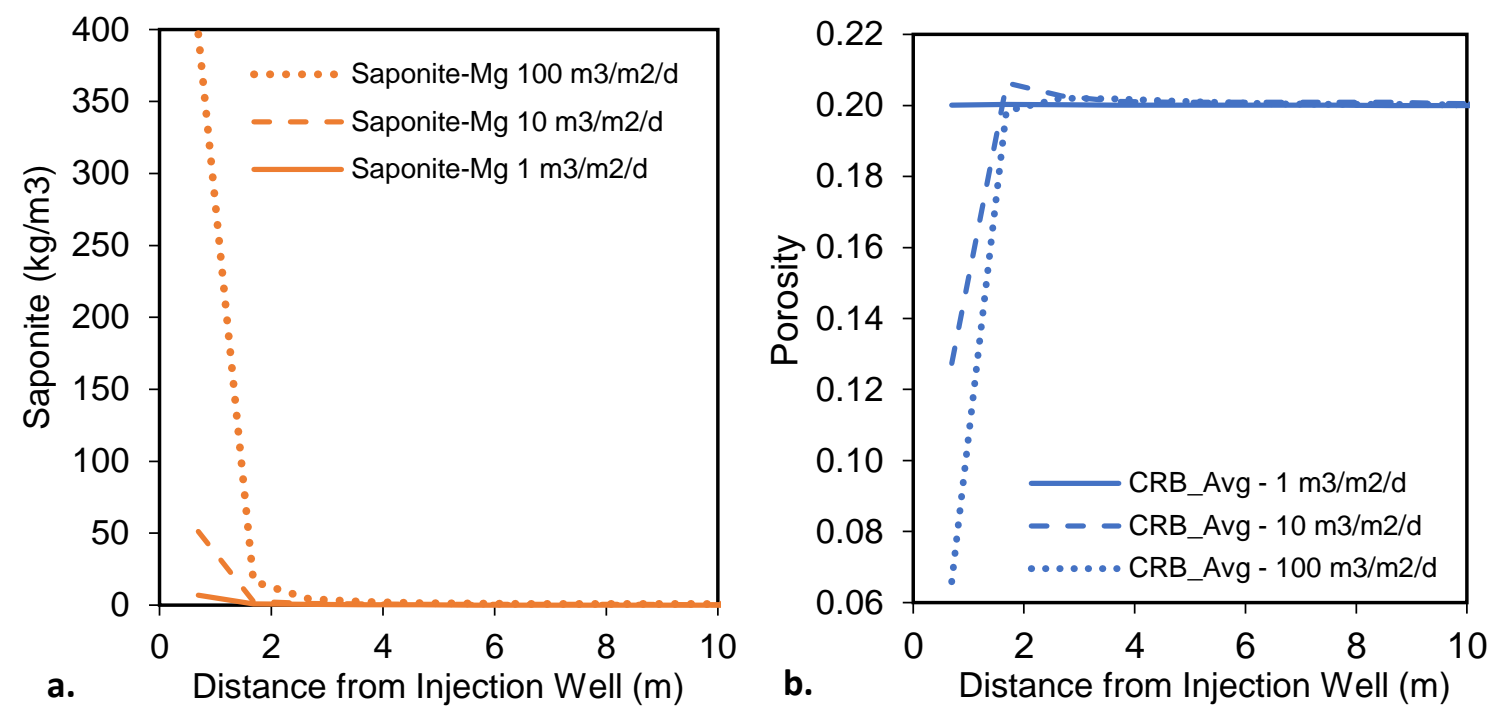

Figure 4.15. a) Saponite distribution after 180 days injecting $70^{\circ} \mathrm{C} A v g C R B$ water into an aquifer with initial porosity of 0.2 at varying injection rates, and b) resulting changes in porosity near the injection site for the same scenarios. Reactive solid volumes are $4.5 \%$ plagioclase and $3.5 \%$ pyroxene for all cases. Models use a radial domain.

Modeling the injection and storage periods with a 2D model of the $\mathrm{X}$ and $\mathrm{Y}$ aquifer dimensions revealed that after 180 days, close to $1 \mathrm{~mol} / \mathrm{L}$ of calcite and 70 $\mathrm{mmol} / \mathrm{L}$ of siderite precipitated near the injection well, in response to a pumping rate of 13.9 L/s (about $1200 \mathrm{~m}^{3} / \mathrm{m}^{2} /$ day) and assuming $100 \%$ of the solid volume is available to react. Slightly more carbonate minerals precipitated up-gradient from the well, where native groundwater mixes with and is heated by the injected water. Farther from the well, where injected water begins to cool, amorphous silica begins to precipitate (though to a lesser extent than carbonate minerals). Overall, the volume of minerals dissolved exceeds 
the volume precipitated, and porosity locally increases near the injection well. Including glass in this results in a similar porosity increase near the well, followed by a ring of decreased porosity.
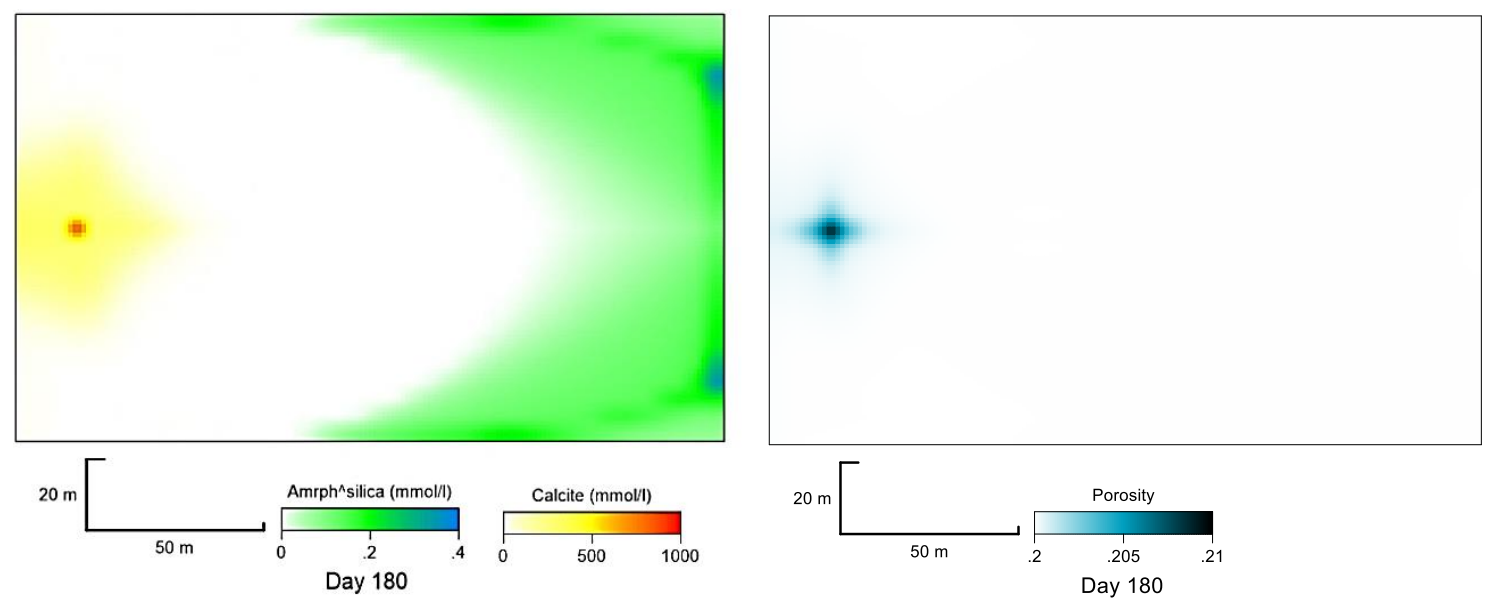

Figure 4.16. Map views of the 2D kinetic transport model, showing calcite and amorphous silica distribution (left) and resulting porosity (right) after pumping hot water through the aquifer for 180 days, assuming reactive solid volumes of $45 \%$ plagioclase and $35 \%$ pyroxene.

Two-dimensional modeling of the injection of $70^{\circ} \mathrm{C} \mathrm{CRB3}$ water and a $10 \%$ reactive solid volume reveals that after 180 days, there is some porosity loss in the immediate vicinity of the injection well (largely due to saponite precipitation) and a slight increase in porosity immediately away from the well (Figure 4.17). Precipitation of calcite and siderite (not shown) occurs mostly just outside that zone of porosity increase. Farther from the well, at the injection (cooling/mixing) front, amorphous silica begins to precipitate (Figure 4.17). However, the amount per unit volume of silica precipitate is $\sim 1000 x$ less than for carbonates and the zone of silica precipitation will migrate with the injection front. 

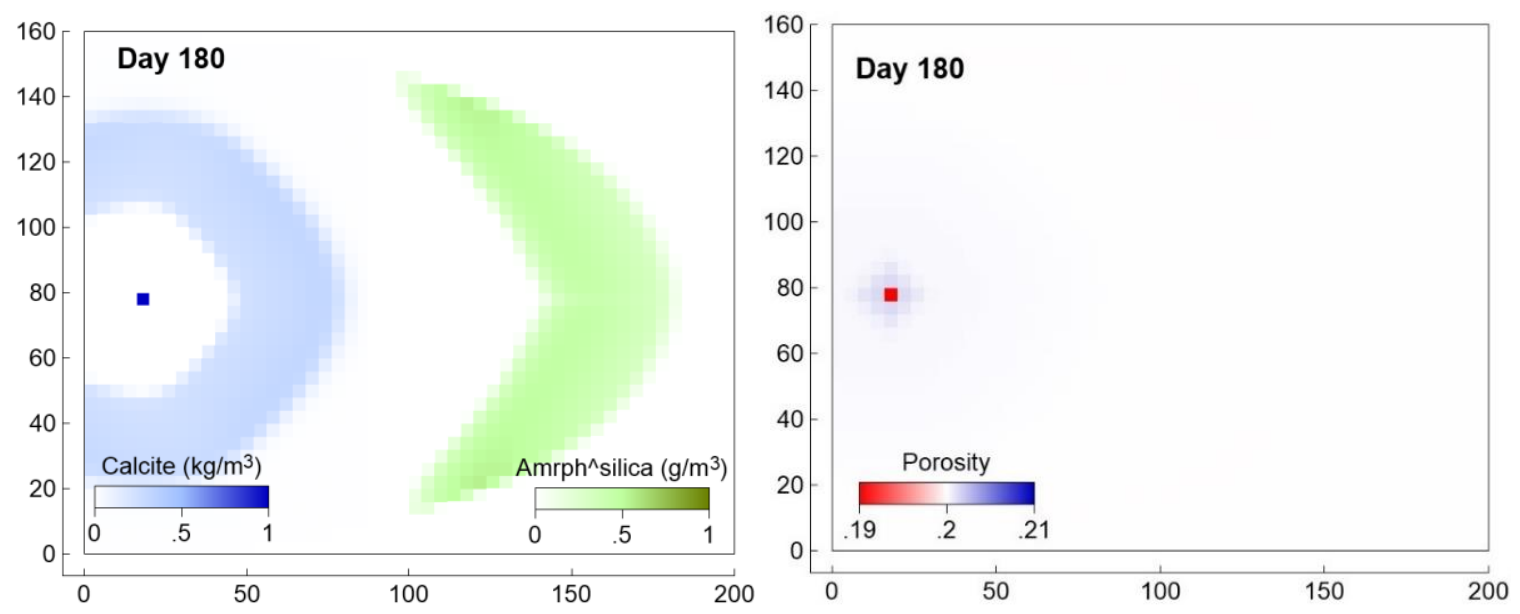

Figure 4.17. Distribution of calcite and amorphous silica deposits after 180 days of injection (siderite, not shown, has similar distribution as calcite) (left). Map view of 2D model results showing changes in aquifer porosity (initially set a 0.20 ) near a well injecting $70^{\circ} \mathrm{C} \mathrm{CRB3}$ waters (with carbonate precipitates removed during heating) at 14 $\mathrm{L} / \mathrm{s}$, and $4.5 \%$ plagioclase and $3.5 \%$ pyroxene initial reactive solid volumes (right). Model coordinates in meters; well located at $\mathrm{x}=20, \mathrm{y}=80 \mathrm{~m}$.

\subsubsection{Successive Cycles}

Modeling the recycling of water between two ("hot" and "cool") reservoirs indicate that both reservoirs may experience porosity loss (Figure 4.18) when assuming a $10 \%$ reactive volume of primary minerals. In the $70^{\circ} \mathrm{C}$ reservoir, saponite and calcite formation causes a porosity loss in the immediate vicinity of the injection well, followed by a slight porosity increase downgradient. However, the greatest changes to porosity in the $70^{\circ} \mathrm{C}$ reservoir occur during the initial cycles and impacts may be less severe and possibly reversed in subsequent cycles, as water temperatures are maintained within more narrow limits and water chemistries are held closer to saturation with respect to key minerals. The $40^{\circ} \mathrm{C}$ reservoir shows a slight porosity increase after the first cycle, as primary minerals dissolve in response to the elevated temperature. In later cycles, 
porosity decreases near the injection well due to precipitation of clays and silica minerals. Very little mineral precipitation is observed during surface heating and cooling.
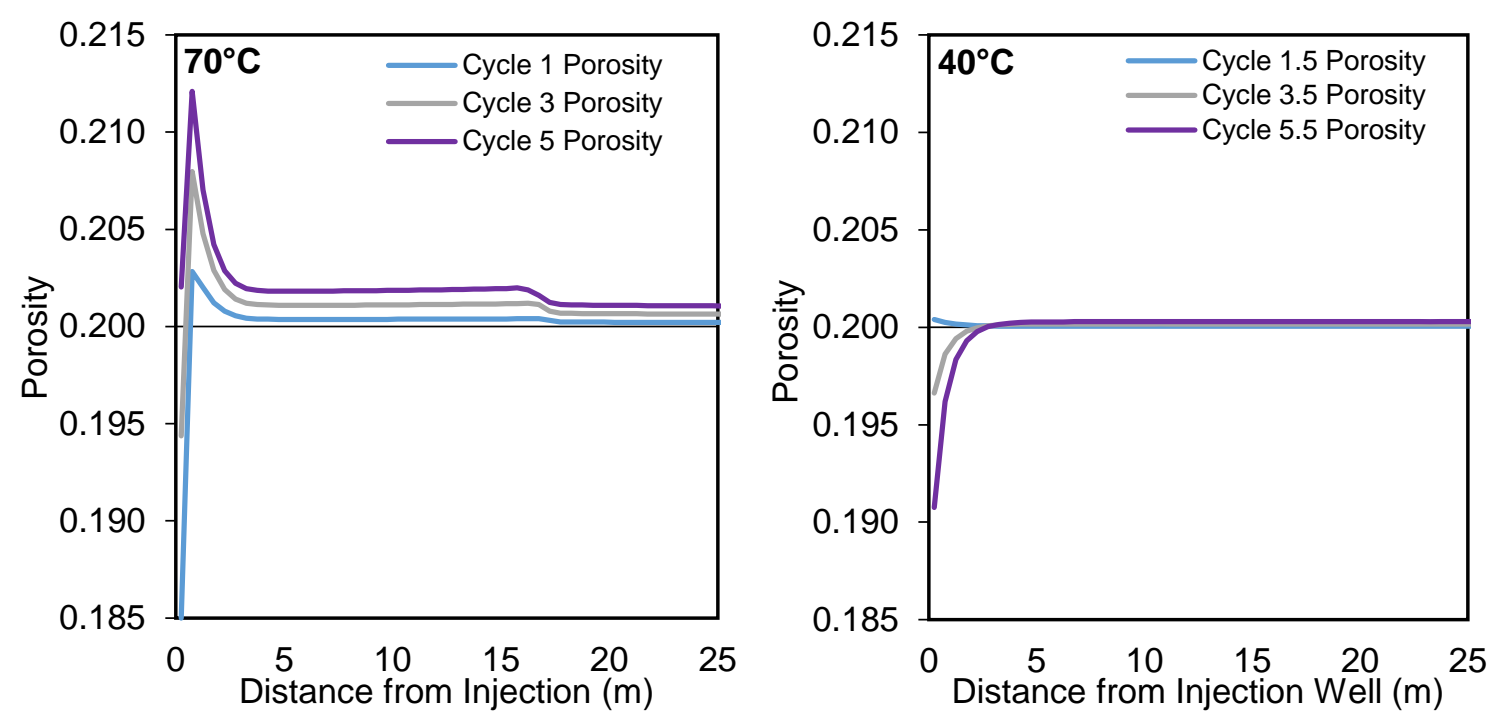

Figure 4.18. Changes in porosity after 5 successive cycles of pumping/recovery/pumping in the primary aquifer ( " $70^{\circ} \mathrm{C}$ ", right) and re-injection of cooled water into a separate reinjection zone (“40 ${ }^{\circ} \mathrm{C}$ ", left).

Tracking the water chemistry after each cycle reveals that as water is subject to successive heating injection, storage, and extraction cycles, very little change in composition occurs (Figure 4.19). Water does become very slightly depleted with respect to magnesium and calcium, and enriched with sodium, potassium, and chloride with repeated cycling. This is most likely a reflection of the mineral assemblage included in the model. In reality, $\mathrm{Na}$ and $\mathrm{K}$ can substitute into clay structures for $\mathrm{Ca}$ and $\mathrm{Mg}$ via cation exchange (Table 4.3) and would likely do so as $\mathrm{Ca}$ and $\mathrm{Mg}$ become scarce. The system may begin to precipitate $\mathrm{Na}$ and $\mathrm{K}$ bearing clays, rather than $\mathrm{Ca}$ and $\mathrm{Mg}$ clays as water continues to circulate and becomes depleted with respect to divalent cations. 
Chloride may also build up over time, given the high solubility of salts. However, overall the water equilibrates rapidly under modeled conditions, and any changes in chemistry are small.

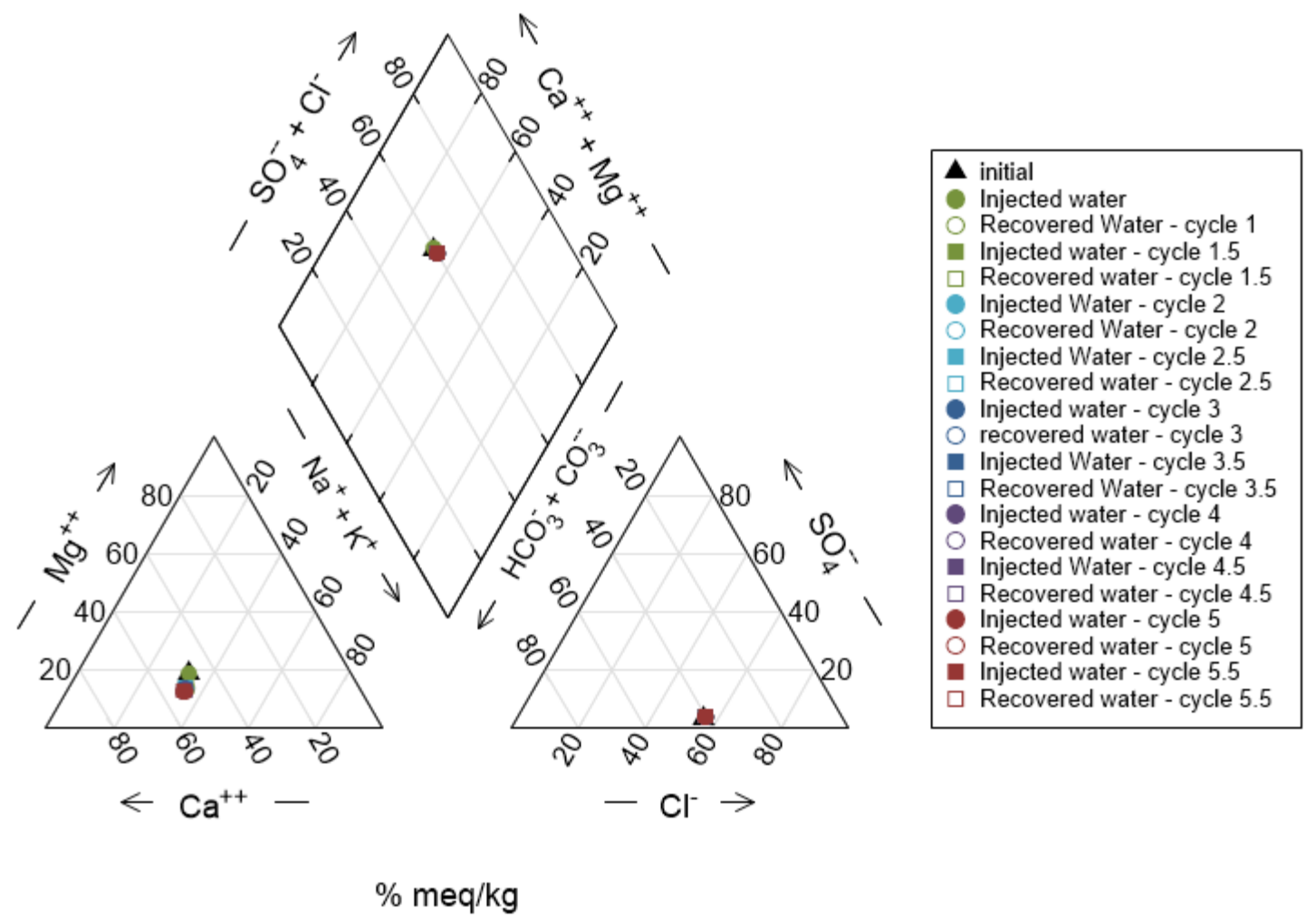

Figure 4.19. Piper diagram of injected and recovered water compositions for each cycle, excluding glass (left) and including glass (right).

\subsection{Discussion}

The total amount of mineral precipitation and dissolution likely to occur within the aquifer is heavily dependent on pumping rates and volumes, and the availability of reactive solids. As equilibrium modeling results are reported on a per liter basis, they can be multiplied by the number of liters moving through the system to determine the mass of minerals likely to precipitate within the aquifer based on the pumping rate. Transport 
models constrain the spatial distribution of this mass, estimating that most mineralization occurs within 1-10 $\mathrm{m}$ of the injection well, though this area extends with greater injection volumes. Most models report clays and siderite are the first minerals to form, with calcite formation occurring farther out from the injection well. As a result, clays may be of greatest concern near the injection site and hazard the greatest risk for scale formation near the well. Small amounts of amorphous silica precipitate where injected and native groundwater mix, due to the cooling of injected waters and decreased silica solubility. These results suggest two zones of mineralization; one immediately surrounding the injection well, and another farther out where injected and native waters mix (Figure 4.16). As water is repeatedly injected and extracted, moving back and forth through the aquifer, these zones may broaden and become more diffuse. Additionally, when considering radial flow outwards from the injection well (which is best captured by the 2D transport models), mineral dissolution and precipitation will also become more diffuse with distance from the well.

While modeling suggests calcite, siderite, and Mg-saponite (or another clay phase) are the primary minerals of concern, equilibrium models suggest Feoxyhydroxides and Fe-bearing smectite clays may also be important if waters are oxidized through contact with the atmosphere at any point during the cycle. In the long term, clay minerals may alter to a zeolite phase such as clinoptilolite.

Modeling results suggest the amount of mineral precipitation and dissolution likely to occur in response to TES, and thus any impacts on porosity or permeability, depends on the aquifer mineralogy and extent of previous hydrothermal alteration. In 
models excluding basaltic glass, hot water injection appears to dissolve a greater volume of minerals than is re-precipitated, resulting in a net increase in porosity surrounding the injection well. However, when glass is included in kinetic transport models, a greater volume of minerals is precipitated than dissolved, causing a porosity loss. Without sampling, the glass content of the target zone cannot be definitively determined. Additionally, the amount of reactive surfaces will dictate the extent to which mineral dissolution or precipitation dominates the system. Models show that a greater reactive solid volume (e.g. $100 \%$ of the matrix) results in more silicate and primary mineral dissolution, leading to porosity increases near the injection well. However, smaller reactive solid volumes (e.g. $10 \%$ or $1 \%$ ) result in more mineral precipitation than dissolution, leading to porosity losses near the well.

Heating simulations revealed several mineral phases that reach saturation but were not included in models of the TES system. These minerals (clinochlore-14, and clinozoisite) were excluded because of a lack of literature identifying them within the CRBG- though they have been identified in Icelandic basalts (Aradóttir et al., 2012). Without sampling the local CRBG, we cannot determine if this is because these secondary mineral phases are not present, or if there is simply a lack of research on the subject.

Modeling successive TES cycles predicts very little mineral precipitation at the surface after the first cycle. Though waters are still heated and cooled at the surface, temperature gradients are significantly smaller after the first cycle and waters are closer to saturation with respect to the secondary mineral assemblage, reducing the potential for 
scaling at the surface. Surface scaling may ultimately depend on whether the temperatures to which water is heated and cooled are enough to overcome activation energy barriers for carbonate precipitation (upon heating) or silica precipitation (upon cooling) and whether flow rates are slow enough for precipitates to form in pipes rather than be transported to the aquifer as colloidal material. Models suggest most precipitation and dissolution reactions within the aquifer occur during the first injection and storage period, and that with each successive cycle, slightly more mineral mass is precipitated and dissolved. This gradually magnifies the changes in porosity observed after the first cycle, whether that be a porosity increase or a decrease. However, this is an estimate of the most extreme scenario. After the first cycle, as the reservoirs thermally equilibrate, mineral precipitates may build up where they initially deposit, and/or may cover the reactive surfaces of the dissolving primary minerals, limiting both dissolution (in the case of the $70^{\circ} \mathrm{C}$ reservoir) and additional precipitation driven by primary mineral dissolution (in the case of the $40^{\circ} \mathrm{C}$ reservoir). Clay minerals may still react (or re-react) to form alternate clay phases or zeolite minerals, and the resulting changes in mineral volumes may impact the long term porosity.

By using equilibrium modeling to simulate surface heating, cooling, and precipitation, the resulting water used to simulate injection is the most ionically depleted water possible. Injecting a less depleted water may result in less dissolution and more (or more immediate) secondary mineralization, particularly if colloidal material is transported into the aquifer. There is also a large amount of uncertainty related to the extent of previous hydrothermal alteration, water composition, reactive surface area, and 
the redox state of waters in the target zone. Without water samples from the vicinity of Portland's South Waterfront, we also cannot accurately predict the saturation state of waters in the lower CRBG, or the extent to which they may have mixed with saline waters from underlying marine strata. 


\section{CHAPTER 5: CONCLUSIONS}

This study provides insights into low-temperature hydrothermal alteration in basalts below $100^{\circ} \mathrm{C}$, a temperature range which is poorly studied. It also contributes to local understanding of the hydrogeochemistry of the Columbia River Basalt aquifer system in western Oregon. As a feasibility study, this research relied on previously published groundwater quality data for the Portland Basin and surrounding regions. This resulted in the compilation of a water quality database focused on groundwater quality of the CRBG in western Oregon. Analysis of this database revealed that water composition varies widely within the CRBG aquifer system. The identified water types range from low-TDS recharge waters, to high TDS waters enriched with respect to $\mathrm{Na}$ and $\mathrm{Cl}$. CRBG waters approach saturation with respect to calcite with increasing depth. Elevated $\mathrm{Na}$ and $\mathrm{Cl}$ concentrations in some CRBG groundwaters are likely the result of upwelling saline or brackish water from underlying units, facilitated by faulting throughout the Portland Basin.

Laboratory scale batch reaction experiments were conducted to simulate TES in the CRBG. Post-reaction rock samples were examined using a scanning electron microscope and water samples were analyzed using the IC and ICP-MS. Water analysis revealed that in addition to calcite solubility, water chemistry in the CRBG is controlled by a complex series of aluminosilicate dissolution and precipitation reactions. SEM analysis did not reveal any obvious experimentally induced alteration but did provide insight into possible alteration products and the extent of previous weathering in interflow zones. Reactions most likely consist of dissolving primary minerals or clays 
which are unstable at elevated temperatures, followed by precipitation of carbonates and smectite clays.

A series of geochemical reaction models were constructed to explore the occurrence and extent of these reactions through different stages of TES operation. Models included the initial groundwater extraction and heating, injection of heated waters into- and reactions with- the CRBG aquifer matrix, mixing between hot injected and ambient temperature native waters, and multiple cycles of injection and extraction. Models were utilized to explore the impacts of different groundwater compositions, atmospheric conditions, reactive phases and reactive phase surface areas, a range of injected water temperatures, and varying pumping rates. Models ultimately determined that minimizing heating and flow, and maintaining a closed system, will minimize waterrock interactions. However, the extent and impact of these reactions varies greatly depending on the initial water composition and the available reactive surface area of the minerals present.

The major ion chemistries of native CRBG groundwaters evolve by dissolution of primary silicates until waters reach saturation with respect to calcite, at which point $\mathrm{Ca}$ is removed via precipitation and $\mathrm{Na}+\mathrm{K}$ vs. total cation ratios increase. Locally, waters may be impacted by mixing with upwelled saline water from underlying units, presumably along cross-cutting structures or open boreholes. Therefore, the TES site should be carefully chosen to avoid structures that would enable upwelling of cooler waters from deeper units. 
Because the solubilities of some common phases (including calcite, siderite, and saponite-Mg) decrease with increasing temperature, elevated temperatures can result in extensive mineral precipitation. Reaction rates for carbonate precipitation are typically orders of magnitude faster than for clays, so precipitation of carbonate minerals (chiefly, calcite and siderite) has the potential to form extensive scale deposits within pipes and heat exchange systems upon heating, particularly if native groundwaters are evolved and already saturated with respect to calcite. Ideally, the target zone would also be chosen to avoid water that is saturated with respect to calcite, though less evolved waters may still reach saturation with calcite, siderite, and or saponite clay above $\sim 50^{\circ} \mathrm{C}$. Precipitation of these phases in the aquifer, or transfer of suspended precipitates to the aquifer, could result in significant declines in porosity and permeability, likely at or near the injection site.

The impact of TES operation on aquifer porosity and permeability will depend on the composition of groundwaters and on the nature and extent of available reactive surfaces in contact with injected waters. Most kinetic transport simulation scenarios indicate some loss of porosity near the injection point when injected waters are heated to $70^{\circ} \mathrm{C}$. Such loss is minimized, though not necessarily eliminated, when waters are only heated to $\sim 50^{\circ} \mathrm{C}$. Under the most optimistic conditions (less evolved waters, ample reactive silicate surfaces, lower temperatures, and or low to modest flow rates), a slight increase in porosity near the injection point may occur. Under the worst-case scenarios (mature waters that are saturated or oversaturated with respect to calcite, an absence of reactive silicates as in calcite-lined fracture porosity, higher temperatures, and higher 
flow rates), significant porosity loss (>10\%) may occur within one seasonal cycle. Modeling the recycling of waters between two reservoirs maintained at $70^{\circ} \mathrm{C}$ and $40^{\circ} \mathrm{C}$ suggests porosity loss in both reservoirs, but that some porosity may be recovered in the $70^{\circ} \mathrm{C}$ reservoir over multiple cycles.

Silica precipitation is likely to occur at the cooling / mixing front in the TES reservoir. However, the volumes precipitated are unlikely to cause significant porosity loss and over time the cooling front and associated mineral buildup may migrate with expansion of the hot water mass. Similarly, extracted hot waters that have accumulated additional silica through dissolution of primary silicates may precipitate silica scale upon cooling in the heat exchange system or reinjection zone.

Model results suggest the TES system would benefit from installation of a water softener prior to heating, which will reduce carbonate scale formation at the surface as water moves through pipes and the heat exchange system. This may also reduce the extent of mineral dissolution and precipitation observed within the aquifer. Carbonate precipitation can also be minimized during surface heating by maintaining closed system conditions. Minimizing the amount of heating will minimize water-rock interactions (including silica dissolution and precipitation) that stem from the resulting disequilibrium. Taking these steps may be beneficial not only for TES, but for other basalt storage applications as well.

Constraining the extent to which mineral precipitation and dissolution reactions occur is also complicated by uncertainties with respect to the mineral phases exposed in pore spaces, their reactive surface areas, and kinetic rates. Expanding what is known 
about the target zone in terms of its water chemistry, the nature of porosity, and the extent of previous secondary mineralization, will allow for more accurate modeling of the geochemical impacts from TES cycles. Therefore, the next phase of the Portland Basin TES feasibility study would ideally include exploratory drilling and water quality sampling. 


\section{REFERENCES}

Ahern, E. and Perkins, R. (2016). Hydrogeologic Characterization of the Warren Bench Area, Columbia County, Oregon. Report to McNulty Water People's Utility District.

Ames, L.L., and McGarrah, J.E. (1980). Hanford basalt flow mineralogy (No. PNL2847). Battelle Pacific Northwest Labs, Richland, WA (USA).

Aradóttir, E.S.P., Sonnenthal, E.L., and Jónsson, H. (2012). Development and evaluation of a thermodynamic dataset for phases of interest in $\mathrm{CO}_{2}$ mineral sequestration in basaltic rocks: Chemical Geology, v. 304-305, p. 26-38.

Baker, L., Strawn, D., McDaniel, P., Fairley, J., \& Bishop, J. (2012). Hydrologic and geochemical controls on nontronite formation in terrestrial Columbia River Basalts and implications for clay formation on Mars. LPI Contributions, v. 1680.

Beeson, M.H., (1985), Regional correlations within the Frenchman Springs Member of the Columbia River Basalt Group: New insights into the middle Miocene tectonics of northwestern Oregon: Oregon Geology., v. 47.

Benson, L. V., \& Teague, L. S. (1982). Diagenesis of basalts from the Pasco Basin, Washington; I, Distribution and composition of secondary mineral phases: Journal of Sedimentary Research, v. 52(2), 595-613.

Bethke, C. M. (2008). Geochemical and Biogeochemical Reaction Modeling, Cambridge, Cambridge University Press, 543 p.

Blakely, R. J., Wells, R. E., Tolan, T. L., Beeson, M. H., Trehu, A. M., \& Liberty, L. M. (2000). New aeromagnetic data reveal large strike-slip (?) faults in the northern Willamette Valley, Oregon. Geological Society of America Bulletin, v. 112(8), p. 1225-1233.

Blakely, R. J., Wells, R. E., Yelin, T. S., Madin, I. P., \& Beeson, M. H. (1995). Tectonic setting of the Portland-Vancouver area, Oregon and Washington: Constraints from low-altitude aeromagnetic data: Geological Society of America Bulletin, v. 107(9), p. 1051-1062.

Burns, E.R., Williams, C.F., Ingebritsen, S.E., Voss, C.I., Spane, F.A., and DeAngelo, J. (2015). Understanding heat and groundwater flow through continental flood basalt provinces: insights gained from alternative models of permeability/depth relationships for the Columbia Plateau, USA: Geofluids, v. 15, p. 120-138. 
Burns, E.R., Williams, C.F., Tolan, T., and Kaven, J.O. (2016). Are the Columbia River Basalts, Columbia Plateau, Idaho, Oregon, and Washington, USA, a Viable Geothermal Target? A Preliminary Analysis: 41st Workshop on Geothermal Reservoir Engineering, p. 1-11.

Burt, W., and Augustine, C. (2010). City of Tualatin - Year 2009 ASR Pilot Test Results. City of Tualatin.

Burt, W., Conlon, T., Tolan, T.L., Wells, R.E., and Melady, J. (2010). Hydrogeology of the Columbia River Basalt Group in the northern Willamette Valley, Oregon, The Geological Society of America Field Guide, v. 15, p. 697-736.

Cabeza, L.F., Martorell, I., Miró, L., Fernández, A.I., and Barreneche, C. (2015). Introduction to thermal energy storage (TES) systems: Cambridge, [England], Woodhead Publishing, p. 1-28.

City of Portland, Bureau of Planning and Sustainability. (2017). Clean Energy. Retrieved from https://www.portlandoregon.gov/bps/41462

Cummings, M.L., Trone, P.M., and Pollock, J.M. (1989). Geochemistry of colloidal silica precipitates in altered Grande Ronde Basalt, northeastern Oregon, U.S.A.: Chemical Geology, v. 75, p. 61-79.

Deutsch, W.J., Jenne, E.A., and Krupka, K.M. (1982). Solubility equilibria in basalt aquifers: the Columbia PLateau, eastern Washington, U.S.A.: Chemical Geology, v. 36 , p. 15-34.

Eaton, L.G., and Cook, R.C. (2012). City of Cornelius Aquifer Storage and Recovery Limited License Application and Pilot Test Work Plan. City of Cornelius.

Economides, M. et al. (1996). 6. Production Engineering, in Standard Handbook of Petroleum and Natural Gas Engineering, Elsevier, p. 363-983.

Evarts, R.C., O'Connor, J.E., Wells, R.E., and Madin, I.P. (2009). The Portland basin: A (big) river runs through it, GSA Today, v. 19, p. 4-10.

Gannett, M. W., \& Caldwell, R. R. (1998). Geologic framework of the Willamette Lowland aquifer system, Oregon and Washington (No. 1424). US Geological Survey. 
Gislason, S.R., and Oelkers, E.H. (2003). Mechanism, rates, and consequences of basaltic glass dissolution: II. An experimental study of the dissolution rates of basaltic glass as a function of $\mathrm{pH}$ and temperature: Geochimica et Cosmochimica Acta, v. 67, p. 3817-3832.

Hearn, P.P., Steinkampf, W.C., Bortleson, G.C., and Drost, B.W. (1985). Geochemical Controls on Dissolved Sodium in Basalt Aquifers of the Columbia Plateau, Washington. US Department of the Interior, Geological Survey.

Hearn, P.P., Steinkampf, W.C., White, L.D., and Evans, J.R. (1990). Geochemistry of Rock-Water Reactions in Basalt Aquifers of the Columbia River Plateau: Proceedings of a U.S. Geological Survey workshop on environmental geochemistry, p. 63-68.

Hellevang, H., Pham, V.T.H., and Aagaard, P. (2013). Kinetic modelling of $\mathrm{CO}_{2}$-waterrock interactions: International Journal of Greenhouse Gas Control, v. 15, p. 3-15.

Horst, A. (2019). Seismic Source Characterization of faults in the Portland and Tualatin Basins and a Paleoseismic study of the Gales Creek fault, OR (Master's Thesis). Portland State University, Portland, Oregon.

Jayne, R.S., and Pollyea, R.M. (2018). Permeability correlation structure of the Columbia River Plateau and implications for fluid system architecture in continental large igneous provinces, Geology, v. 46.

Johnson, J., Anderson, G., \& Parkhurst, D. (2000). Database "thermo. com. V8. R6. 230," Rev. 1-11. Lawrence Livermore Natl. Lab., Livermore, California.

Jones, C. (2016). Groundwater-Surface Water Interactions near Mosier, Oregon (Master's Thesis). Portland State University, Portland, Oregon.

Ketrenos, N.T. (1986). The stratigraphy of the Scappoose formation, the Astoria formation, and the Columbia River basalt group in northwestern Columbia County, Oregon (Master's Thesis). Portland State University, Portland, Oregon.

Liberty, L.M., Hemphill-Haley, M.A., and Madin, I.P. (2003). The Portland Hills Fault: Uncovering a hidden fault in Portland, Oregon using high-resolution geophysical methods, Tectonophysics, v. 368, p. 89-103.

Palandri, J.L., and Kharaka, Y.K. (2004). A Compilation of Rate Parameters of Water- 
Mineral Interaction Kinetics for Application to Geochemical Modeling, https://pubs.usgs.gov/of/2004/1068/pdf/OFR_2004_1068.pdf (accessed July 2019).

Palmer, C.D., and Cherry, J.A. (1984). Geochemical reactions associated with low temperature thermal energy storage in aquifers: Canada Geotechnical Journal, p. 475-488.

Palmer, C.D. (2015). Reservoir temperature estimator (RTEst) user's manual, in Improved geothermometry through multivariate reaction-path modeling and evaluation of geomicrobiological influences on geochemical temperature indicators: Idaho National Laboratory, INL/EXT-14-33959.

Parkhurst, D. L. (1995). User's guide to PHREEQC-A computer program for speciation, reaction-path, advective-transport, and inverse geochemical calculations: Water Resources Investigations Report, v. 95(4227), p. 1-143.

Perlinger, J.A., Almendinger, J.E., Urban, N.R., and Eisenreich, S.J. (1987). Groundwater geochemistry of Aquifer Thermal Energy Storage: Long-term test cycle: Water Resources Research, v. 23, p. 2215-2226.

Rattray, G.W., and Ginsbach, M.L. (2014). Geochemistry of Groundwater in the Beaver and Camas Creek Drainage Basins, Eastern Idaho Scientific Investigations Report.

Reidel, S.P., Camp, V.E., Tolan, T.L., and Martin, B.S. (2013). The Columbia River flood basalt province: stratigraphy, areal extent, volume, and physical volcanology: Geological Society of America Special Paper, v. 497.

Reidel, S.P., Tolan, T.L., Hooper, P.R., Beeson, M.H., Fecht, K.R., Bentley, R.D., and Anderson, J.L. (1989). The Grande Ronde Basalt, Columbia River Basalt Group; Stratigraphic descriptions and correlations in Washington, Oregon, and Idaho: Geological Society of America Special Paper, v. 497, p. 21-54.

Rimstidt, J.D., and Barnes, H.L. (1980). The kinetics of silica-water reactions: Geochimica et Cosmochimica Acta, v. 44, p. 1683-1699.

Sanjuan, B., \& Girard, J. P. (1996). Review of kinetic data on carbonate mineral precipitation. BRGM report, 39062.

Scanlon, D. (2019). Tracking the Spatial and Temporal Evolution of the Portland and Tualatin Basins, Northwest Oregon (Master's Thesis). Portland State University, 
Portland, Oregon.

Schulze-Makuch, D. (2005). Longitudinal Dispersivity Data and Implications for Scaling Behavior: Ground Water, v. 43, p. 443-456.

Stillings, L. L., Drever, J. I., Brantley, S. L., Sun, Y., \& Oxburgh, R. (1996). Rates of feldspar dissolution at pH 3-7 with 0-8 m M oxalic acid: Chemical Geology, v. 132(1-4), p. 79-89.

Strawn, D.G., Baker, L.L., Sprenke, K.F., and Rember, W.C. (2012). Celadonite in continental flood basalts of the Columbia River Basalt Group: American Mineralogist, v. 97, p. 1284-1290.

Tolan, T.L., Lindsey, K., and Porcello, J. (2009a). A Summary of Columbia River Basalt Group Physical Geology and its Influence on the Hydrogeology of the Columbia River Basalt Aquifer System: Columbia Basin Ground Water Management Area of Adams, Franklin, Grant, and Lincoln Counties.

Tolan, T.L., Martin, B.S., Reidel, S.P., Anderson, J.L., Lindsey, K.A., and Burt, W. (2009b). An introduction to the stratigraphy, structural geology, and hydrogeology of the Columbia River Flood-Basalt Province: A primer for the GSA Columbia River Basalt Group field trips.

University of Cincinnati (2018). UC Business Analytics R Programming Guide, Hierarchical Cluster Analysis. University of Cincinnati. http://ucr.github.io/hc_clustering

Van Atta, R.O., and Kelty, K.B. (1985). Scappoose Formation, Columbia County, Oregon; new evidence of age and relation to Columbia River Basalt Group: $A A P G$ Bulletin, v. 69, p. 688-698.

Van Pham, T.H., Aagaard, P., and Hellevang, H. (2012). On the potential for $\mathrm{CO}_{2}$ mineral storage in continental flood basalts - PHREEQC batch- and 1D diffusionreaction simulations: Geochemical Transactions, v. 13, p. 5.

Vlassopoulos, D., Goin, J., Zeliff, M., Porcello, J., Tolan, T., and Lindsey, K. (2009). Groundwater Geochemistry of the Columbia River Basalt Group Aquifer System: Columbia Basin Ground Water Management Area of Adams, Franklin, Grant, and Lincoln Counties. 
Wells, R.E. (1998). Fore-arc migration in Cascadia and its neotectonic significance: Geology, v. 26, p. 759-762.

Wells, R.E., Niem, A.R., Evarts, R.C., and Hagstrum, J.T. (2010). The Columbia River Basalt Group - From the gorge to the sea: The Geological Society of America Field Guide, v. 15, p. $737-774$.

Winter, J. D. (2001). An introduction to igneous and metamorphic petrology (Vol. 697). New Jersey: Prentice hall.

Yelin, T.S., and Patton, H.J. (1991). Seismotectonics of the Portland, Oregon, region: Bulletin of the Seismological Society of America, v. 81, p. 109-130. 


\section{APPENDIX A: COMPILED GROUNDWATER CHEMISTRY DATA}

\section{Supplementary Data Files}

Supplementary Data File Description: The accompanying Excel workbook lists the hydrogeologic units and locations for compiled wells in the Portland, Tualatin, and Northern Willamette Basins (Table A-1), and the associated water chemistry data (Table A-2) including temperature, $\mathrm{pH}$, major cations and anions, and trace elements. Table A-3 provides summary statistics of groundwater chemistry for each hydrogeologic unit, and Table A-4 provides calculated saturation indices and summary statistics for select mineral phases. Table A-5 provides the results of mixing models. Wells are identified by a reference ID which includes the basin, hydrogeologic unit, and sample number (for example, PB-CRB-1 is Portland Basin, Columbia River Basalt, sample 1). The accompanying PDF contains additional figures, including a map and piper diagram showing CRB wells color coded by cluster, and a figure demonstrating the chemistry of end member and mixed composition waters.

Filename: ES_AppedixA1-5_2019.xlsx, ES_AppendixA_Figures_2019.pdf 


\section{APPENDIX B: BATCH REACTION EXPERIMENTAL DATA}

\section{Supplementary Data Files}

Supplementary Data File Descriptions: The first supplementary file consists of an Excel workbook which includes an expanded table listing the experiment samples included in batch reaction experiments and their beginning and ending dates (Table B-1), as well as experimental results for cation analysis using the ICP-MS (Table B-2) and anions and alkalinity (Table B-3). The next file includes a compilation of XRD reports, including the full XRD analysis results for samples of the Wapshilla Ridge, Ortley, interflow zone, Sentinel Bluffs, and clay from the Sexton Quarry. A file showing images and spectra from SEM analysis of batch reacted heating and cooling experiments is also included. The last file contains modeling scripts for the inverse models discussed in section 3.2.4.

Filenames: ES_AppedixB-1-3_2019.xlsx,ES_AppendixB_XRD_2019.pdf, ES_AppendixB_SEM_2019.pdf, ES_AppendixB_InverseModels_2019.pdf 


\section{APPENDIX C: MODELING SCRIPTS AND PARAMETERS}

\section{Supplementary Data Files}

Supplementary Data File Descriptions: Supplementary files include equilibrium modeling scripts for both open and closed system conditions, and for each water type included in modeling efforts. Modeling scripts for 1D and 2D kinetic transport models are also included. A range of values were used for bracketed inputs in modeling scripts. See Chapter 4 for details.

Filenames: ES_AppendixC_ModelScipts_2019.pdf 